\title{
Climate-Smart Development
}

Adding up the benefits of actions that help build prosperity, end poverty and combat climate change

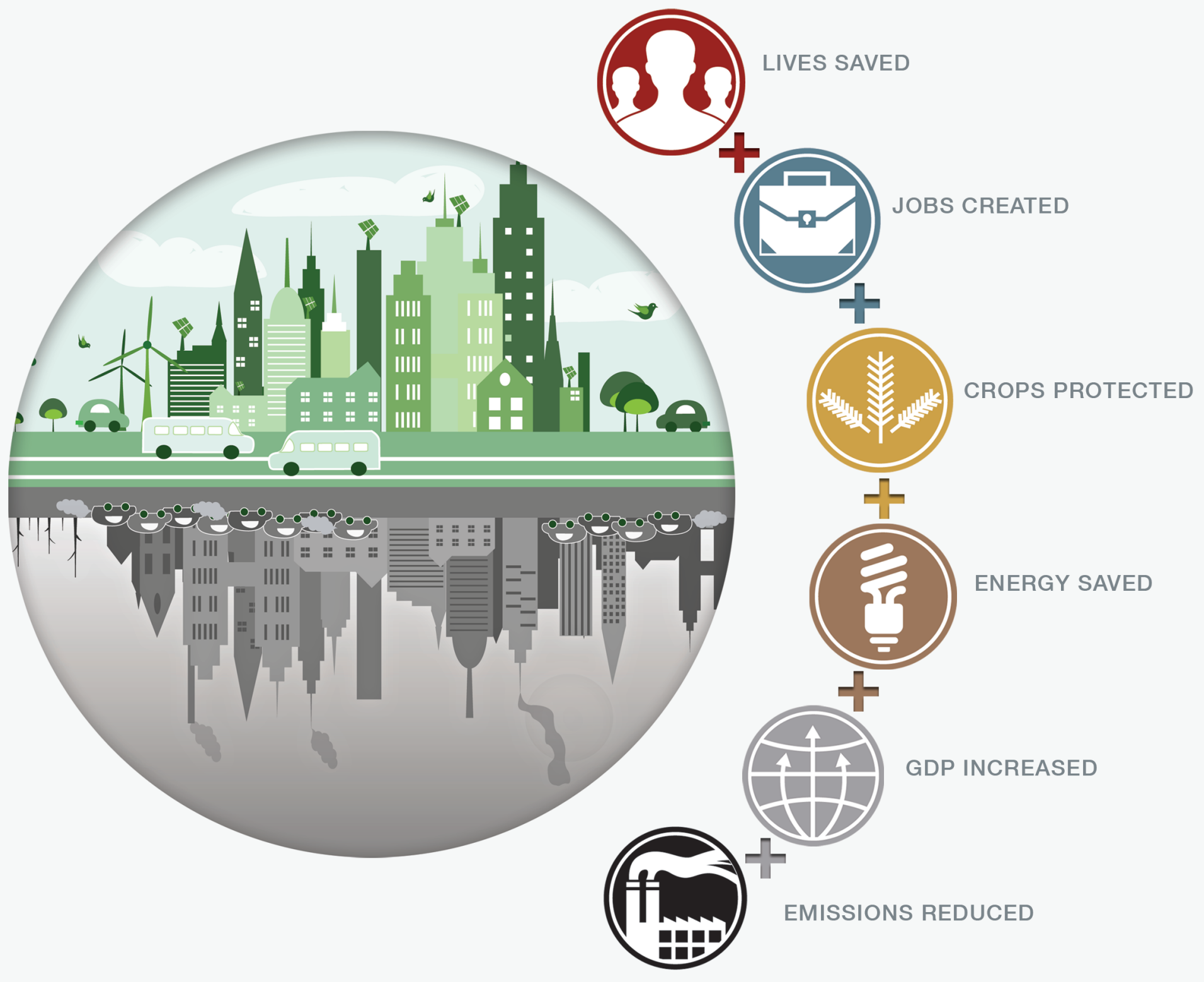

C ClimateWorks FOUNDATION 



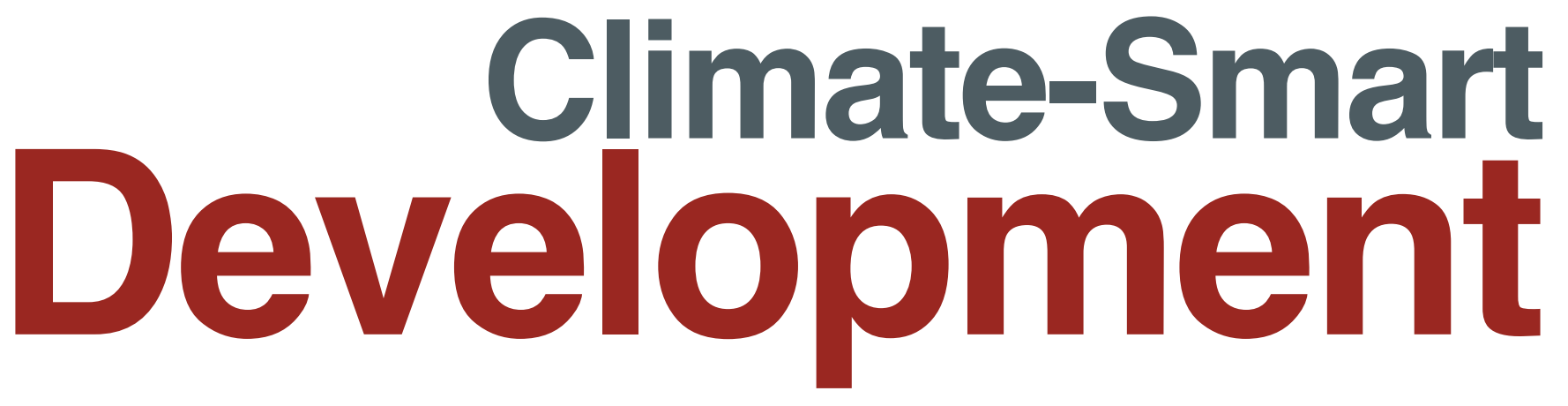

Adding up the benefits of actions that help build prosperity, end poverty and combat climate change 
@2014 International Bank for Reconstruction and Development/The World Bank and ClimateWorks Foundation

The World Bank

1818 H St NW

Washington DC 20433

Telephone: 202-473-1000

Internet: www.worldbank.org
ClimateWorks Foundation

235 Montgomery Street, Suite 1300

San Francisco, CA 94104

USA

Internet: www.climateworks.org

This work is a joint product of the World Bank and the ClimateWorks Foundation. The findings, interpretations, and conclusions expressed in this work do not necessarily reflect the views of the World Bank, its Board of Executive Directors, or the governments they represent.

The World Bank does not guarantee the accuracy of the data included in this work. The boundaries, colors, denominations, and other information shown on any map in this work do not imply any judgment on the part of the World Bank concerning the legal status of any territory or the endorsement or acceptance of such boundaries

\section{Rights and Permissions}

The material in this work is subject to copyright. Because the World Bank and ClimateWorks encourage dissemination of their knowledge, this work may be reproduced, in whole or in part, for noncommercial purposes as long as full attribution to this work is given.

Any queries on rights and licenses, including subsidiary rights, should be addressed to World Bank Publications, The World Bank Group, 1818 H St. NW, Washington, DC 20433, USA; fax: 202-522-2422; email: pubrights@worldbank.org.

Cover image courtesy of Shutterstock.com. 


\section{Contents}

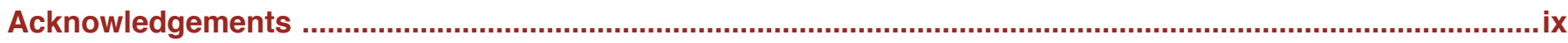

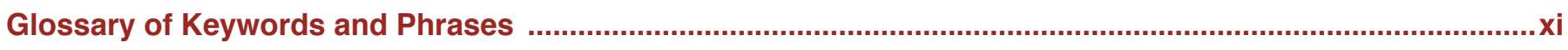

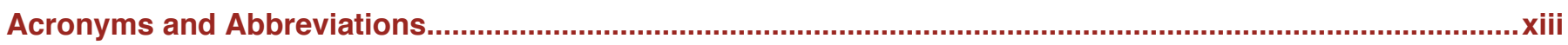

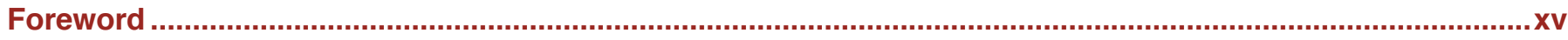

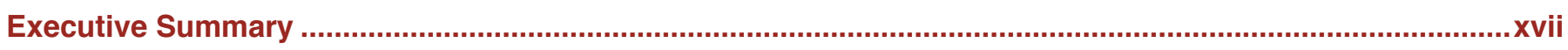

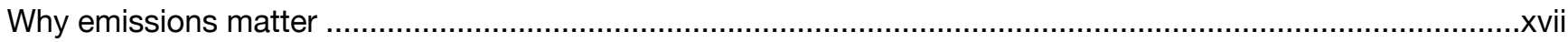

Achieving development and climate goals simultaneously ..........................................................................

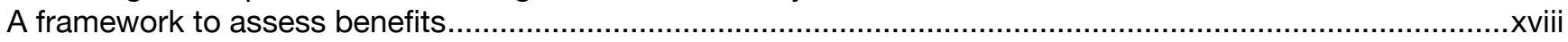

Case studies demonstrate sizeable benefits ...........................................................................................

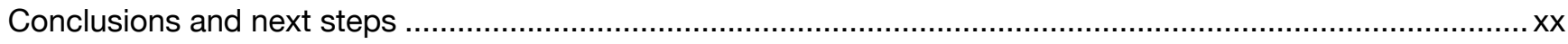

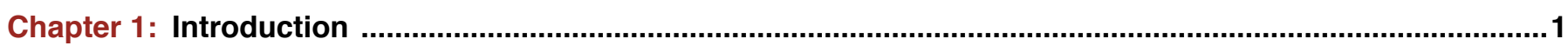

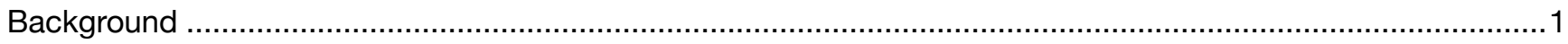

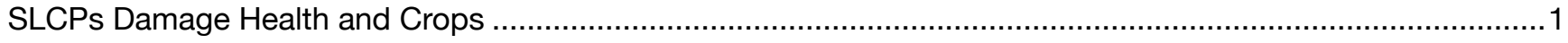

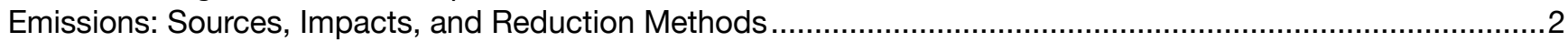

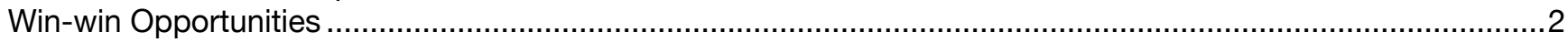

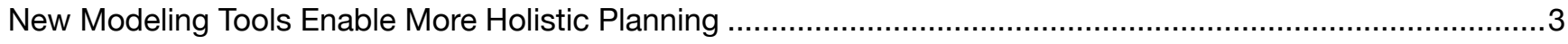

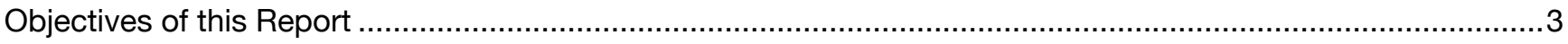

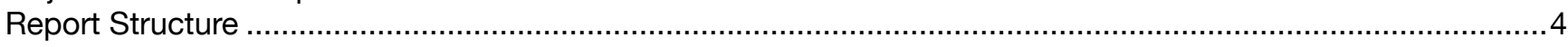

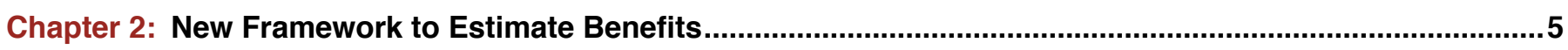

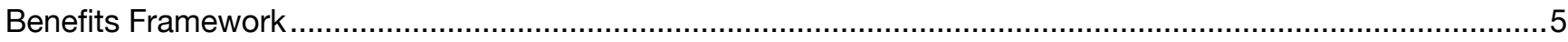

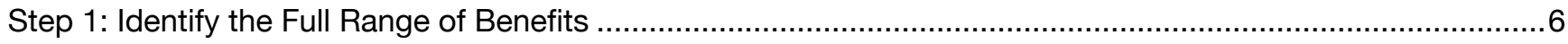

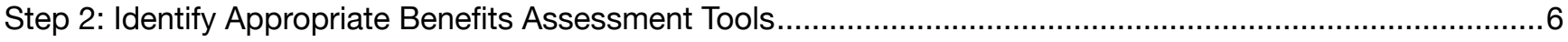

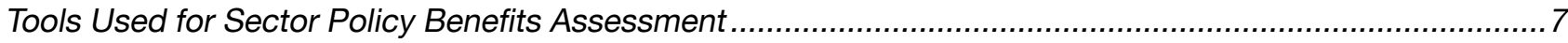

Tools Used for Development Project Benefits Assessment.................................................................

Step 3: Identify an Appropriate Macroeconomic Tool ..............................................................................

Limitations of Bottom-up and Macroeconomic Modeling ..................................................................

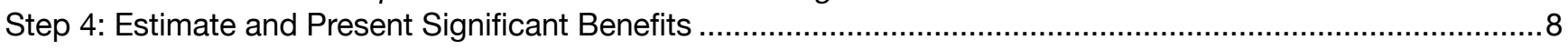




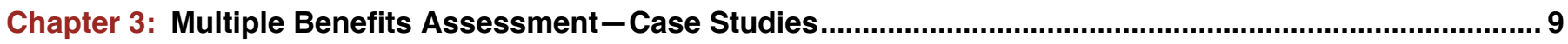

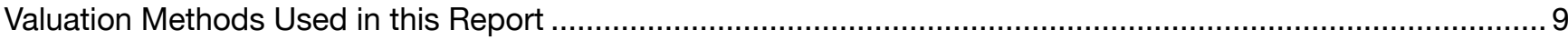

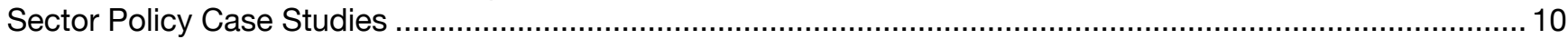

Sector Policy Case Study 1: Shift to Clean Transport ....................................................................... 11

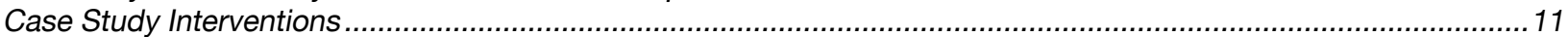

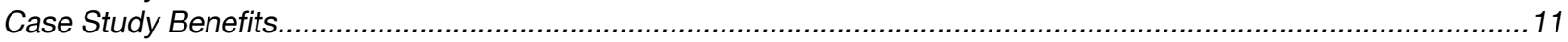

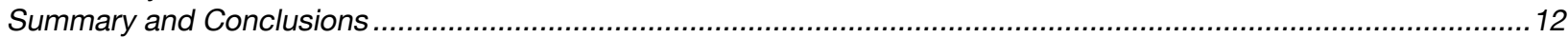

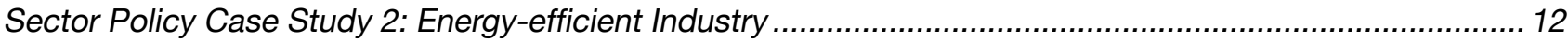

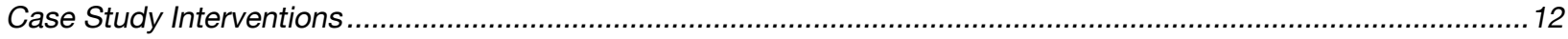

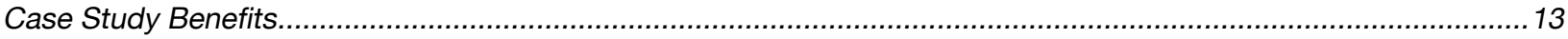

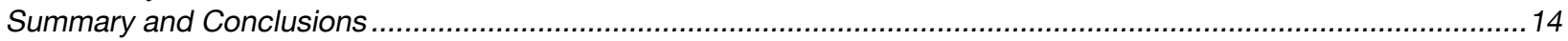

Sector Policy Case Study 3: Energy-efficient Buildings ................................................................... 15

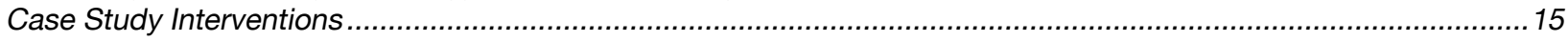

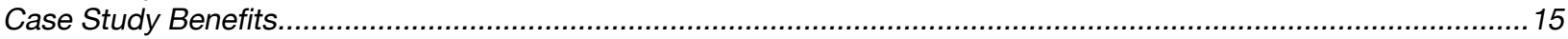

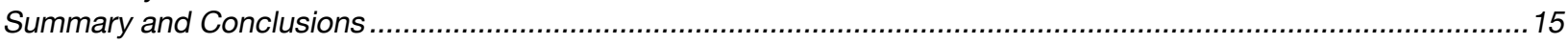

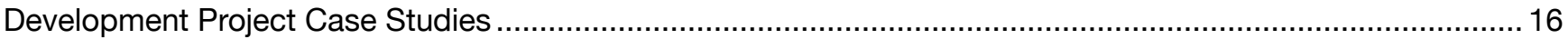

Development Project Case Study 1: Sustainable Transportation in India ............................................... 17

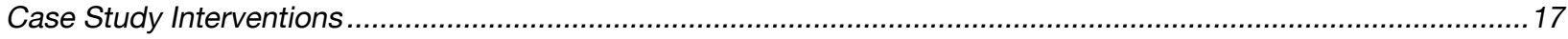

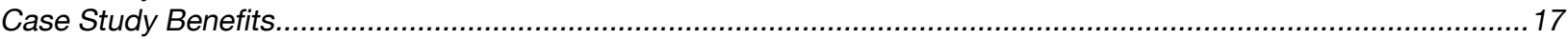

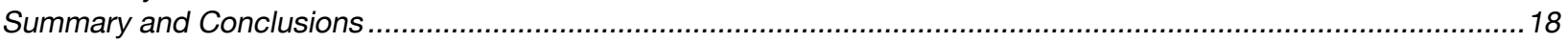

Development Project Case Study 2: Integrated Solid Waste Management in Brazil................................... 18

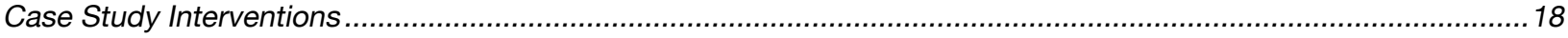

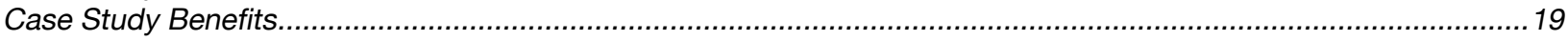

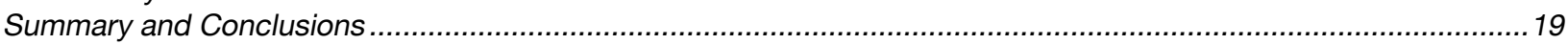

Development Project Case Study 3: Cleaner Cookstoves in Rural China ................................................ 20

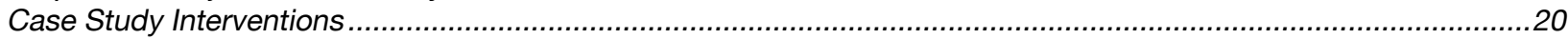

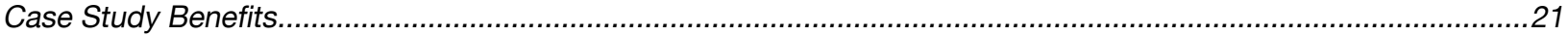

Summary and Conclusions ......................................................................................................................

Development Project Case Study 4: Biogas Digesters and Photovoltaic Systems in Mexican Agriculture.... 22

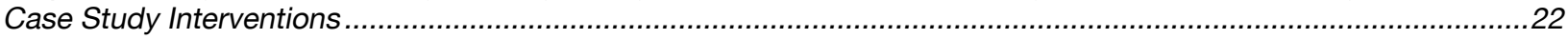

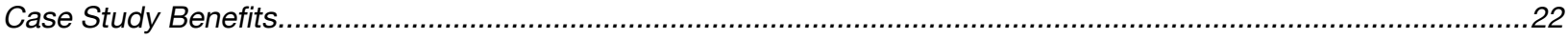

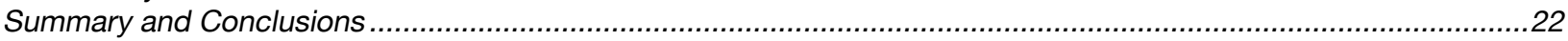

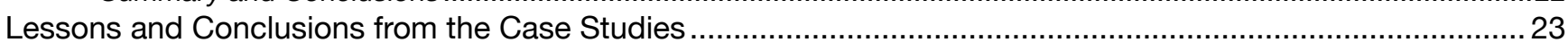

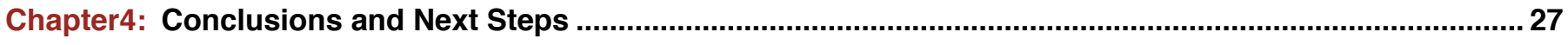

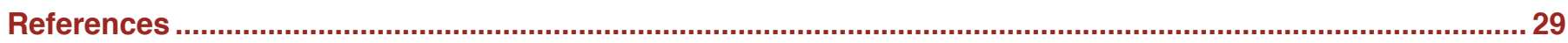

Annex A: Summary of Health, Agricultural, and Climate Benefits from Emissions Reduction........................33

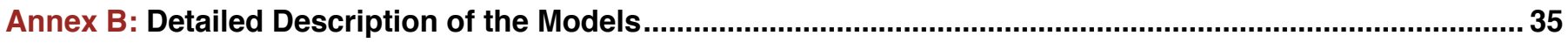

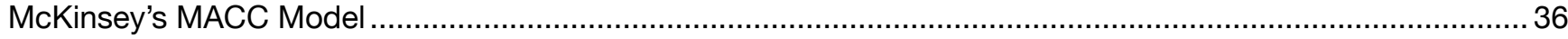

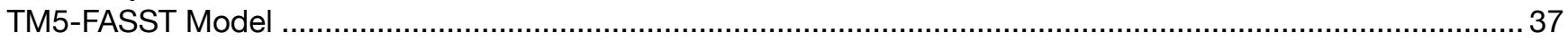

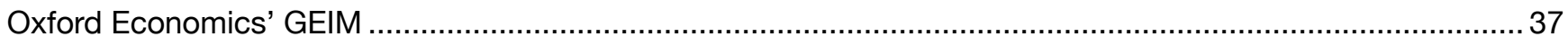

Annex C: Details and Data for Sector Policy Case Studies......................................................................... 41

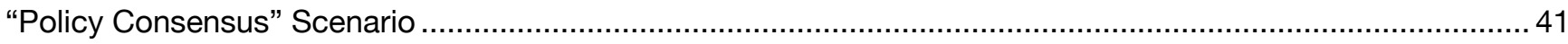

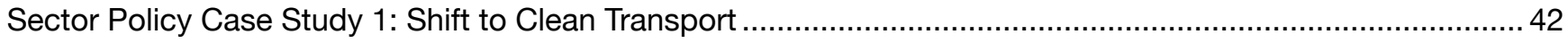

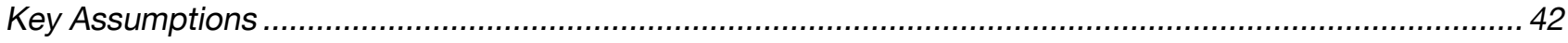

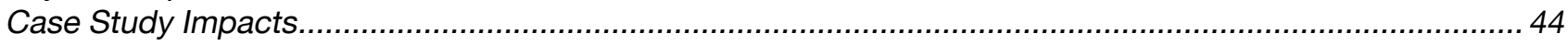

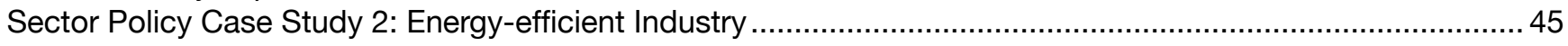

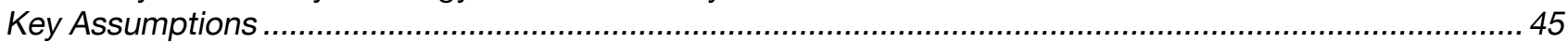

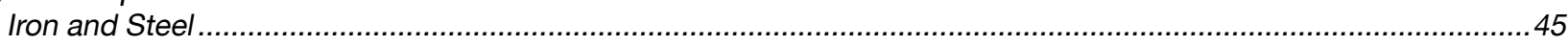

Cement.

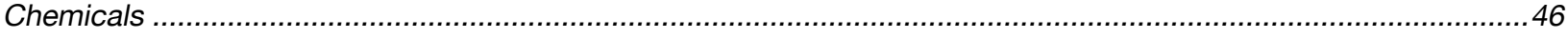

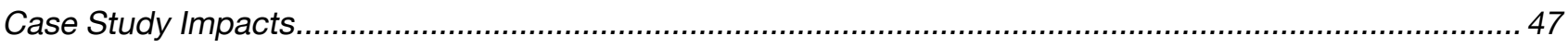

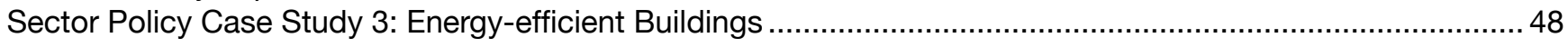


Key Assumptions . .48

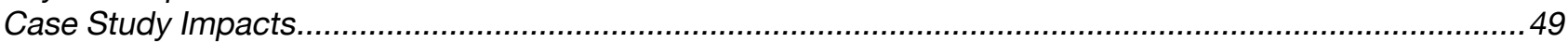

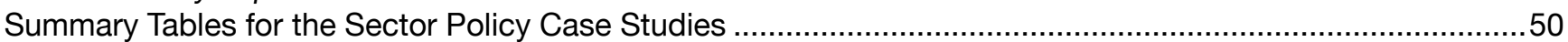

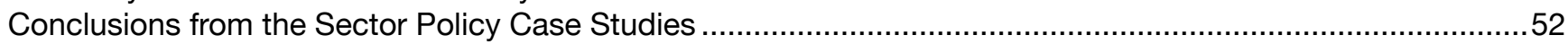

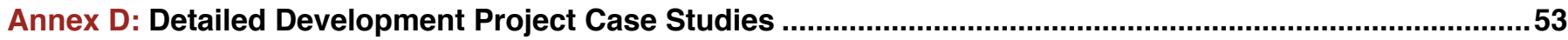

Development Project Case Study 1: Sustainable Transportation in India ....................................................53

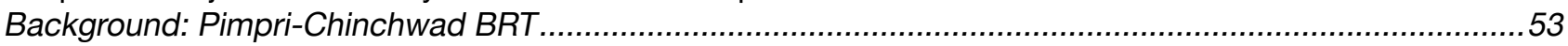

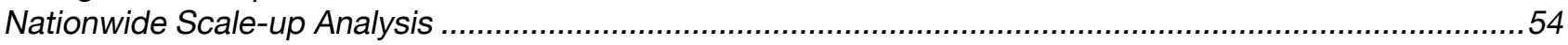

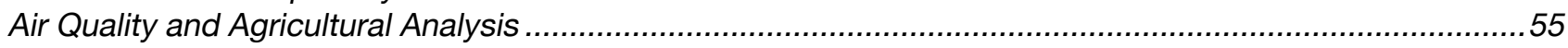

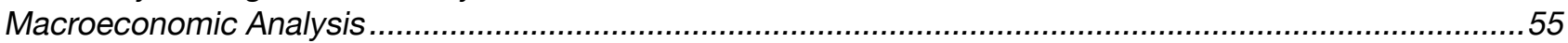

Monetization of Benefits and Comparison with Stated Project Benefits................................................55

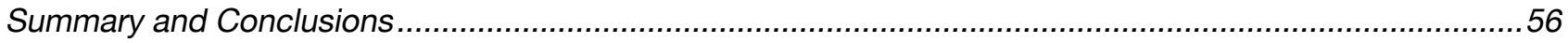

Development Project Case Study 2: Integrated Solid Waste Management in Brazil ......................................56

Background: Benefits of Integrated Solid Waste Management..........................................................56

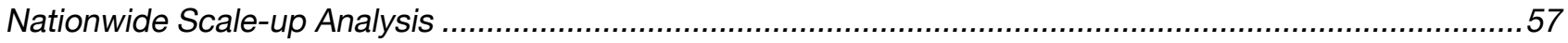

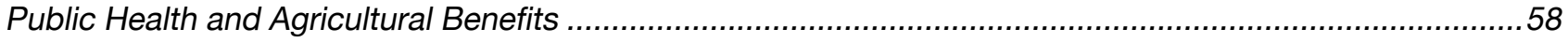

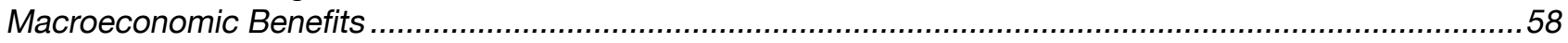

Monetization of Benefits and Comparison to Stated Project Benefits .....................................................59

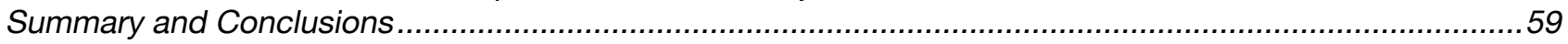

Development Project Case Study 3: Cleaner Cookstoves in Rural China...................................................59

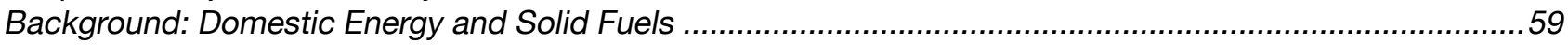

Nationwide Analysis: Clean Cookstoves for the Rural Poor ...............................................................6

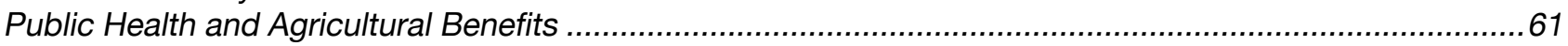

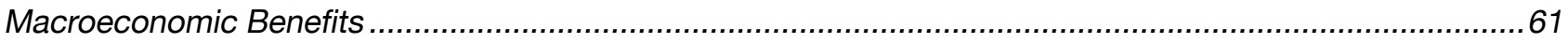

Monetization of Benefits and Comparison to Stated Project Benefits .....................................................61

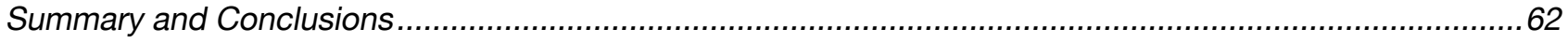

Development Project Case Study 4: Biogas Digesters and Photovoltaics in Mexican Agriculture .....................62

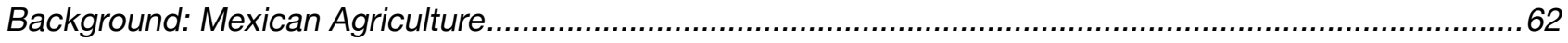

Nationwide Scale-up Analysis: Biodigesters and PV Systems for Pig and Dairy Farms...........................63

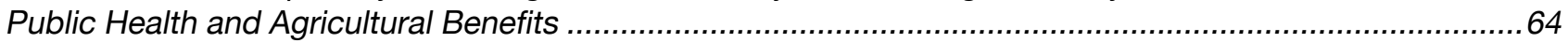

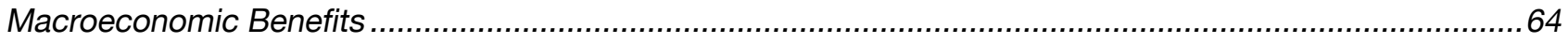

Monetization of Benefits and Comparison to Stated Project Benefits ...................................................64

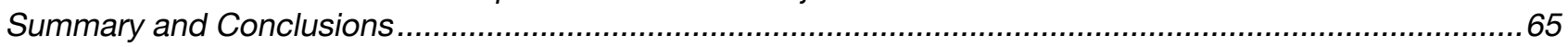

\section{FIGURES}

Figure E.1: Total annual benefits in 2030 of key sector policies in six regions.................................................... xix

Figure E.2: Aggregate benefits over 20 years of four development projects ..................................................... xix

Figure 2.1: Analytical Framework Used for the Policy and Project Case Studies ...................................................

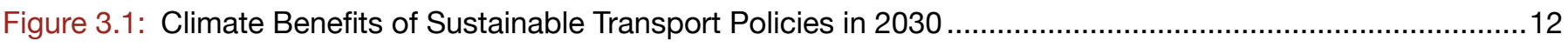

Figure 3.2: Socioeconomic and Climate Benefits of Sustainable Transport Policies in 2030 by Region..................12

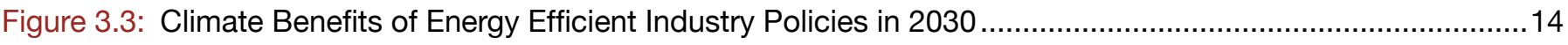

Figure 3.4: Socioeconomic and Climate Benefits of Energy-efficient Industry Policies in 2030 by Region..............14

Figure 3.5: Climate Benefits of Energy-efficient Building Policies in 2030.........................................................15

Figure 3.6: Socioeconomic and Climate Benefits of Energy-efficient Building Policies in 2030 by Region .............16

Figure 3.7: Socioeconomic and Climate Benefits of Sustainable Transportation in India.....................................18

Figure 3.8: Socioeconomic and Climate Benefits of Integrated Solid Waste Management in Brazil.......................20

Figure 3.9: Socioeconomic and Climate Benefits of Cleaner Cookstoves in Rural China ...................................21

Figure 3.10: Socioeconomic and Climate Benefits of Biodigesters and PV in Mexican Agriculture.........................23 


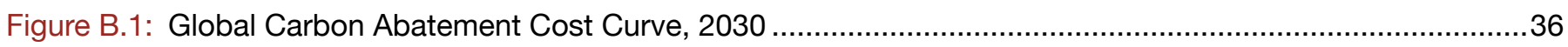

Figure B.2: Main Transmission Channels in Oxford Economics' GEIM Model..................................................38

Figure C.1: Oil Prices in 2010 Dollars for Baseline, Policy Consensus and All Policy Case Study Scenarios...........42

Figure C.2: Road Transport Marginal Abatement Cost Curve, 2030 (six focus regions) ........................................43

Figure C.3: Conventional Passenger Vehicle Efficiency by Region, BAU vs. Case Study .....................................4 44

Figure C.4: Underlying Global Scenario Power Mix (2030) ..........................................................................4

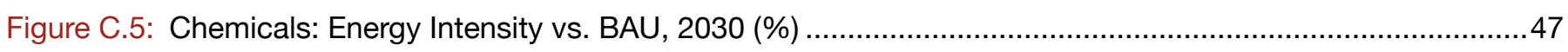

Figure C.6: Industry Marginal Abatement Cost Curve, 2030 (Six Focus Regions) ..............................................4

Figure C.7: Buildings Marginal Abatement Cost Curve, 2030 (Six Focus Regions) ..............................................49

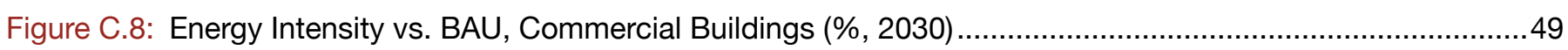

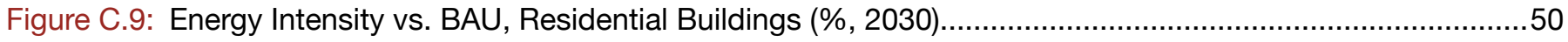

Figure D.1: Lifecycle GHG Emissions $\left(\mathrm{MtCO}_{2} \mathrm{e} / \mathrm{yr}\right)$ for All Scenarios...........................................................58

\section{TABLES}

Table 1.1: $\mathrm{CO}_{2}$, Methane, and Black Carbon Emissions Sources, Impacts, and Reduction Methods. ......................2

Table 3.1: Sector Policy Case Studies: Comparison of Costs and Benefits per Metric Ton of $\mathrm{CO}_{2} \mathrm{e}$ Abated............24

Table 3.2: Sector Policy Case Studies: Monetized Health, Agricultural, and Energy Benefits in $2030 \ldots \ldots \ldots \ldots \ldots \ldots . . . . . .24$

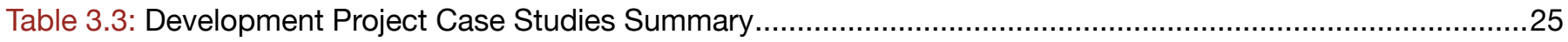

Table 3.4: Development Project Case Studies: Summary of Global and Local Benefits ......................................26

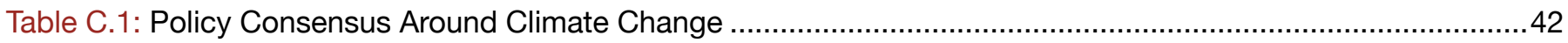

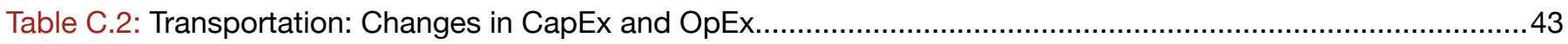

Table C.3: Underlying Scenario Fuel Price Assumptions by Region...................................................................4

Table C.4: Underlying Assumptions on Incremental Costs of Plug-in Hybrid and Electric Vehicles.........................44

Table C.5: Iron and Steel: Changes in CapEx and OpEx, BAU vs. Case Study.................................................46

Table C.6: Cement: Changes in CapEx and OpEx, BAU vs. Case Study .........................................................46

Table C.7: Chemicals: Changes in CapEx and OpEx, BAU vs. Case Study …..................................................4 47

Table C.8: Buildings: Commercial and Residential CapEx Changes, BAU vs. Case Study ....................................49

Table C.9: Changes in Non- $\mathrm{CO}_{2}$ Emissions for the Three Sector Policy Case Studies ........................................50

Table C.10: Avoided Premature Mortality for the Three Sector Policy Case Studies..............................................51

Table C.11: Increase in Crop Yields from a Shift to Energy-efficient Industry.....................................................51

Table C.12: Monetized Health and Agricultural Benefits of the Sector Policy Case Studies ..................................51

Table C.13: Energy Savings from Sector Policy Case Studies for the Six Focus Regions for 2030 ........................51

Table C.14: Annual Avoided Premature Mortalities from the Sector Policy Case Studies for 2020..........................51

Table C.15: Annual Increase in Crop Yields from the Sector Policy Case Studies for 2020...................................52

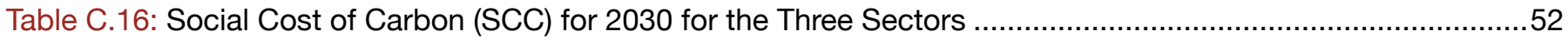

Table D.1: Multiple Benefits Potential of Sustainable Transportation (BRT) Initiatives in India ...............................56

Table D.2: Multiple Benefits Potential of Integrated Solid Waste Management in Brazil ........................................60

Table D.3: Multiple Benefits Potential of Clean Cooking Solutions in China........................................................62

Table D.4: Multiple Benefits Potential of Sustainable Agriculture in Mexico.........................................................65 


\section{BOXES}

Box 3.1: Sector Policy Case Study 1 Benefits: Shift to Clean Transport …......................................................13

Box 3.2: Sector Policy Case Study 2 Benefits: Energy-efficient Industry ..........................................................14

Box 3.3: Sector Policy Case Study 3 Benefits: Energy-efficient Buildings ......................................................... 16

Box 3.4: Development Project Case Study 1 Benefits: Sustainable Transportation in India ...................................17

Box 3.5: Development Project Case Study 2 Benefits: Integrated Solid Waste Management in Brazil ...................19

Box 3.6: Development Project Case Study 3 Benefits: Clean Cookstoves in Rural China......................................21

Box 3.7: Development Project Case Study 4 Benefits: Biogas Digestion and PV in Mexican Agriculture ................23

Box B.1: Two Integrated Planning Approaches That Paved the Way .................................................................35 



\section{Acknowledgements}

The ClimateWorks Foundation and the World Bank would like to thank the modeling teams, the reviewers, and the project task teams for their contributions to the development of this report.

The modeling work for the report was conducted by Rita Van Dingenen (Joint Research Centre, European Commission), Sarah Hunter (Oxford Economics), and Sudhir Gota (Clean Air Asia).

The ClimateWorks task team included Surabi Menon and Laura Segafredo (co-Task Team Leaders). Ruoting Jiang, formerly at ClimateWorks, provided analysis support for the modeling work; Seth Monteith designed the graphics and Debra Jones edited the report. Management oversight was provided by Charlotte Pera.

The task team from the World Bank included Sameer Akbar and Gary Kleiman (co-Task Team Leaders), Samuel Oguah,
Robert Bisset, Fionna Douglas, Stacy Morford, Venkat Gopalakrishnan, Karin Rives, and Samrawit Beyene. Management oversight was provided by Karin Kemper and Jane Ebinger. Advice on the macroeconomic analysis was provided by Kirk Hamilton, Erika Jorgenson, and Stéphane Hallegatte. The report was peer-reviewed by Masami Kojima, Andreas Kopp, Muthukumar Mani, Tijen Arin, and Carter Brandon. Inputs were also gratefully received from the following World Bank staff: Nupur Gupta, Om Prakash Agarwal, Gaurav Joshi, Sintana Vergara, Marcus Lee, Farouk Banna, Stephen Hammer, Yabei Zhang, Yun Wu, Charles Feinstein, Svetlana Edmeades, Tim Valentiner, Guillermo Hernández, Onno Ruhl, Gloria Grandolini, Klaus Rohland, and Deborah Wetzel. 



\section{Glossary of Keywords and Phrases}

Anthropogenic: Human-caused.

Black Carbon (BC): A small, dark particle that warms the earth's climate. Although black carbon is a particle rather than a greenhouse gas, it is the second-largest climate warmer after carbon dioxide. Unlike carbon dioxide, black carbon is quickly washed out and can be eliminated from the atmosphere if emissions stop. Reductions would also improve human health.

Carbon Dioxide $\left(\mathbf{C O}_{2}\right)$ : The greenhouse gas that contributes the most to global warming. While more than half of the $\mathrm{CO}_{2}$ emitted is removed from the atmosphere within a century, some fraction (about 20 percent) of emitted $\mathrm{CO}_{2}$ remains in the atmosphere for many thousands of years.

Global Burdens of Disease: A study to estimate the number of worldwide deaths annually from different diseases or environmental causes; can also be divided into different regions and groups. See http://www.healthmetricsandevaluation.org/gbd.

Global Public Goods Benefits: Benefits such as protection of ecosystem services, reduced acid deposition and infrastructure loss, and reduced climate change impacts that are realized beyond the jurisdiction where a policy is implemented or a project carried out.

Hydrofluorocarbons (HFCs): Chemical replacements for ozonedepleting substances being phased out by the Montreal Protocol. These substances are used in heating and cooling systems and as aerosols. Although less damaging to the ozone layer than what they replace, they can have very large global warming potentials.
Local Socioeconomic Benefits: Benefits such as GDP growth, employment gains, reduced energy and fuel costs, time savings, improved water and air quality, higher crop yields, improved public health, and reduced mortality that are realized in the jurisdiction that enacts the policy or project.

Methane $\left(\mathbf{C H}_{4}\right)$ : A greenhouse gas that only lasts an average of 12 years in the atmosphere; it is an extremely powerful warmer during that period. One molecule of methane warms about 25 times more than $\mathrm{CO}_{2}$ over 100 years (and 72 times as much over 20 years).

Mitigation: Actions to address climate change by decreasing greenhouse gases and other climate-forcing agents.

Ozone $\left(\mathbf{O}_{3}\right)$ : A harmful pollutant and greenhouse gas that only forms though complex chemical reactions with other substances in the atmosphere (e.g., methane); it can harm human health and crops.

Radiative Forcing: A measure of the net change in the energy balance of the earth with space; that is, the incoming solar radiation minus outgoing terrestrial radiation. At the global scale, the annual average radiative forcing is measured at the top of the atmosphere, or tropopause. Expressed in units of warming rate (watts, W) per unit of area (meters squared, $\mathrm{m}^{2}$ ).

Short-lived Forcers or Short-lived Climate Pollutants (SLCPs): Substances such as methane, black carbon, tropospheric ozone, and some hydrofluorocarbons that have a significant impact on near-term climate change and a relatively short 
lifespan in the atmosphere compared to carbon dioxide and other longer-lived gases.

Synergistic Economic Benefits: Macroeconomic benefits from multiplier effects, forward linkage of investment, and potential cross-sector interactions; for example, indirect health and agriculture benefits that would result from the electrification of the transport sector if the power sector simultaneously reduced its carbon intensity and co-pollutant emissions due to a performance standard or a renewable energy mandate.
Systems Approach: An approach capturing the direct and indirect benefits of policies and projects and quantifying their macroeconomic impacts; it is meant to capture the interconnectedness between identified benefits.

Tropospheric Ozone: Sometimes called ground-level ozone, this refers to ozone that is formed or resides in the portion of the atmosphere from the earth's surface up to the tropopause (the lowest $10-20 \mathrm{~km}$ of the atmosphere). 


\section{Acronyms and Abbreviations}

\begin{tabular}{|c|c|c|c|}
\hline $\mathrm{Ag}$ & Agriculture & IIASA & International Institute for Applied Systems Analysis \\
\hline BAU & Business-as-usual scenario & ICE & Internal combustion engine \\
\hline \multirow[t]{2}{*}{ BenMAP } & Environmental Benefits Mapping and Analysis & KCAL & Kilocalories \\
\hline & Program of the U.S. EPA & LFG & Landfill gas \\
\hline $\mathrm{BC}$ & Black carbon & LPG & Liquefied petroleum gas \\
\hline BRT & Bus rapid transit system & MACC & Marginal Abatement Cost Curve \\
\hline CapEx & Capital expenditures & MOUD & Ministry of Urban Development (of the \\
\hline \multirow[t]{2}{*}{ CCAC } & \multirow{2}{*}{$\begin{array}{l}\text { Climate and Clean Air Coalition to Reduce Short- } \\
\text { Lived Climate Pollutants }\end{array}$} & & Government of India) \\
\hline & & Mt & Megaton (million metric tons) \\
\hline $\operatorname{CCS}$ & Carbon capture and storage & MSW & Municipal solid waste \\
\hline CGE & Computable General Equilibrium model & NMVOC & Non-methane volatile organic compounds \\
\hline $\mathrm{CH}_{4}$ & Methane & NPV & Net present value \\
\hline $\mathrm{CO}$ & Carbon monoxide & $\mathrm{N}_{2} \mathrm{O}$ & Nitrous oxide \\
\hline $\mathrm{CO}_{2}$ & Carbon dioxide & $\mathrm{O}_{3}$ & Ozone \\
\hline $\mathrm{CO}_{2} \mathrm{e}$ & Carbon dioxide equivalent & OC & Organic carbon \\
\hline $\mathrm{CW}$ & ClimateWorks Foundation & OpEx & Operational costs or expenditures \\
\hline EU & European Union (refers to EU27) & PAD & Project Appraisal Document \\
\hline EV & Electric vehicle & PM & Particulate matter \\
\hline \multirow{2}{*}{$\begin{array}{l}\text { EPA } \\
\text { FASST }\end{array}$} & U.S. Environmental Protection Agency & $\mathrm{PM}_{2.5}$ & Particulate matter with an aerodynamic diameter \\
\hline & $\begin{array}{l}\text { Fast Scenario Screening Tool for Global Air Quality } \\
\text { and Instantaneous Radiative Forcing }\end{array}$ & PPP & $\begin{array}{l}\text { less than } 2.5 \text { microns } \\
\text { Purchasing power parity }\end{array}$ \\
\hline \multirow[t]{4}{*}{ GAINS } & Greenhouse Gas and Air Pollution Interactions & PV & Photovoltaic \\
\hline & and Synergies: a model that provides a framework & RoW & Rest of world \\
\hline & for the analysis of co-benefits reduction strategies & SLCP & Short-lived climate pollutants \\
\hline & from air pollution and greenhouse gas sources & $\mathrm{SRC}$ & Source receptor coefficient \\
\hline GBD & Global burden of disease & TM5 & Chemical Transport Model (maintained by the \\
\hline GDP & Gross domestic product & & European Commission's Joint Research Center and \\
\hline GHG & Greenhouse gas & & the model on which the FASST tool is based) \\
\hline GEIM & $\begin{array}{l}\text { Global Energy and Industry Model of Oxford } \\
\text { Economics }\end{array}$ & TEEMP & $\begin{array}{l}\text { Transportation Emissions Evaluation Models for } \\
\text { Projects }\end{array}$ \\
\hline GEF & Global Environment Facility & TSP & Total suspended particulates \\
\hline & Gross national income & U.S. & United States \\
\hline & Government of Mexico & UNEP & United Nations Environment Programme \\
\hline \multirow{2}{*}{$\begin{array}{l}\text { Gt } \\
\text { IBRD }\end{array}$} & Gigaton (billion metric tons) & WAVES & $\begin{array}{l}\text { Wealth Accounting and the Valuation of Ecosystem } \\
\text { Services }\end{array}$ \\
\hline & $\begin{array}{l}\text { International Bank for Reconstruction and } \\
\text { Development }\end{array}$ & WB & World Bank \\
\hline
\end{tabular}





\section{Foreword}

The evidence is clear that climate change is already hurting the poor. It is damaging infrastructure, threatening coastal cities, and depressing crop yields, as well as changing our oceans, jeopardizing fish stocks, and endangering species.

The UN Intergovernmental Panel on Climate Change (IPCC) has shown more clearly than ever before that climate change is real, and that it has impacted every continent and all oceans. Consecutive IPCC reports make clear that we are ill-prepared to manage the risks of climate change and the impact it brings, and that global emissions of greenhouse gases are rising faster than ever before, despite reduction efforts.

No one will escape the impact. Climate change poses a severe risk to global economic stability. Without urgent mitigation action, ending extreme poverty by 2030 will not be possible.

At the World Bank Group, we know it doesn't have to be like this. We believe it is possible to reduce emissions and deliver jobs and economic opportunity, while also cutting health care and energy costs. This report provides powerful evidence in support of that view.

This publication, Climate-Smart Development, highlights scalable development solutions and builds on research to quantify the social benefits of climate action. The report simulates case studies of policies that could lead to emissions reductions in three sectors: transportation, industry, and the energy efficiency of buildings.

It also describes the national-level impact that scaling-up development solutions could have in five large countries and the
European Union. If enacted together, these policies could reduce greenhouse gas emissions by the same amount as taking two billion cars off the streets.

The report also looks at four country-specific projects and the impact they would have if scaled-up nationwide. For example, if India built 1,000 kilometers of new bus rapid transit lanes in about twenty large cities, the benefits over 20 years would include more than 27,000 lives saved from reduced accidents and air pollution, and 128,000 long-term jobs created. It would also have large, positive effects on India's GDP, its agriculture, and the global climate.

Climate-Smart Development is a collaboration with the ClimateWorks Foundation, and provides a framework to better understand the climate risks and benefits in everything we do. The report's findings show clearly that development done well can deliver significant climate benefits.

I recommend this publication to policy makers and development practitioners alike.

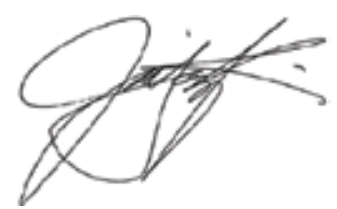

Dr. Jim Yong Kim

President, World Bank Group 



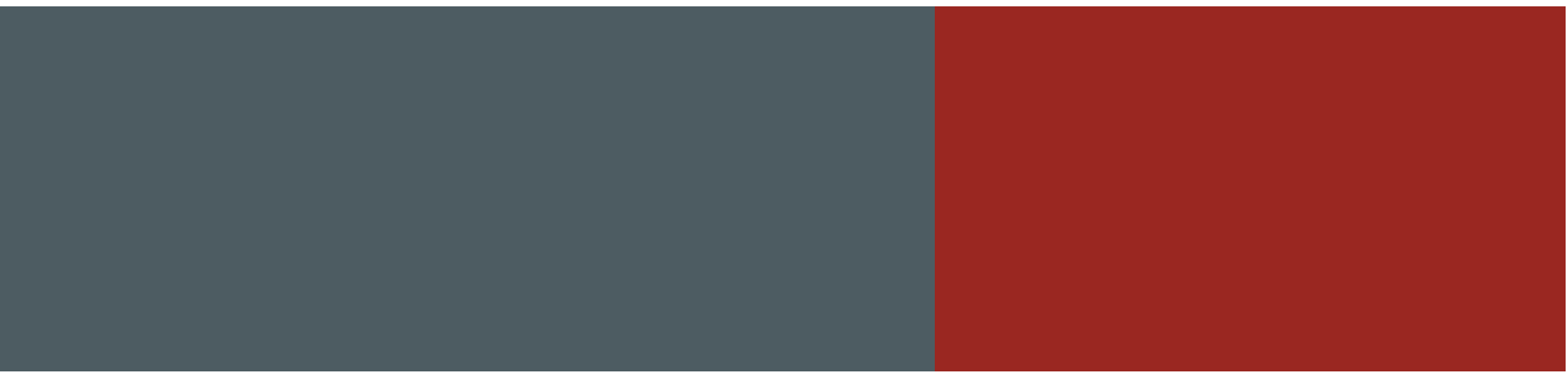

\section{Executive Summary}

Officials responsible for a nation's economy have been primarily concerned with delivering jobs, stimulating growth, and promoting competitiveness. They are also becoming worried about the effects climate change will inflict on their country's economic future. Increasingly, these officials want to know if there are investments and efforts that can advance urgent development priorities and, at the same time address the challenges of our rapidly warming world.

Thanks to a growing body of research, it is now clear that climate-smart development can boost employment and can save millions of lives. Smart development policies and projects can also slow the pace of adverse climate changes. Based on this new scientific understanding, and with the development of new economic modeling tools to quantify these benefits, it is clear that the objectives of economic development and climate protection can be complementary.

This report uses new modeling tools to examine the full range of benefits ambitious climate mitigation policies can produce across the transportation, industry and building sectors in the United States, China, the European Union, India, Mexico and Brazil. This report also describes the multiple benefits of four development project simulations scaled up to the national level.

The report builds on recent efforts to estimate the development benefits ${ }^{1}$ that come with a reduction in climate pollutants. These include economic growth, new jobs, improved crop yields, enhanced energy security, healthier people, and millions of lives saved. In many cases these benefits accrue quickly, and they accrue locally, primarily in the nation where action is taken.

\section{Why emissions matter}

Climate change impacts impose undeniable burdens on economic development by causing significant damage to agriculture, water resources, ecosystems, infrastructure, and human health. These impacts are proving to be devastating for the world's most vulnerable populations.

Emissions of carbon dioxide and other greenhouse gases must be substantially reduced to keep the world from exceeding the $2{ }^{\circ}$ Celsius threshold of global warming. ${ }^{2}$ While efforts to reduce these climate pollutants, despite some progress, have been slow, recent scientific evidence suggests that cutting so-called "short-lived climate pollutants," which are responsible for up to 40 percent of the current warming, can have immediate climate impacts. ${ }^{3}$ Complementary actions on greenhouse gases and short-lived climate pollutants can slow the rate of near-term warming, push back dangerous tipping points ${ }^{4}$ and provide time to allow the world's poorest people to adapt to the changing climate.

Among the short-lived climate pollutants, black carbon and methane are climate forcers but they are also air pollutants that injure human health and diminish agriculture production. By reducing them, it is possible to prevent the deaths of 2.4 million people and boost crop production by 32 million tons of crops that would have been lost each year. ${ }^{5}$ In rural areas, millions of people can be saved from premature death by switching to clean

\footnotetext{
1 Note that the term co-benefit is not used in this report as it implies a primary benefit whereas this work seeks to demonstrate the many reasons for undertaking emission reductions without assigning a preference for one benefit over another.

2 "Turn Down the Heat: Why a $4{ }^{\circ} \mathrm{C}$ Warmer World Must Be Avoided," World Bank, 2012a.

3 Short-lived Climate Pollutants (SLCPs) such as methane, black carbon, tropospheric ozone, and some hydrofluorocarbons have a significant impact on near-term climate change and a relatively short lifespan in the atmosphere compared to carbon dioxide and other longer-lived gases.

4 With warming beyond $2^{\circ} \mathrm{C}$, the risk of crossing activation thresholds for nonlinear tipping elements in the Earth System and irreversible climate change impacts increases. These include Amazon rain forest die-back, ocean ecosystem impacts, and ice sheet destabilization, "Turn Down the Heat: Why a $4^{\circ} \mathrm{C}$ Warmer World Must Be Avoided," World Bank, 2012a.

5 "Integration of Short-Lived Climate Pollutants in World Bank Activities," World Bank, 2013a.
} 
cooking solutions. In cities, commuters can save time, and many thousands of asthma and heart attacks can be alleviated, through improved transit systems. Limiting these pollutants through smart development enhances economies, stimulates production, leaves populations healthier and slows the rate of climate change.

\section{Achieving development and climate goals simultaneously}

Policies that reduce GHG emissions and other short-lived climate pollutants can have clear economic, health, and other social benefits. For example, a policy that encourages more efficient transportation-including fuel efficient vehicles, and effective public transit-will save fuel and time which improves energy security and labor productivity. These policies can also reduce smog-related respiratory problems, thus saving lives, and improve visibility, benefiting local investment in sectors such as tourism and recreation. Similarly, a project to improve solid waste management may initially be pursued for its sanitation and health benefits; it can also reduce methane emissions that may boost crop yields and save energy. All these gains directly contribute to economic growth.

At the project level, these benefits have often been left out of economic analyses because many health and environmental benefits were not easily quantifiable. This has left decision makers with analyses that are incomplete. Recent efforts to better estimate the full impacts of proposed development projects have produced several new analytical tools and models. With these new tools, economists can more fully assess the multiple impacts of pollutants and estimate the value of emission reductions. Today's tools can also model the synergistic impacts of harms and benefits as they flow through the economy.

\section{A framework to assess benefits}

This report attempts to quantify investments that represent a true economic gain in terms of increased economic productivity. ${ }^{6}$ It does so by applying new modeling tools that give a fuller accounting of the benefits of near-term and long-term climate and development interventions. The report:

- Introduces a holistic, adaptable framework to capture and measure the multiple benefits of reducing emissions of several pollutants

- Demonstrates how local and national policymakers, members of the international development community, and others can use this framework to design and analyze policies and projects
- Contributes a compelling rationale for effectively combining climate action with sustainable development and green growth worldwide

The report responds to demand from countries that are striving to advance local development priorities and needs for resilient, low carbon growth. By looking at policies and projects more holistically, one can better assess the overall value of actions that reduce emissions of GHGs and short-lived climate pollutants, and provide a more compelling case for coordinated development and climate action.

The report proposes the following framework to analyze policies and projects:

1. Identify the full range of benefits that result from a project or policy, including improved health, crop yields, energy savings, job growth, labor productivity, and economic growth

2. Select appropriate assessment tools that provide insight on each measurable benefit

3. Choose the appropriate macroeconomic tool to analyze direct and synergistic economic benefits

4. Estimate the full range of benefits and present results using metrics relevant to the audience

Several simulated case studies are used in this study to demonstrate how to apply this analytical framework. The case studies cover multiple pollutants (particulate matter, primarily black carbon; and GHGs, including methane, a precursor to ozone, and $\mathrm{CO}_{2}$ ) and multiple sectors (transportation, industry, buildings, waste, and agriculture). They demonstrate the frameworks' benefits from two perspectives: sector policies applied at the national or regional level, and projects implemented at the sub-national level. By applying the framework to analyze both types of interventions, the report demonstrates the value of this approach for national and local policymakers, international finance organizations, and others.

The report focuses on assessing the multiple benefits of simulated policy and project case studies. These analyses should be viewed as "full implementation simulations" relative to a business-as-usual scenario. The benefits quantified have an optimistic bias because they do not necessarily include transaction costs, risks, market distortions, and other factors that would be included in a policy implementation evaluation. Nonetheless, they offer an important building block to refine the approaches, methods, and tools for multiple-benefit analysis. The results also

6 Work has already been undertaken to expand consideration of some hidden costs of mitigation, such as Paltsev, S. and Capros, P. (2013). A similar effort on benefits is needed.

7 Here "full implementation" means that it is assumed that policies and programs achieve their full technical potential. Additional education and outreach or other program costs may be required to achieve this full potential. 
highlight the need to fine-tune the modeling tools to represent real-world conditions more accurately.

\section{Case studies demonstrate sizeable benefits}

Three simulated case studies analyzed the effects of key sector policies to determine the benefits realized in six regions ${ }^{8}$ (the United States, China, the European Union, India, Mexico, and Brazil) and the impact on global GDP. The sector policies include regulations, taxes, and incentives to stimulate a shift to clean transport, improved industrial energy efficiency, and more energy efficient buildings and appliances.

The annual benefits ${ }^{9}$ of just these policies in 2030 include an estimated GDP growth of between $\$ 1.8$ trillion and $\$ 2.6$ trillion. Approximately 94,000 premature pollution-related deaths could be avoided. Additionally, the policies would avoid production of 8.5 billion metric tons of carbon dioxide equivalent $\left(\mathrm{CO}_{2} \mathrm{e}\right)^{10}$ emissions and almost 16 billion kilowatt-hours of energy saved, a savings roughly equivalent to taking 2 billion cars off the road. These policies alone would account for 30 percent of the total reduction needed in 2030 to limit global warming to $2^{\circ} \mathrm{C}$. ${ }^{11}$ Figure E.1 illustrates annual benefits for three case studies in 2030 for key sectors.

This report also presents results of four simulated case studies that analyzed several sub-national development projects, scaled up to the national level, to determine the additional benefits (beyond the economic net present value typically calculated in project financial analysis) over the life of each project, generally 20 years. Four project simulations were studied: expanded bus

Figure E.1: Total annual benefits in 2030 of key sector policies in six regions

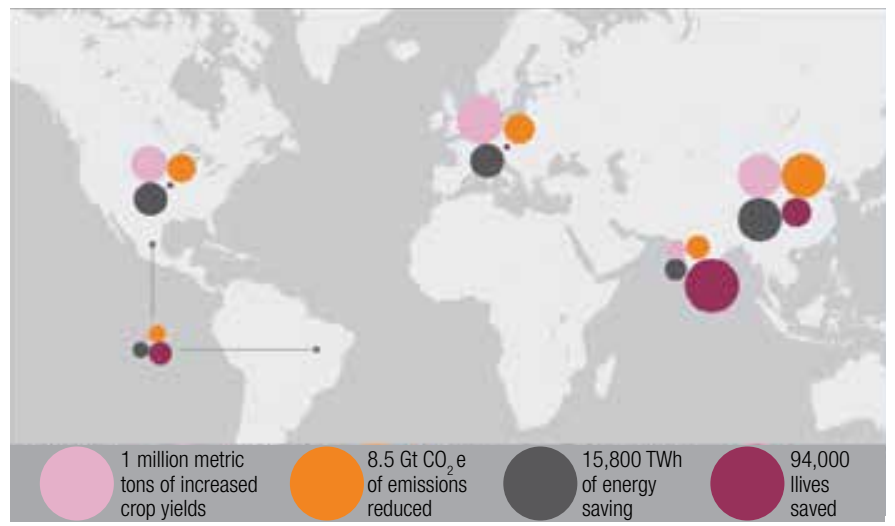

Note: (Results for Mexico are combined with Brazil's.) rapid transit in India, integrated solid waste management in Brazil, cleaner cookstoves in rural China, and biogas digestion and solar photovoltaics in Mexican agriculture.

The aggregate benefits over the life of the projects are estimated to include more than 1 million lives saved, about 1 million-1.5 million tons of crop losses avoided, and some 200,000 jobs created. These projects could reduce $\mathrm{CO}_{2}$ e emissions by 355 million-520 million metric tons, roughly equivalent to shutting down 100-150 coal-fired power plants. This equates to about $\$ 100$ billion- $\$ 134$ billion in additional value for just three of these projects in India, Brazil, and Mexico when accounting for health benefits, avoided crop losses, GDP benefits, and the social benefits of carbon mitigation (beyond direct project benefits such as the value of carbon finance assets, reduced operating costs and other project-related economic benefits). In China, the estimated value of avoided premature death alone would come to more than $\$ 1$ trillion. Figure E.2 illustrates potential benefits for four project simulations scaled to the national level.

8 These five large countries and the European Union are referred to as "six regions" throughout the report for simplicity.

9 Since the sector policy case studies covered a limited number of pollutants (methane and BC, but not other co-pollutants), the health and agricultural benefits are underestimated. However, even with the limited emissions data included in this study, the resulting benefits can be significant.

$10 \mathrm{CO}_{2}$ equivalents $\left(\mathrm{CO}_{2} \mathrm{e}\right)$ as used in this report include only $\mathrm{CO}_{2}, \mathrm{BC}$, methane $\left(\mathrm{CH}_{4}\right), \mathrm{HFCs}$, and nitrous oxide $\left(\mathrm{N}_{2} \mathrm{O}\right)$.

11 To limit the average global temperature increase to $2^{\circ} \mathrm{C}, 2030$ emissions must be limited to approximately $35 \mathrm{Gt} \mathrm{CO}_{2} \mathrm{e}$ (UNEP, 2013; Spiegel and Bresch, 2013); business-as-usual emissions are estimated at $63 \mathrm{Gt} \mathrm{CO}_{2} \mathrm{e}$ in 2030.

Figure E.2: Aggregate benefits over 20 years of four development projects

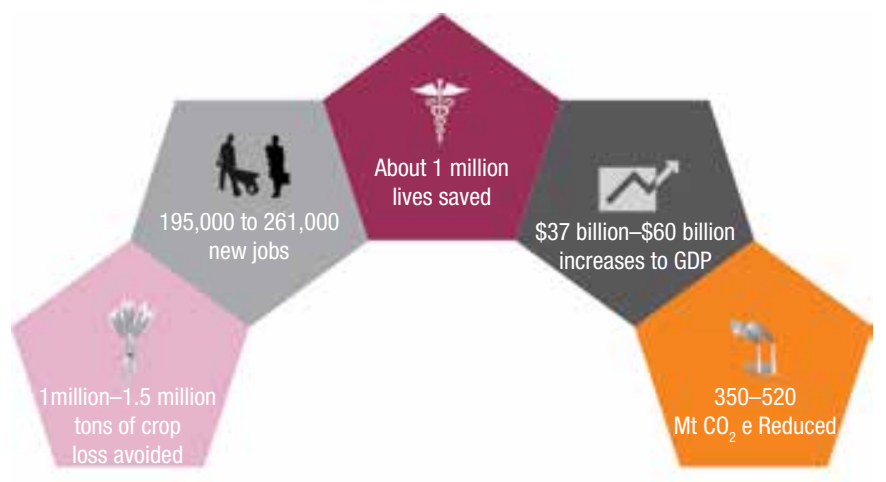

Sustainable Transport: Cleaner Coookstoves: Solid Waste Management: Biogas Digastion \& PV

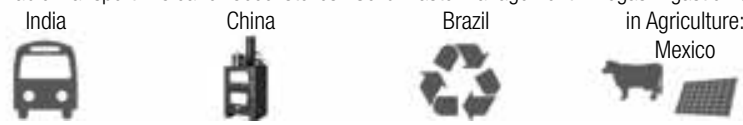

Source: Authors. 


\section{Conclusions and next steps}

This analysis shows that by using the proposed framework, actions can be identified that secure growth, increase jobs and competitiveness, save lives and slow the rate of climate changes.

Many development efforts-across a range of sectors-hold the promise of economic growth as borne out by economic analysis. Activities that also reduce emissions-across a range of pollutants-deliver health, agriculture and other socioeconomic benefits that are integral to a broader development agenda. Quantifying and including these benefits, where possible, can reveal the broader socioeconomic value of projects while enhancing the case for climate mitigation. Given the rising cost of inaction on climate change, it is imperative that the broad benefits of smart development be included in economic analyses.

As a result of limitations in the framework and available modeling tools, this report does not provide project-level evaluation for decision making nor does it focus on policy implementation issues or costs, which are required for comprehensive policy evaluation. ${ }^{12}$ The report does however highlight areas where additional research could improve limitations with the framework. For example, improved tools are needed to account for behavioral changes such as shifting to public transit and advanced cookstoves, and to explicitly account for the full climate change costs of emissions. ${ }^{13}$ The framework also needs additional work to tailor its application at the individual project level. Areas for research include:

- Further benefits assessments based on more comprehensive emissions data

- Multi-sector macroeconomic analysis that better illustrates the synergistic benefits (for example, using cleaner energy sources to supply the increased power demand for electric cars could yield greater benefits than clean transport or clean power in isolation)

- Additional macroeconomic analysis to reflect the additional benefits of green versus non-green investment options

As scientists continue to clarify the many ways that local air pollution, short-lived climate pollutants, and greenhouse gases harm health, welfare, and the environment, the framework presented in this report can be honed to better account for these costs by providing more complete economic analyses.

Ultimately, climate change is an issue for the whole economy and all facets of development. All policy makers, whether in government cabinets or corporate boardrooms, need to understand where they can get development and climate benefits from the decisions they make. Similarly, those charged with informing decisions from a climate perspective need to able to present more complete analysis and evidence of the broad impacts of their projects and policies.

12 The policy case studies use data from a marginal abatement cost curve model that only considers project costs to implement a technology for a transition and thus is limited in use for full-scale analysis of implementation costs for policies. As a result, the outcomes presented have no prescriptive value in terms of policy evaluation. Rather, due to the limitations of existing information and assumptions, they provide illustrative simulations of how additional benefits could be quantified and integrated into policy evaluation in the future.

13 The social cost of carbon (SCC) is used to monetize the climate change damage avoided when $\mathrm{CO}_{2}$ is reduced. Lacking specific World Bank guidance on the social cost of carbon, values developed by the US Interagency Working Group on Social Cost of Carbon (2013) are used. The SCC accounts for changes in agricultural productivity, human health, and property damage from increased flood risks (US EPA, 2013, http://www.epa.gov/climatechange/EPAactivities/economics/scc.html); however, it does not include all the damage caused by increased $\mathrm{CO}_{2}$ and may evolve as scientific understanding develops further. This does not constitute a World Bank endorsement of these values. The SCC is very sensitive to the discount rate used. In addition, the climate change costs of black carbon emissions are not accounted for. 


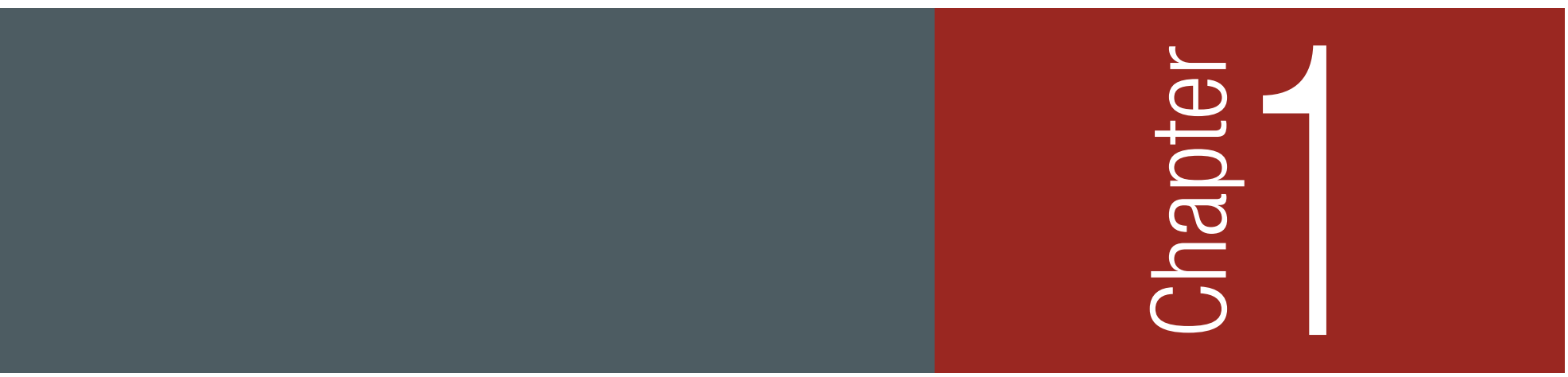

\section{Introduction}

\section{Background}

Climate change is a fundamental threat to sustainable economic development, with devastating impacts on agriculture, water resources, ecosystems, and human health. Immediate, substantial reductions in $\mathrm{CO}_{2}$ and other long-lived GHGs are needed to avoid a $4{ }^{\circ} \mathrm{C}$ warmer world (UNEP 2011a). While every region will be affected, those least able to adapt-the poor and most vulnerable-will be hit hardest.

The large and dominant role of $\mathrm{CO}_{2}$ emissions in raising global average temperature remains unchanged; understanding of the effects of greenhouse gases and other pollutants on the climate system, however, is improving. Other pollutants-namely methane $\left(\mathrm{CH}_{4}\right)$, ozone $\left(\mathrm{O}_{3}\right)$, black carbon $(\mathrm{BC})$, and some hydrofluorocarbons (HFCs), collectively referred to as short-lived climate pollutants (SLCPs) - are now recognized for their potency and as a significant cause of global warming (Methane and HFCs are included in the Kyoto protocol). Although these pollutants have a much shorter lifetime ${ }^{14}$ in the atmosphere than $\mathrm{CO}_{2}$, recent estimates indicate that SLCPs may be responsible for 30-40 percent of overall present-day global warming (Molina et al. 2009; Bond et al. 2013). Reducing emissions of SLCPs now could reduce warming by up to $0.6^{\circ} \mathrm{C}$ by 2050 (Hu et al. 2013; UNEP 2011a and b; Shindell et al. 2012) and avoid or delay potentially dangerous "tipping points" in important climatic systems (Molina et al. 2009).

To avoid the long-term threat of climate change, the world must still reduce $\mathrm{CO}_{2}$ emissions. But reducing SLCP emissions could slow the rate of warming over the next two to four decades, providing time for the poor and vulnerable to adapt to a changing climate.

\section{SLCPs Damage Health and Crops}

The opportunity to mitigate near-term warming is only one reason to reduce SLCP emissions. In addition, air pollution ${ }^{15}$ imposes an undeniable burden on development and threatens many emerging economies (World Bank 2013d). The United Nations Environment Programme (UNEP) estimates that fast action to reduce emissions of SLCPs could avoid an estimated 2.4 million premature deaths from outdoor air pollution annually by 2030 and about 32 million tons of crop losses per year. ${ }^{16}$

A growing body of scientific literature analyzing the effects of air pollution on health and agricultural activities is rapidly emerging. Observational and modeling studies indicate that outdoor air pollution results in more than 3 million deaths annually, with another 3.5 million or more deaths attributed to household-related air pollution (Lim et al. 2012; Silva et al. 2013; Fang et al. 2013; Avnery et al. 2013). In addition, these and other studies have documented that hundreds of millions of metric tons of crop losses could be avoided each year by reducing emissions. Reducing emissions of $\mathrm{BC}$ and methane (which aids in the formation of tropospheric ozone) can provide significant development benefits, including improved health and increased agricultural yields (UNEP/WMO 2011). Annex A explores this literature more fully.

\footnotetext{
14 Compared with hundreds of years or more for $\mathrm{CO}_{2}$, the average lifetime of methane and many HFCs is less than 15 years; BC persists for less than two weeks. 15 SLCPs and air pollution are directly linked through black carbon, which is one component of the air pollutant $\mathrm{PM}_{2.5}$ (particulate matter with a diameter of 2.5 microns or less), and methane, which is a precursor to ground-level ozone pollution. 16 "Integration of Short-Lived Climate Pollutants in World Bank Activities," World Bank (June 2013).
} 
Crucially, the health benefits of reducing black carbon emissions (especially from biomass cookstoves and transport in Asia and Africa) would be realized immediately and almost entirely in the regions that reduce their emissions. China and India especially will reap the benefits of some reductions, such as reduced background ozone, because of their large populations and agricultural sectors.

\section{Emissions: Sources, Impacts, and Reduction Methods}

Emissions are often categorized by how long they persist in the atmosphere.

Long-lived greenhouse gases include carbon dioxide, nitrous oxide, and some $\mathrm{HFCs}$. $\mathrm{CO}_{2}$ is naturally present in the atmosphere; it is also emitted from burning fossil fuels and biomass, and by certain chemical reactions (e.g., cement manufacturing). Nitrous oxide $\left(\mathrm{N}_{2} \mathrm{O}\right)$ is emitted from agricultural, transportation, and industrial sources; its impact on health and agriculture is limited in the examples in this report. Hydrofluorocarbons are used in heating and cooling systems and aerosols; because HFCs do not contribute to health or crop damage, their emissions are not covered in this report. ${ }^{17}$

SLCPs include methane, black carbon, and some other HFCs. Methane is released as a fugitive emission from oil and gas production and distribution, agriculture (including livestock and rice farming), decomposition of municipal solid waste, and other sources. In addition to its warming effect, methane leads to the formation of ground-level ozone, a component of smog, which can cause significant crop damage, respiratory illnesses, and other harmful impacts. BC comes from incomplete combustion of carbon-rich fuel; it is a component of particulate matter and is a risk factor for cardiopulmonary disease and can trigger asthma, heart attacks, and strokes.

Greenhouse gas emissions are usually measured as carbon dioxide equivalents $\left(\mathrm{CO}_{2} \mathrm{e}\right)$.

\section{Win-win Opportunities}

Many projects and policies offer the opportunity to control $\mathrm{CO}_{2}$ and SLCP emissions simultaneously; doing so can deliver both local socioeconomic benefits and global climate benefits, and reduce the net cost of action to mitigate climate change. ${ }^{18}$

Several studies indicate the multiple possible synergies that can be achieved by combining measures that address climate change with efforts to improve air quality or energy security (West et al. 2013; Bollen et al. 2009; Shindell et al. 2012). These studies

\footnotetext{
17 Although $\mathrm{N}_{2} \mathrm{O}$ and $\mathrm{HFC}$ emissions have not been considered from the perspective of potential health or agriculture benefits, their impact in terms of carbon dioxide equivalent radiative forcing reduction has been included in the calculations of the policy intervention scenarios in this report.

18 The term co-benefits generally refers to additional benefits, such as reduced outdoor pollution, that may be associated with a global climate policy. The benefits described here include climate and socioeconomic benefits associated with both $\mathrm{CO}_{2}$ and SLCP reductions and may be considered as multiple or comprehensive benefits.
}

Table 1.1: $\mathrm{CO}_{2}$, Methane, and Black Carbon Emissions Sources, Impacts, and Reduction Methods.

\begin{tabular}{|c|c|c|c|}
\hline Pollutant & Sources & Impacts & Reduction methods \\
\hline $\begin{array}{l}\text { Carbon dioxide } \\
\left(\mathrm{CO}_{2}\right)-\text { Atmospheric } \\
\text { lifetime: hundreds of years } \\
\text { or more }\end{array}$ & $\begin{array}{l}\text { Emitted from burning fossil fuels } \\
\text { and biomass, and by certain } \\
\text { chemical reactions (e.g., cement } \\
\text { manufacturing). }\end{array}$ & - $\quad$ Global warming & $\begin{array}{l}\text { - } \quad \text { More-efficient buildings, appliances, } \\
\text { equipment, industrial processes, transport } \\
\text { systems, and vehicles } \\
\text { - } \quad \text { Cleaner sources of energy } \\
\text { - Improved forest and land management }\end{array}$ \\
\hline $\begin{array}{l}\text { Methane }\left(\mathrm{CH}_{4}\right)- \\
\text { Atmospheric lifetime: } \\
12 \text { years }\end{array}$ & $\begin{array}{l}\text { Released as a fugitive emission } \\
\text { from oil and gas production and } \\
\text { distribution, agriculture (including } \\
\text { livestock and rice farming), } \\
\text { decomposition of municipal solid } \\
\text { waste, and other sources. }\end{array}$ & $\begin{array}{ll}\text { - } & \text { Global warming } \\
\text { - } & \text { Precursor to ground-level } \\
\text { - } & \text { Significant crop damage } \\
\text { - } \quad \text { Respiratory illness and } \\
\text { other health problems }\end{array}$ & $\begin{array}{l}\text { - } \quad \text { Recovery and use from coal mines and oil } \\
\text { production; reduced leaks from natural gas } \\
\text { production and pipelines } \\
\text { - Improved management of municipal waste } \\
\text { and wastewater, including recycling, } \\
\text { composting, and gas capture and use } \\
\text { - } \quad \text { Anaerobic digestion of livestock manure } \\
\text { Improved rice irrigation }\end{array}$ \\
\hline $\begin{array}{l}\text { Black carbon (BC) - } \\
\text { Atmospheric lifetime: days } \\
\text { to weeks }\end{array}$ & $\begin{array}{l}\text { A component of particulate matter } \\
\text { emitted by incomplete combustion } \\
\text { of carbon-rich fuel, including open } \\
\text { burning, residential heating and } \\
\text { cooking, diesel-powered vehicles } \\
\text { and equipment, and old industrial } \\
\text { sources. }\end{array}$ & $\begin{array}{l}\text { - } \quad \text { Short-lived climate forcer, } \\
\text { especially in northern } \\
\text { latitudes } \\
\text { - } \quad \text { Reduced visibility } \\
\text { Cardiopulmonary disease, } \\
\text { asthma, heart attacks, and } \\
\text { strokes }\end{array}$ & $\begin{array}{l}\text { - Standards to reduce vehicle emissions, } \\
\text { including diesel particle filters and } \\
\text { elimination of high-emitting vehicles } \\
\text { More-efficient cookstoves, heaters, brick } \\
\text { kilns, and coke ovens } \\
\text { - Cleaner fuels }\end{array}$ \\
\hline
\end{tabular}


conclude that the multiple benefits of a package of controls are often greater than the individual benefits considered separately; these benefits can reduce the marginal cost when controls are implemented together. They also demonstrate that efforts to reduce SLCP emissions can improve public health, reduce crop losses, and slow the rate of near-term climate change, thereby aiding sustainable development. Recent studies indicate that reducing emissions of $\mathrm{BC}$ and methane may also help reduce sea-level rise (Hu et al. 2013).

Recent work by the World Bank (2013b) in India finds that the combined cost of outdoor and indoor air pollution is more than $\$ 40$ billion annually, or more than three percent of India's 2009 GDP. When other environmental degradation is factored in, including crop, water, pasture, and forest damage, the total is closer to 5.7 percent of India's GDP. This mostly affects the poorest members of society.

The growing recognition of SLCPs' deleterious effects on climate, health, agriculture, and the environment suggests that capturing many of these "externalities" can strengthen the economic rationale for projects or policies that reduce SLCPs.

\section{New Modeling Tools Enable More Holistic Planning}

New methods and tools for capturing multi-pollutant health, agricultural, and environmental benefits allow for expanded economic analysis that more fully accounts for their monetary value. These tools translate the estimated emissions reductions from interventions in various energy systems (using engineering systems models) into changes in atmospheric concentrations (using chemical transport models) and estimate health and agricultural benefits (via concentration-response models and valuation tools).

Two innovative programs helped usher in these modern, synergistic, multi-pollutant air quality and energy planning tools: the European Convention on Long-Range Transboundary Air Pollution and the U.S. market-based approach to controlling acid rain under the Clean Air Act, where advanced economic efficiency is a major driver of the design of air quality management programs (see Box B-1 in Annex B).

The continued integration of energy, economic, and air quality planning has resulted in a new breed of tools ${ }^{19}$ that, when linked together, provide comprehensive benefits calculations, often with monetized value as an output. The advent of these tools enables broader economic analysis of emissions-reduction programs, including improved internalization of externalities than was previously feasible. This report explicitly focuses on expanding benefits analysis, as others (for example, Paltsev and
Capros 2013) have already explored the subject from the cost perspective.

\section{Objectives of this Report}

This report describes efforts by the ClimateWorks Foundation and the World Bank to quantify the multiple economic, social, and environmental benefits associated with policies and projects to reduce emissions in select sectors and regions. The report has three objectives:

- To develop a holistic, adaptable framework to capture and measure the multiple benefits of reducing emissions of several pollutants.

- To demonstrate how local and national policymakers, members of the international development community, and others can use this framework to design and analyze policies and projects.

- To contribute a compelling rationale for effectively combining climate action with sustainable development and green growth worldwide.

By using a systems approach ${ }^{20}$ to analyze policies and projects, this work illustrates ways to capitalize on synergies between efforts to reduce emissions and spur development, minimize costs, and maximize societal benefits.

This report uses several case studies to demonstrate how to apply the analytical framework. The case studies approach this analysis from two perspectives: sector policies applied at the national or regional level and development projects implemented at the sub-national level. The sector policy case studies are based on ClimateWorks' portfolio analysis. The development project case studies are based on World Bank-financed projects, scaled up to the national level. By applying the framework to analyze both types of interventions, this report demonstrates the efficacy of this approach for national and local policymakers, international finance organizations, and others.

These case studies show that climate change mitigation and air quality protection can be integral to effective development efforts and can provide a net economic benefit. Quantifying the benefits of climate action can facilitate support from constituencies interested in public health and food and energy security; it

\footnotetext{
19 These include the U.S. EPA's Environmental Benefits Mapping and Analysis Program (BenMAP), the European Commission Joint Research Centre's Fast Scenario Screening Tool (TM5-FASST), and a new rapid assessment tool being developed by the Climate and Clean Air Coalition to Reduce Short-lived Climate Pollutants (CCAC). 20 The systems approach refers to the incorporation of sector-specific tools to analyze direct benefits and the use of a macroeconomic tool to expand the scope of the indirect benefits included. It is meant to indicate the interconnectedness between identified benefits.
} 
can also advance the international discussion of effective ways to address climate change while pursuing green growth.

\section{Report Structure}

The current chapter provides background information on the pollutants covered in this report and identifies opportunities to achieve both (local) socioeconomic and (global) climate objectives by reducing emissions. It also introduces new modeling tools that enable broader economic analysis of emissions-reduction programs. Chapter 2 explains how these tools can be combined to develop an effective framework to analyze policies and projects. Chapter 3 demonstrates the framework, using several policy- and projectbased case studies to estimate the multiple benefits of emissions reductions from a regional or national level. Finally, Chapter 4 explores the challenges to operationalizing the framework and presents conclusions from the study. 


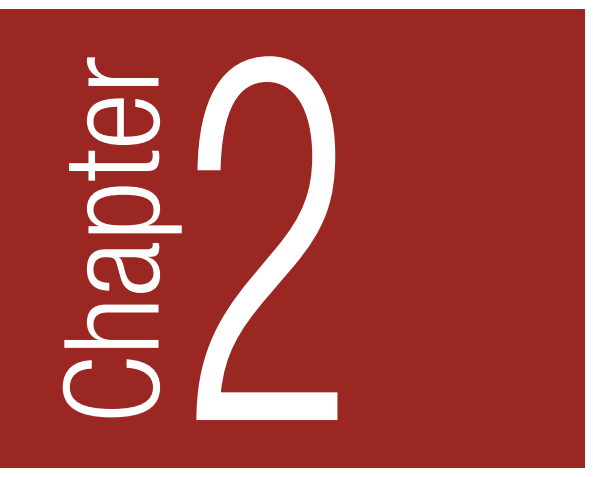

\section{New Framework to Estimate Benefits}

The analysis presented in this report uses recently developed emissions modeling and assessment tools and an integrated macroeconomic model. Prior analyses added some environmental externalities into cost-benefit analyses by quantifying and monetizing specific benefits and adding them individually to the benefits side of the ledger. The framework proposed here advances this work by taking a systems approach, integrating multiple benefits into a macroeconomic model to demonstrate the additional benefits that can accrue-in terms of GDP and employment-as the benefits flow through the economy. All of these benefits are not routinely captured in cost-benefit approaches; new tools make it possible, however, to include many of them in project and policy analyses where emissions can be quantified.

\section{Benefits Framework}

The framework to assess the multiple benefits of projects and policies to reduce emissions of GHGs and SLCPs follows these steps:

1. Identify the full range of benefits: These should include all potential benefits that result from a project or policy, including:

a. Local socioeconomic benefits-such as GDP growth, employment gains, reduced energy and fuel costs, time savings, improved water and air quality, higher crop yields, improved public health, and reduced mortality-that are realized in the jurisdiction that enacts the policy or undertakes the project. b. Global public goods benefits-such as protection of ecosystem services, reduced acid deposition and infrastructure loss, and reduced climate change impacts-that are realized beyond the jurisdiction that carries out the policy or project. For example, reduced sulfate and methane emissions can have large downwind benefits (i.e., beyond the locality that reduced the emissions).

c. Combined benefits that can be realized both locally and globally. While it is important for nations to realize the local benefits of emissions control, it is equally important for them to recognize the shared benefits that accrue to them when their neighbors and other global actors reduce their emissions.

2. Identify appropriate benefits assessment tools: These should include available tools that provide insight on each measurable benefit at the scale or resolution appropriate to the analysis. Selection (or development) of suitable analytical tools is critical. For example, several slightly different tools are used in this report for individual case studies, but entirely different tools may be used as long as they adequately assess the relevant benefits. Those benefits that cannot be quantitatively assessed should be qualitatively described and included in economic analysis.

3. Identify an appropriate macroeconomic tool: This model should enable analysis of economic benefits across sectors and types of benefits. For example, health or agricultural benefits may have a positive effect on other areas of the economy (e.g. labor productivity, household disposable income); energy savings in one sector might benefit another sector (e.g. by reducing energy costs and the investment needed to supply energy). 
4. Estimate significant benefits: Appropriate metrics should be used to measure significant benefits, and the results should be presented so that they are meaningful to the audience they affect. For example, while economic effects might best be presented in monetary terms for policymakers, talking about the impact on cardiovascular health might be more relevant to health officials. Similarly, presenting benefits in terms of crop yields is likely to resonate more with farmers.

This framework is consistent with the World Bank's paradigm of "inclusive green growth" (World Bank 2012b) in that it recognizes the limitations of traditional cost-benefit analysis and attempts to supplement it by quantifying additional benefits to more completely demonstrate the value of green growth strategies. Because different benefits resonate with different audiences at the regional, national, and sub-national levels, it is worthwhile to acknowledge all the benefits in economic analysis, even if not all can be monetized.

\section{Step 1: Identify the Full Range of Benefits}

The first step in applying the framework requires consideration of all potential economic, social, and environmental benefits that a project or policy may yield at the local and global levels. Many common interventions in the energy, transportation, and building sectors are likely to have similar benefits.

For World Bank-financed development projects, socioeconomic benefits are likely to be among the primary motivations, and they should be assessed as part of routine project appraisal. All indirect economic impacts should be considered, such as multiplier and flow-through effects that result from linkages in the economy (for example, whether project investment results in greater manufacturing or construction services) or the effects of complementary economic policies (such as changes in structural relationships due to incentives for local purchases). Studies have shown that reduced traffic congestion enhances economic development (UNEP 2011c; ESCAP 2007) and improved health leads to greater labor force productivity (Sanderson et al. 2013). These economic benefits should be included in analyses; this involves reviewing potentially significant effects and ensuring they are represented appropriately in available modeling tools.

Some socioeconomic benefits are difficult to include in an economic analysis because they are not easily quantified or their assessment relies on contingent valuation methodologies (such as willingness to pay for various benefits). For emissions reduction activities, these benefits can include improved public health and higher crop yields; reduced infrastructure losses from acid rain; improved visibility (which has its own intrinsic value and reduces economic losses in the tourism, aviation, and recreation industries); and time savings due to new public transit. These less tangible benefits can have spillover effects on the macro-economy; for example, good urban environmental quality is important to attract and retain the talented professionals who drive wealth creation in knowledge-based economies (Florida 2000).

Environmental benefits are similarly treated as an externality in most economic analyses. As the WAVES partnership ${ }^{21}$ for Natural Capital Accounting demonstrates, however, many countries are beginning to reflect the costs of reduced ecosystems services on their national ledgers. Environmental benefits include biodiversity, ecosystem services, and reduced climate change impacts.

\section{Step 2: Identify Appropriate Benefits Assessment Tools}

Many types of integrated assessment models are widely used to estimate the benefits or impacts associated with emissions reductions. For example, the partial-equilibrium Global Change Assessment Model (GCAM) models the impacts of climate change policies and technologies on GHG emissions, energy consumption, production, and the economy linked to the energy sector (Clarke et al. 2008). The Greenhouse Gas and Air Pollution Interactions and Synergies (GAINS) model is used in co-benefits studies to assess the health and ecosystem impacts of particulate pollution, acidification, eutrophication, and tropospheric ozone (Amman et al. 2008). Several other technology models also simulate anthropogenic systems and their linkage to the atmosphere, quantifying several benefits. These include top-down and bottom-up approaches, and they have evolved significantly as a result of regulatory programs that have emphasized economic efficiency (See Box B-1 in Annex B).

Key features of these models include their ability to estimate the regional costs and a range of benefits of alternative emissions control strategies, and to identify cost-effective measures to achieve specified emissions reduction targets. This study used a variety of models to determine changes in emissions, in costs, and in health, agricultural, and other economic benefits.

The particular tools chosen for this study should be viewed as examples only. The World Bank's low-carbon growth studies (ESMAP 2012) provide many other examples of methods to assess long-term mitigation potential and benefits even though the overarching goal of those studies was to reduce the emissions trajectory of growth at the country level.

\footnotetext{
21 Wealth Accounting and the Valuation of Ecosystem Services: http://www. wavespartnership.org/waves/.
} 


\section{Tools Used for Sector Policy Benefits Assessment}

This report relied on two models to analyze the benefits of the policy-based case studies (See Figure 2.1 and Annex B):

- Marginal abatement cost curve model (MACC). Developed by McKinsey \& Co. (Enkvist et al. 2009) with ClimateWorks support, this model estimates potential emissions reductions and associated costs. Although not as detailed as sector-specific models, it represents a unified view of the available technical measures to reduce GHG emissions or SLCPs, their emissions reduction potential $\left(\mathrm{MtCO}_{2} \mathrm{e}\right)$, and the associated cost $\left(\$ / \mathrm{tCO}_{2} \mathrm{e}\right)$ in a specific year for different regions and countries. The abatement potential and corresponding costs are calculated relative to a business-as-usual scenario (BAU) in a given year. ${ }^{22}$ In this study, impacts in 2030 are considered.

- Fast Scenario Screening Tool (TM5-FASST). Developed by the European Commission Joint Research Centre (Van Dingenen et al. 2009), this model estimates health and agricultural impacts. This model links emissions of pollutants in a given source region to downwind pollutant levels (at the national level and globally) using meteorology and atmospheric chemistry. Pollutant levels are then used to calculate impacts by applying specific dose-response functions from scientific literature. The outputs include lives saved per year from avoided cardiopulmonary, respiratory, and lung-cancer-related causes, as well as changes in agricultural yields for maize, rice, wheat, and soybean.

\section{Tools Used for Development Project Benefits Assessment}

The four development project case studies used several sectorspecific tools and bottom-up analyses to estimate the benefits of the interventions, including TM5-FASST and:

- Transportation Emissions Evaluation Models for Projects (TEEMP) (GEF 2010). Developed by Clean Air Asia (ADB 2013), this model quantifies emissions and multiple benefits (such as reduced accidents and travel time), and uses simplified analysis to determine the economic feasibility of a project. As a technology-oriented model, it relies on projected demand as an input rather than independently assessing the future demand for new technologies. ${ }^{23}$

- Environmental Assessment of Solid Waste Systems and Technologies (EASEWASTE). Developed by the Technical University of Denmark (Kirkeby et al. 2008), this life-cycle assessment model follows waste management from generation through collection, transportation, and treatment, and calculates the environmental emissions and impacts of alternative treatment scenarios.
Two development project case studies, on biogas digesters and improved cookstoves, relied on project experience and expert judgment to estimate emissions reductions and benefits. The focus of the analysis in all cases is to demonstrate an adaptable framework to assess benefits.

\section{Step 3: Identify an Appropriate Macroeconomic Tool}

For all of the case studies in this report, the outputs from the MACC, FASST, and other tools are fed into the Global Energy Industry

22 The identification of least-cost $\mathrm{CO}_{2} \mathrm{e}$ abatement opportunities does not equate to an endorsement of the proposed interventions or actions in all cases. Rather this tool is utilized as one possible basis for collectively assessing the additional benefits of a given set of emissions reduction measures. Individual abatement measures and opportunities should be carefully selected on the basis of individual country context and development appropriateness.

23 TEEMP does not address the analytical need for tools that account for consumer preference, behavior change, and structural relationships that reinforce existing transportation patterns (such as zoning regulations and infrastructure deployment). These tools require further research and development. In the absence of tools to do this enhanced analysis, however, TEEMP can provide basic estimates of benefits that could come from the most common transportation systems.

Figure 2.1: Analytical framework used for the policy and project case studies

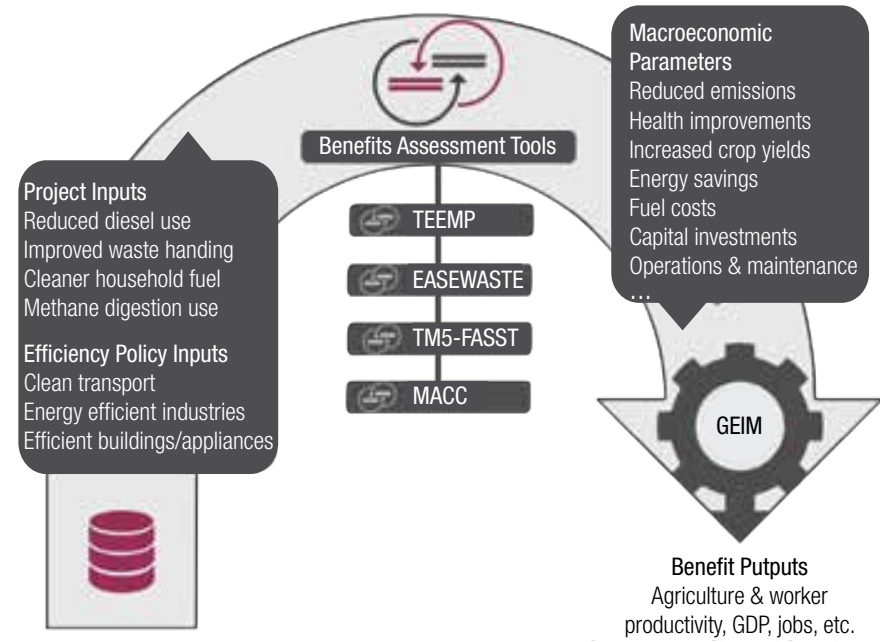

Note: Health and agricultural benefits were included in the macroeconomic model only when they were large enough to have a significant impact on the variables included in the GEIM. The specific changes that result from sector policies and development projects are analyzed to determine their emissions reductions. Specific data-such as changes in transportation modes, waste handling, building regulations, and pollutant levels-are fed into appropriate benefits assessment tools to quantify the multiple benefits. These benefits are then fed into a macroeconomic model to demonstrate the additional economic benefits that can accrue. 
Model (GEIM) from Oxford Economics, which calculates the macroeconomic implications of climate and air quality interventions. Macroeconomic models are quantitative tools routinely used to evaluate the impact of economic and policy shocks-particularly policy reforms-on the economy as a whole. These models reproduce (in a stylized manner) the structure of the whole economy, including the economic transactions among diverse agents (productive sectors, households, the government, and others). This approach is especially useful when the expected effects of policy implementation are complex and materialize through different transmission channels, as is the case with climate and energy policies. Details about the GEIM can be found in Annex B.

\section{Limitations of Bottom-up and Macroeconomic Modeling}

Combining bottom-up (MACC) and top-down (macroeconomic modeling) approaches has advantages and disadvantages. Bottomup models disaggregate energy consumption across sectors and consider specific energy technologies with technical and economic parameters, but they often neglect to account for feedbacks in the economy and the effects of international energy markets. Top-down models are good at identifying complex and dynamic interactions among macroeconomic variables, but they are very aggregated and lack the level of resolution necessary to inform policymaking. Additionally, top-down macroeconomic models show only how real resources are reallocated among economic activities after the economy has "equilibrated" following a shock to the system (e.g., an oil price change); they generally cannot easily model the gradual uptake of new technologies. Both kinds of models depend crucially on some simplifying assumptions that do not reflect real-world conditions. This can be remedied to a certain extent by tailoring the scenarios to specific needs, but uncertainties remain that must be recognized and highlighted when presenting the results. ${ }^{24}$

Another concern with respect to economic analysis of capital investment relates to the Keynesian effects of some projects. For example, disaster reconstruction aid might generate significant economic activity with GDP benefits, but it does not improve productivity; rather it simply replaces productive capacity that was lost in a disaster. Assuming some slack in the economy, all spending will produce multiplier effects on GDP, or "Keynesian benefits." Thus analysis must carefully distinguish any productivity benefits that result from green investment.

In this analysis, the GEIM model deals with Keynesian effects to some extent by recognizing the long-term drag on the economy caused by capital investment. Any additional investment that does not improve efficiency or expand productive capacity puts a drag on the economy in the long term. The transmission channel for this is essentially crowding out: the additional investment increases demand and, as a result, GDP and the rate of inflation; in response, the central bank raises interest rates, which causes demand (in particular investment) to fall and GDP to move back toward baseline levels. If the additional investment is large enough, it will crowd out a significant portion of capacity-expanding investment, which will in turn result in lower potential and actual output in the long run. ${ }^{25}$

To the extent that GDP rises above baseline levels in the case studies in this report, it reflects an increase in productivity or energy efficiency that results in sustainable economic development. In future analyses, it may be appropriate to compare GDP growth for a proposed intervention with the Keynesian effects associated with a default alternative project, such as the average distribution of historic public investment. The net effect would represent the benefit or cost of the proposed intervention.

\section{Step 4: Estimate and Present Significant Benefits}

The fourth step in the framework requires that the benefits are measured and presented appropriately for various audiences. This involves selecting metrics that are meaningful to the audience, and not all benefits can or should be monetized and aggregated. Economic effects should be presented in monetary terms, such as net present value or change in GDP. Specific health benefits may be more relevant to public health officials than the statistical monetized value of avoided mortalities. Tons of avoided crop losses will likely resonate most with farmers and agricultural policymakers.

The next chapter shows how this framework can be applied, and the benefits of a variety of case studies are estimated using a range of metrics. For policymakers, information on mitigation costs and benefits help identify policies that can optimize development or welfare benefits while also attaining environmental goals. For international finance and development organizations, the results of different scenarios indicate which sectors and regions stand to benefit most from financial interventions. For non-climate philanthropists and analysts, the economic, social, and environmental benefits provide insights on how emissions mitigation measures can also improve public health and food and energy security.

\footnotetext{
24 At least one round of iteration between macroeconomic models and technology models should be conducted to allow the fixed parameters of technology models to be updated based on macroeconomic responses. The iteration process will likely produce only minor changes, relative to the initial estimate and was not conducted here given the preliminary nature of this analysis.

25 In some cases, additional investment also expands a country's capital stock (e.g., building new power plants, adding new public transit systems); in other cases, green capital investments may not do so if they strand assets before their normal retirement age. This effect is not included to a significant degree in the case studies that follow.
} 


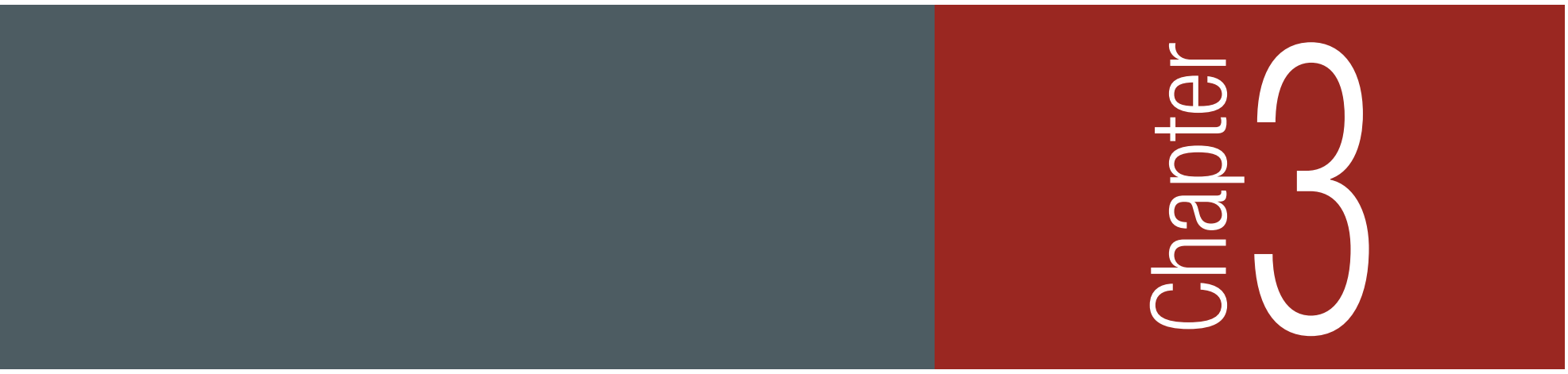

\section{Multiple Benefits Assessment-Case Studies}

The framework described in the preceding chapter was applied to two types of case studies to demonstrate the estimation of benefits from two perspectives: (1) sector policies applied at the national or regional level, and (2) development projects implemented at the sub-national level. By applying the framework to analyze both types of interventions, this report demonstrates the efficacy of this approach for national and local policymakers, international finance organizations, and others. A summary of the case studies is presented in this chapter, and more detailed descriptions are contained in Annex C (for sector policies) and Annex D (for development projects).

\section{Valuation Methods Used in this Report}

This report uses the following methods to monetize the benefits of climate and development action:

- Value of statistical life (VSL): Adjusting for differences in income and purchasing power, the following values of statistical lives saved were established (all reported in 2010 purchasing power parity in U.S. dollars).Using methods recommended by the OECD (2011), values for OECD member countries were based on a U.S. value of $\$ 7,887,511$ (U.S. EPA Guidance 2000); ${ }^{26} \mathrm{EU}, \$ 5,713,388$ and Mexico, $\$ 3,055,289$. Values for non-OECD countries were derived by averaging available estimates of locally determined VSLs:27 Brazil, $\$ 1,555,802$; China, \$700,635; and India, \$967,998.

- Crop values: For agricultural sectors, this report uses the 2010 World Bank average grain crop price of $\$ 171.80^{28}$ per ton for the crops considered (maize, wheat, rice, and soybeans) and further estimates that each metric ton of cereal contains three million kilocalories (kcal) of energy. Assuming a daily calorie need of 3,000 kilocalories of energy (kcal), this translates into about one million kcal per person per year. Hence one metric ton of cereal can feed three people for one year (Cassidy et al. 2013; Nellemann et al. 2009).

- Social cost of carbon: $\mathrm{CO}_{2}$ emissions reductions are valued in this report based on U.S. government estimates of the social cost of carbon, which project changes in agricultural productivity, human health, and property damage from increased flood risks. ${ }^{29}$ Due to limited data availability and uncertainty, however, this social cost of carbon does not account for all the damage caused by increased $\mathrm{CO}_{2}$, and it does not explicitly account for the health and agriculture benefits of reduced SLCP emissions. This report uses the average values (\$34 per ton in 2010, rising due to increased damages over time to approximately $\$ 55$ per ton in 2030) obtained using discount rates of $2.5,3$, and 5 percent in 2010 dollars (U.S. Interagency Working Group on Social Cost of Carbon 2013). Benefits derived using the 3 percent discount rate are presented in the main text for illustration, but sensitivity to other social discount rates is presented in the annexes.

26 Following OECD (2011), an income elasticity of 0.8 was used for inter-country transfer within the OECD. All 2010 VSLs were indexed over time based on projected national income (GDP) growth, assuming income elasticity of 1 (assumes current value will hold the same relationship to income as in the future).

27 China: Wang and He (2010), Hammit and Zhou (2006), Qin et al. (2000), Zhang (1999), Liu and Zhao (2011); India: Shanmugam (1997), Alberani et al. (1999), Bussolo \& O’Connor (2001), Madheswaran (2007); Brazil: Markandya (1998), Serôa Da Motta et al. (1997), Ortiz et al. (2009).

28 data.worldbank.org.

29 US EPA (2013): http://www.epa.gov/climatechange/EPAactivities/economics/ scc.html. Note that these damages are largely based on modeled climate impacts due to increased extreme weather such as hurricanes, floods, and droughts. These do not overlap with the benefits from avoided air pollution and agricultural losses. 
- Carbon finance value: GHG reductions can help finance certain projects through the sale of certified emissions reductions in various carbon markets, such as the Clean Development Mechanism (CDM) and the EU Emissions Trading System. The value of the emissions reduction is determined by individual market conditions and does not reflect the full value to society.

- $\mathrm{CO}_{2}$ mitigation cost: The cost per ton of avoided $\mathrm{CO}_{2}$ emissions is determined by the MACC model.

- Effect on GDP: The macroeconomic impacts of the multiple benefits as they flow through the economy are calculated using the GEIM model. A discount rate of 10 percent is used (consistent with Belli et al. 1998) within the GEIM macroeconomic calculations. However, social discount rates of $2.5,3$, and 5 percent were used to calculate the net present value of GDP and other socioeconomic benefits. Again, the central value of 3 percent was used for illustrative purposes in the main text, but sensitivity to the other social discount rates is presented in the annexes.

- Project benefits: The stated benefits of World Bank-financed development projects are calculated as the net present value of the stream of annual benefits less costs over the life of a project (scaled to the national level for the case studies presented). These stated benefits might include new revenue streams (such as fees collected) and cost savings (such as reduced energy or transit costs).

- Energy savings: The monetized values for energy savings are obtained by assuming a price of oil of $\$ 80 /$ barrel in 2010 dollars, in accordance with the scenario assumptions of MACC 3.0 (see Annex C) and applying the following equivalences: $1 \mathrm{GWh}$ $=8.6 \mathrm{e}^{-5}$ Mtoe and 1 Mtoe $=7.33$ Mboe (IEA, BP). This is a rather crude, imprecise estimate, but it is nonetheless useful in providing an order of magnitude of the monetary savings associated with the emission reductions in each case study.

\section{Sector Policy Case Studies}

The case studies presented below analyze three key sector policy interventions needed to address the mitigation gap identified by UNEP (2013). They describe policy changes, including regulations, incentives, and taxes, to stimulate specific measures ${ }^{30}$ to cut emissions from three sectors: transportation, industry, and buildings relative to a "no new policy" baseline scenario. ${ }^{31}$ The analysis includes impacts in five countries and one region-China, India, the EU, the U.S., Mexico, and Brazil (subsequently, for simplicity, referred to in this report as "six regions")-plus the impact on global GDP. This analysis refers to the U.S. and the E.U. as developed countries and to China, India, Mexico, and Brazil as emerging economies. The case studies use the MACC model to identify all quantified opportunities to reduce emissions of $\mathrm{CO}_{2} \mathrm{e}^{32}$ with a mitigation cost below $\$ 80 / \mathrm{tCO}_{2} \mathrm{e}^{33}$ (Spiegel and Bresch 2013; Dinkel et al. 2011).

These mitigation costs are defined as the incremental cost of a low-emission technology compared with the reference case, measured in $\$ / \mathrm{tCO}_{2} \mathrm{e}$. These costs include two key components: (1) the annualized repayments for capital expenditure (CapEx), or the additional investments in new technology or replacement infrastructure necessary to achieve the GHG emission reductions, and (2) the operational costs or savings (OpEx), fuel- and nonfuel-related, associated with each abatement opportunity. The abatement costs can therefore be interpreted as pure project costs incurred to install and operate each low-emitting technology. Other key elements-transaction costs, communication/information costs, subsidies or explicit $\mathrm{CO}_{2}$ costs, taxes, and the economic impacts of investing significantly in low-emitting technology (such as advantages from technology leadership)-are deliberately excluded from the cost calculations.

Since data is only available for black carbon and methane, the health and agricultural benefits estimated here are conservative. ${ }^{34}$ They therefore have a negligible impact on the economy relative to the size of the economy and the labor force. A future study (see footnote 51 in Annex C) will examine similar benefits for mitigating a larger suite of pollutants.

As described in the prior chapter, the quantified SLCP emission reductions from the MACC model are fed into the TM5-FASST tool to model the resulting health and agricultural impacts in 2030 (see Annex C for the 2020 values). Although the impacts are mostly seen in the regions where emissions are reduced, downwind impacts in other regions are also observed. These emissions reductions and impacts, including reduced mortality and decreased crop damage,

\footnotetext{
30 The selection of certain lowest-cost SLCP interventions in each sector does not constitute an explicit endorsement. Rather these interventions were selected as a reasonable basis to demonstrate how to quantify multiple development benefits. In practice, each potential measure should be considered in the context of local development circumstances and appropriateness.

31 The power sector was not analyzed in this study because a similar breakdown for non- $\mathrm{CO}_{2}$ emissions was not available from the cost-curve model.

$32 \mathrm{CO}_{2}$ e includes $\mathrm{CO}_{2}, \mathrm{BC}$, methane $\left(\mathrm{CH}_{4}\right)$, HFCs, and nitrous oxide $\left(\mathrm{N}_{2} \mathrm{O}\right)$. HFCs are not considered in this analysis because they have no quantifiable impact on health and crops. The impact of $\mathrm{N}_{2} \mathrm{O}$ on health and agriculture is limited in the cases considered here. Because other ozone precursors are not considered, agricultural yields are mainly affected by methane controls (Avnery et al. 2011).

33 This value was selected because higher-cost measures tend to be early-stage technologies whose development is difficult to project. Choosing this threshold limits the mitigation potential to roughly 76 percent of the total potential identified in the cost curve. That figure drops to 68.5 percent at $\$ 66 / \mathrm{tCO}_{2} \mathrm{e}\left(€ 50 / \mathrm{tCO}_{2} \mathrm{e}\right)$ and 67.5 percent at $\$ 53 / \mathrm{tCO}_{2} \mathrm{e}\left(€ 40 / \mathrm{tCO}_{2} \mathrm{e}\right)$. See Annex $\mathrm{C}$ for a detailed representation of all mitigation opportunities in the road transport, industry, and building sectors considered in the sector policy case studies, including those above $\$ 80 / \mathrm{tCO}_{2} \mathrm{e}$.

34 Agricultural impacts are only shown for the industry sector mainly due to methane emissions; agricultural impacts for transport and buildings are not available since only $\mathrm{BC}$ emissions are available in these sectors (and these have a negligible impact on agriculture).
} 
are fed into the GEIM. The resulting outputs include changes in GDP and employment. The "transmission channels" 35 and results are summarized below.

Each sector policy case study analyzes the macroeconomic results of two scenarios in order to estimate the lower and upper bounds of possible effects of the policy interventions.

Scenario 1 makes two key assumptions:

a. Self-financed transition: Each country pays for the full costs of the transformations required to reduce GHG emissions.

b. No technology transfer: Developed countries produce all the new (cleaner, more efficient) technology needed to transform each sector, which boosts their exports and emerging markets import the necessary technology.

Scenario $\mathbf{2}$ is similar to Scenario 1 but makes different assumptions:

a. International climate finance: Developed countries pay for 60 percent of the capital expenditures incurred by emerging economies to reduce GHG emissions on a prorata basis depending on their GDP.

b. Accelerated technology transfer: Emerging economies produce 80-100 percent of the new (cleaner, more efficient) technology needed to transform each sector, while developed countries produce 100 percent of their own technology.

Results are categorized as global or local benefits. As explained in Chapter 2, global public goods benefits include reduced climate change impacts and the transboundary benefits of reduced emissions; local socioeconomic benefits include health and other benefits realized within the five focus countries and one region that reduce emissions. Changes to GDP are presented on a global basis. The social value of carbon is based on the social cost of carbon explained above, using a 3 percent discount rate. Values for different discount rates are shown in Annex C. For monetizing global value of lives saved, the VSL for India is used as most of the global total is found in the South Asian region.

\section{Sector Policy Case Study 1: Shift to Clean Transport}

GHG emissions from the transportation sector account for about 13 percent of global total; of that, emissions from road transport account for about 80 percent of total transport emissions. These numbers highlight the opportunity for governments and the private sector to work together to reduce the carbon intensity of transportation.

\section{Sector Policy Case Study 1: Shift to Clean Transport}

This case study assumes policy interventions that achieve a 30-45 percent improvement in the fuel efficiency of conventional vehicles and aggressive penetration of alternative fuel vehicles by 2030 , with hybrid vehicles representing up to 60 percent of new vehicle sales and fully electric vehicles making up 8-12 percent of new vehicle sales in 2030. A mode shift of passengers to public transit is assumed to be two percent metro, eight percent buses, and 10 percent BRT in 2030. Twenty percent of freight traffic is assumed to shift from rubber to rail and five percent from rubber to sea in 2030.

\section{Case Study Interventions}

This case study includes the following changes:

- Improving the fuel efficiency of internal combustion engine vehicles.

- Shifting to hybrid and electric vehicles.

- Transitioning to low-carbon fuels such as bio-ethanol for medium- and heavy-duty vehicles.

- Increasing government investment in transport infrastructure to support the new vehicle types.

- Shifting from cars to public transit (rail, bus, and BRT).

- Shifting freight from trucks to trains (rubber to rail) and ships (rubber to sea).

This case study places greater emphasis on technology change and less on mode shift, in part because it is based on a MACC model that does not fully account for behavior changes such as a shift to mass transit. Thus this model may unfairly compare marginal changes to a carbon-intensive transport mode with the major infrastructure changes needed for an innovative, low-emissions mode. For instance, because recharging networks for electric cars require high fixed investment, the cheapest option would appear to be smaller changes to conventional vehicles. However, climate change uncertainty and inertia argue for early mitigation that requires system-level changes. Despite this drawback of the MACC model, this case study illustrates the economic benefits of such a transition.

\section{Case Study Benefits}

The benefits of a shift to cleaner transportation include substantial fuel savings and reduced air-quality-related complications and deaths resulting from respiratory illnesses. Since households and

35 See Figure B2 in Annex B for an overview of the transmission channels included in this analysis. 
firms would have to buy less fuel, they would have more money to spend on other goods and services; in addition, the reduced demand for oil would lower oil prices, providing a boost to the economy. ${ }^{36}$ The power sector would, however, need to make investments to meet the increased electricity demand from electric vehicles; the costs of this investment would ultimately be paid by consumers. Other benefits, such as time savings and reduced fatalities from improved public transportation systems, are not quantified here.

Global GDP would be about 0.5 percent and 0.8 percent higher than baseline levels in 2030 for Scenarios 1 and 2 (equivalent to $\$ 600$ billion and $\$ 1$ trillion in 2010 dollars, respectively). The impact across countries is, however, heterogeneous. Developed economies would perform best, even in the scenario least favorable to them. For emerging markets, the combination of higher electricity prices and the long-run drag from paying for capital investments (See description of Keynesian effects on Pg. 8), even in the scenario that assumes a significant role for international climate finance, would result in GDP growth being dampened relative to baseline levels in 2030 .

By 2030, the mitigation measures undertaken in the five countries and one region are estimated to save more than 21,000 lives globally each year from avoided premature deaths. Within the focus countries and region, the emissions reductions would reduce air-quality-related mortality by about 20,000 lives per year; in monetary terms, the reduced deaths would be equivalent to $\$ 87$ billion (2010 dollars). India and China account for over 90 percent of the total (see Figure 3.1).

Results of the case study are summarized in Box 3.1.

Figure 3.1: Climate benefits of sustainable transport policies in 2030

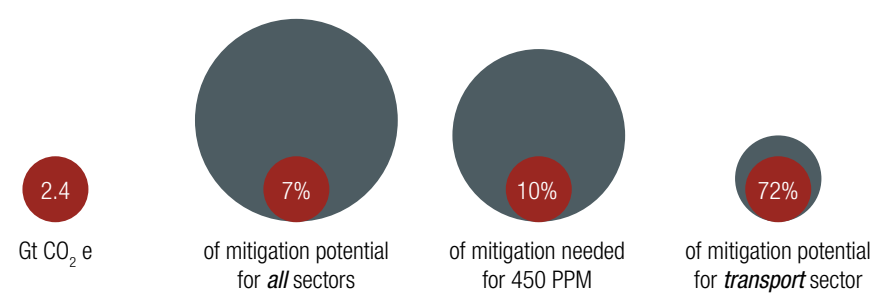

Note: A shift to cleaner transportation would avoid 2.4 Gt of $\mathrm{CO}_{2}$ e emissions at an average mitigation cost of $\$ 169 / \mathrm{tCO}_{2} \mathrm{e}$. $^{a}$ This represents 7 percent of the total global technical mitigation potential (for all sectors), 10 percent of the energy-related emission reductions necessary to stabilize $\mathrm{CO}_{2} \mathrm{e}$ concentration at 450 ppm, and 72 percent of the available global technical potential in the road transport sector

a In other words, these emissions reductions would save money. The abatement cost for society is negative for many of the transportation changes (such as improvements in conventional vehicles) because the payback over the lifetime of the vehicle is assumed to be positive (the fuel cost savings more than offset the initial additional investment in improved technology). Only fuel cost savings are considered; no other benefits are included.

\section{Summary and Conclusions}

As shown in Figure 3.2, a transformation of the transport sector toward more-efficient vehicles and freight and greater use of advanced biofuels and public transit, would have significant economic and health benefits in the six focus regions. These changes would save about $\$ 170$ per ton of avoided $\mathrm{CO}_{2}$ emissions. At the global level, GDP would be about $0.5-0.8$ percent higher than baseline levels in 2030, but the impact across countries would be mixed. Developed economies would perform best, even in the scenario least favorable to them. However, emerging economies, particularly India and China, would reap the greatest benefits in lives saved from reduced air pollution. As noted above, because of limited emissions data, the mortality savings and resulting economic impacts are conservative.

\section{Sector Policy Case Study 2: Energy-efficient Industry}

Direct and indirect ${ }^{37} \mathrm{CO}_{2}$ e emissions from the industrial sector are the single biggest contributor to global emissions. Direct emissions alone account for about 20 percent of global emissions. The cement, chemicals, and iron and steel sectors are the three largest emitters; government policies to reduce their emissions would have a significant impact on the global fight to contain climate change.

\section{Case Study Interventions}

This case study considers the impact of a government-led transformation of industry, including a shift to clean fuels and reduced

36 The transmission channels in this macroeconomic analysis would benefit from better modeling of inter-sector effects. For example, lower oil prices may result in more oil being used in other sectors, reducing the net gain.

37 Indirect emissions in the industrial sector are from electricity consumption.

Figure 3.2: Socioeconomic and climate benefits of sustainable transport policies in 2030 by region

\begin{tabular}{|c|c|c|c|c|c|c|}
\hline Transport & $\begin{array}{l}\text { Brazil \& } \\
\text { Mexico }\end{array}$ & China & EU & India & US & $\begin{array}{l}\text { Monetized } \\
\text { Benefits } \\
\text { (2010 \$bn) }\end{array}$ \\
\hline $\begin{array}{l}\text { Lives } \\
\text { Saved } \\
\qquad 20,000\end{array}$ & $4 \%$ & $31 \%$ & $1 \%$ & $4 \%$ & $0 \%$ & $\$ 87$ \\
\hline $\begin{array}{l}\text { Energy } \\
\text { Saved } \\
\text { 4,700TWh }\end{array}$ & $8 \%$ & $26 \%$ & $31 \%$ & $10 \%$ & $25 \%$ & $\$ 237$ \\
\hline $\begin{array}{l}\text { Emissions } \\
\text { Reduced } \\
2.4 \mathrm{Gt} \mathrm{CO}_{2} \mathrm{e}\end{array}$ & $9 \%$ & $20 \%$ & $41 \%$ & $11 \%$ & $19 \%$ & $\$ 132$ \\
\hline
\end{tabular}




\section{Box 3.1: Sector Policy Case Study 1 Benefits: Shift to Clean Transport}

A transformation of the transport sector in the six focus regions, through more fuel-efficient internal-combustion vehicles, more widespread adoption of electric and hybrid vehicles, greater use of public transport and advanced biofuels, and a shift to more efficient freight, would generate substantial benefits (all values are annual results in 2030 for the six focus regions, unless noted), including:

\section{Local ${ }^{\star}$ Socioeconomic Benefits}

- Lives saved: roughly 20,000 premature mortalities from air pollution avoided per year, with a monetized value of about $\$ 87$ billion.

- Energy saved: about 4,700 TWh, roughly equivalent to 12.5 percent of projected energy consumption in the transport sector and 2.3 percent of projected total global energy demand (cf. IEA WEO 2013).

- Effect on global GDP**: increase of about 0.5-0.8 percent above the baseline, or $\$ 600$ billion- $\$ 1$ trillion, equivalent to $\$ 250-400 / t C O_{2} e$, with uneven effects among countries.

\section{Global Public Goods}

- $\mathrm{CO}_{2}$ e emissions reduction: roughly $2.4 \mathrm{Gt}$ per year.

- Average mitigation cost: $-\$ 169 / \mathrm{tCO}_{2}$ e (MACC).

- Estimated social value of $\mathrm{CO}_{2}$ e reductions: $\$ 132$ billion.

- Additional lives saved: roughly 1,300 premature deaths from air pollution avoided per year outside the six focus regions, with a monetized value of about $\$ 6$ billion.

${ }^{*}$ Local here refers to the six focus regions.

** Although these are global GDP values, the results are driven entirely by shocks inflicted on the economies of the six focus regions.

energy consumption. Specific changes include a switch from coal to natural gas, biomass, and electricity; more-efficient motors, kilns, and coke ovens; and carbon capture and storage.

\section{Case Study Benefits}

The shift to a more energy-efficient industrial sector would have significant impacts on the economy, health, and agricultural productivity. The TM5-FASST model shows that the fuel switch would reduce emissions-related mortalities by about 52,000 lives per year for the six focus regions; the majority of these are in India (see Figure 3.2). In monetary terms, the mortality savings

\section{Sector Policy Case Study 2: Energy Efficient Industry}

This case study considers the impact of policies to shift all industrial sectors away from the dirtiest fuels and to reduce their energy consumption by $8-53$ percent depending on the sector:

- Chemicals: 21-53 percent (about one-third of abatement potential).

- Cement: 8-14 percent (about one-quarter of abatement potential).

- Iron and steel: 8-14 percent (about one-seventh of abatement potential). are equivalent to about $\$ 240$ billion (2010 dollars). In addition, because of reduced crop damage from ozone emissions, yields for four crops (maize, wheat, rice, and soybeans) would increase by about 1.3 million metric tons in the six regions. The EU and China would reap the most agricultural benefits. The global impact of these mitigation measures (including benefits that accrue outside the six focus regions) would result in a total of about 58,000 lives saved per year in 2030, and in an increase in crop yields of 1.72 million tons per year in 2030 .

Based on the GEIM model, global GDP would be about 1-1.2 percent above baseline levels in 2030 in Scenarios 1 and 2 (equivalent to $\$ 1.2$ trillion and $\$ 1.4$ trillion respectively), with heterogeneous impacts across countries. Because developed countries have already made substantial improvements to their industrial energy efficiency, the average gains available from lower energy consumption are limited. In Scenario 1 (which assumes that developed countries produce most of the high-tech infrastructure needed to transform the sector), however, developed countries do gain from an increase in exports of capital goods to emerging economies. For the emerging economies, the potential gains from lower energy use are more significant and, as a result, these countries improve their global competitiveness in both scenarios. While the impact on GDP and jobs is positive everywhere, in Scenario 1 developed countries experience slower growth in GDP and employment than in Scenario 2. In both scenarios, emerging economies see significant employment gains. The results of the case study are summarized in Box 3.2. 
Figure 3.3: Climate benefits of energy efficient industry policies in 2030

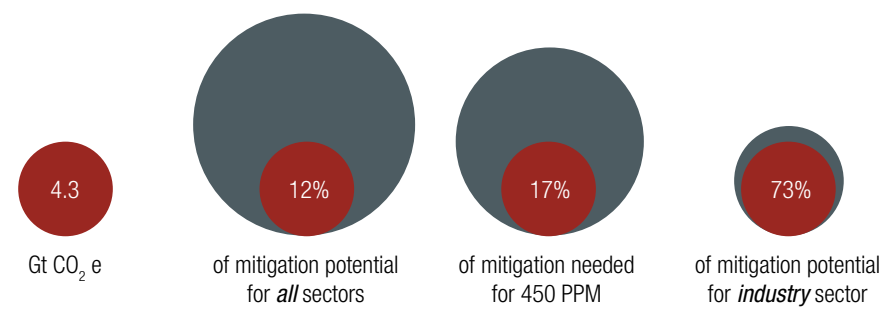

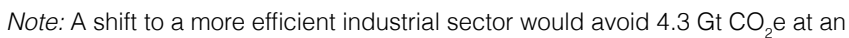
average mitigation cost of $\$ 7 / \mathrm{tCO}_{2} \mathrm{e}$. This represents 12 percent of the total global technical mitigation potential (for all sectors), 17 percent of the energy-related emission reductions necessary to stabilize $\mathrm{CO}_{2}$ e concentration at $450 \mathrm{ppm}$, and 73 percent of the available global technical potential in the industry sector.

\section{Summary and Conclusions}

A more energy-efficient industrial sector would be a key step in the global effort to contain climate change. As shown in Figure 3.4, such a transition would also have significant global economic, health, and agricultural benefits. Global GDP would be about $1-1.2 \%$ above baseline levels in 2030, with uneven impacts across countries. Potential gains from lower energy use are limited for developed countries, because they have already greatly improved their industrial energy efficiency. They could benefit, however, by increasing their exports of high-tech, low-emission capital goods.
Figure 3.4: Socioeconomic and climate benefits of energy efficient industry policies in 2030 by region

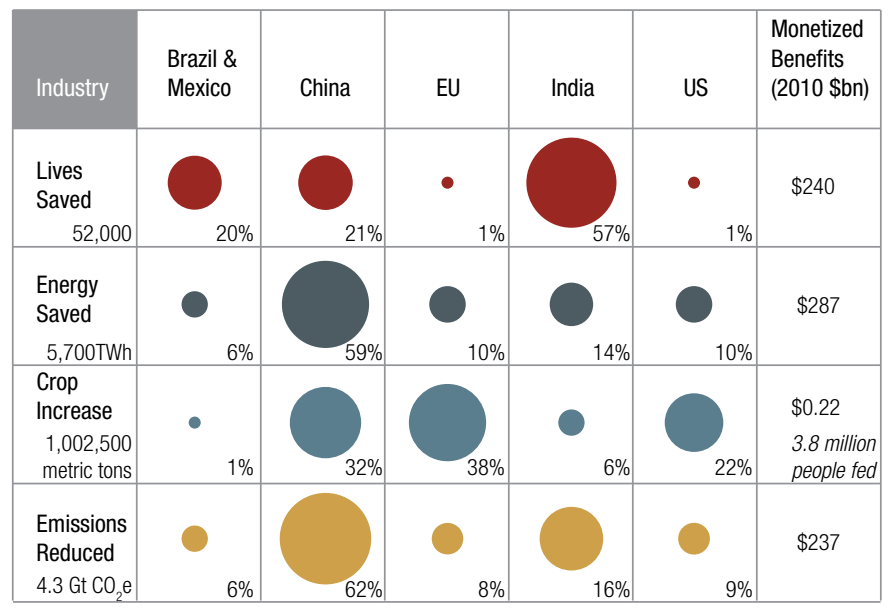

Emerging economies could reap significant gains from lower energy consumption. These countries have the most to gain from new capital investments; by reducing their production costs more on average than developed countries, they improve their competitiveness and gain market share and jobs in both scenarios.

The vast majority of health benefits from reduced air pollution are estimated to occur in emerging economies, particularly in

\section{Box 3.2: Sector Policy Case Study 2 Benefits: Energy Efficient Industry}

A transformation of the industrial sector, through policies that spur a shift to clean fuels and reduced energy consumption, would generate substantial societal benefits (all values are annual results in 2030 for the six focus regions, unless noted), including:

\section{Local* Socioeconomic Benefits}

- Lives saved: 52,000 avoided premature mortalities from air pollution, with a monetized value of $\$ 240$ billion.

- Crops saved: roughly 1.26 million metric tons, enough to feed 3.8 million people for one year and valued at \$216 million.

- Energy saved: more than 5,700 TWh in 2030, equivalent to more than 14 percent of projected energy consumption in the industrial sector and about 3 percent of projected total global energy demand (cf. IEA WEO 2012).

- Effect on global GDP**: increase of about 1-1.2 percent above the baseline, or $\$ 1.2-\$ 1.4$ trillion, equivalent to $\$ 280-\$ 336 / t C O_{2} e$, with uneven effects among countries.

\section{Global Public Goods}

- $\mathrm{CO}_{2} \mathrm{e}$ emissions reduction: roughly $4.3 \mathrm{Gt}$ per year.

- Average mitigation cost: $\$ 7 / \mathrm{tCO}_{2} \mathrm{e}$ (MACC).

- Estimated social value of $\mathrm{CO}_{2}$ e reductions: \$237 billion.

- Additional lives saved: roughly 5,880 premature deaths from air pollution avoided per year outside the six focus regions, with a monetized value of about $\$ 28$ billion.

- Additional crops saved: roughly 460,000 metric tons per year outside the six focus regions, with a monetized value of about $\$ 79$ million.

* Local here refers to the six focus regions.

** Although these are global GDP values, the results are driven entirely by shocks inflicted on the economies of the six focus regions. 
India, Brazil, and China. Crop yields would also rise significantly, especially in the EU, China, and the U.S. As noted above, the health and agriculture benefits are likely understated because of limited emissions data (see Annex C).

\section{Sector Policy Case Study 3: Energy-efficient Buildings}

Although residential and commercial buildings account for a relatively small proportion of global emissions (just under 10 percent), relatively simple and cost-effective improvements in energy efficiency could significantly reduce energy consumption-and therefore energy-related emissions-worldwide.

\section{Case Study Interventions}

This case study presents the impacts of government policies to reduce energy use in residential and commercial buildings through more efficient appliances, electronics, and equipment; better insulation, including retrofits and new construction; and improved heating, cooling, and refrigeration systems.

\section{Case Study Benefits}

Reducing the energy used by buildings would have significant impacts on the economy and human health. The TM5-FASST model estimates that the accompanying reductions in emissions of air pollutants would reduce mortality by about 22,000 lives per year in the focus regions. The vast majority of the avoided deaths are in India (as shown in Figure 3.6), primarily due to the large reduction in black carbon emissions when traditional residential cookstoves are replaced with more fuel-efficient ones (see Table C.1 in Annex C) and dirty fuels are replaced with liquid petroleum gas and other cleaner fuels (Dinkel et al. 2011). In monetary terms, the lives saved would be equivalent to $\$ 102$ billion (2010 dollars) for the six regions considered. The global impact of mitigation measures undertaken in the six focus regions is estimated to result in a total of about 24,000 lives saved per year in 2030 from avoided premature mortality. Because of limited data availability, however, this analysis includes only a small subset of pollutants (primarily $\mathrm{BC}$ ) and an underestimate of emissions mitigated in the buildings sector (Wagner et al. 2013); the estimated health benefits, therefore, are conservative.

From a macroeconomic perspective, the efficiency improvements raise global GDP by 0-0.2 percent in Scenario 1 and 2, respectively (up to $\$ 240$ billion, in 2010 dollars) from the baseline scenario in 2030. As in other sectors, the key transmission channels are the effects of the changes in capital investment and energy consumption; the impacts are heterogeneous across countries. In Mexico, for example, households can achieve greater energy savings, at lower cost, than households in the other countries. ${ }^{38}$ Because the cost of household efficiency improvements is more

\section{Sector Policy Case Study 3: Energy Efficient Buildings}

This case study assumes significant improvements in energy intensity: 15-28 percent in residential buildings and 4-47 percent in commercial buildings. The biggest reductions can be achieved from new construction (about 21 percent of abatement potential), electronics and appliances (about 20 percent), and building retrofits (about 12 percent); the remainder is achieved via reduced HFCs, highly efficient lighting, and water heater and HVAC retrofits.

than recouped through lower energy bills, household incomes in Mexico would rise, boosting consumption and GDP. (In contrast, households in Brazil would make the smallest gains in Scenario 1, where efficiency improvements are relatively limited but carry a significant investment cost.)

The heterogeneous impact on GDP is also reflected in employment. Most countries see some growth in jobs; China and India gain the most in absolute numbers, but the increase in Mexico's GDP means it gains the most jobs relative to its labor force (a 1.3 percent rise in employment above the 2030 baseline). The results of the case study are summarized in Box 3.3 below.

\section{Summary and Conclusions}

Improving the energy efficiency of commercial and residential buildings-including appliances, small equipment, and heating and cooling systems-would support climate change mitigation

38 Most of the emissions in the residential and commercial buildings sector in Mexico are from gas use; thus this sector already has a carbon-efficient baseline. Additionally, with limited use of heating and cooling in buildings, capital costs for an energy-efficient transition is relatively low compared to other countries. As a result, the GDP and efficiency gains are the highest in Mexico compared to the other regions.

Figure 3.5: Climate benefits of energy efficient buildings policies in 2030

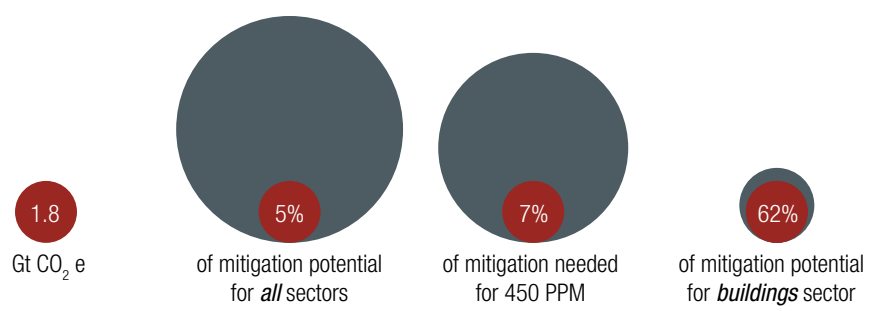

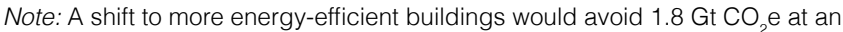
average mitigation cost of $\$ 36 / \mathrm{tCO}_{2} \mathrm{e}$. This represents 5 percent of the total global technical mitigation potential (all sectors), 7 percent of the energy-related emissions reductions necessary to stabilize $\mathrm{CO}_{2}$ e concentration at $450 \mathrm{ppm}$, and 62 percent of the available global technical potential in the buildings sector. 


\section{Box 3.3: Sector Policy Case Study 3 Benefits: Energy Efficient Buildings}

Dramatic reductions in the energy used by residential and commercial buildings—-through government policies that drive more efficient appliances, equipment, insulation, and heating and cooling systems-would generate substantial societal benefits (all values are annual results in 2030 for the six focus regions, unless noted), including:

\section{Local ${ }^{*}$ Socioeconomic Benefits}

- Lives saved: 22,000 premature mortalities from air pollution avoided per year, with a monetized value of $\$ 102$ billion.

- Energy saved: about 5,400 TWh, roughly equivalent to 13 percent of projected energy consumption in the buildings sector and three percent of projected global energy demand (cf. IEA WEO 2012).

- Effect on global GDP**: increase of about 0-0.2 percent above the baseline, or up to $\$ 240$ billion, equivalent to $\$ 134 / \mathrm{tCO}_{2} \mathrm{e}$, with uneven effects among countries.

\section{Global Public Goods}

- $\mathrm{CO}_{2}$ e emissions reduction: Roughly $1.8 \mathrm{Gt}$ per year.

- Average mitigation cost: $\$ 36 / \mathrm{tCO}_{2} \mathrm{e}(\mathrm{MACC})$.

- Estimated social value of $\mathrm{CO}_{2}$ e reductions: $\$ 99$ billion.

- Additional lives saved: roughly 1,800 premature deaths from air pollution avoided per year outside the six focus regions, with a monetized value of about $\$ 9$ billion.

* Local here refers to the six focus regions.

** Although these are global GDP values, the results are driven entirely by shocks inflicted on the economies of the six focus regions.

efforts and benefit human health and the global economy. Global GDP would be about 0-0.2 percent above baseline levels in 2030, but the impact across countries is uneven and largely independent of their income levels. Mexico performs relatively strongly, as its households are able to save significant energy at relatively little cost, which in turn boosts real incomes, consumption, and GDP.

As in other sectors, the vast majority of health benefits from reduced air pollution would occur in emerging economies, particularly India and China. Although not quantified here, impacts

Figure 3.6: Socioeconomic and climate benefits of energy efficient buildings policies in 2030 by region.

\begin{tabular}{|c|c|c|c|c|c|c|}
\hline Buildings & $\begin{array}{l}\text { Brazil \& } \\
\text { Mexico }\end{array}$ & China & EU & India & US & $\begin{array}{l}\text { Monetized } \\
\text { Benefits } \\
(2010 \text { \$bn) }\end{array}$ \\
\hline $\begin{array}{l}\text { Lives } \\
\text { Saved } \\
22,000 \\
\end{array}$ & $1 \%$ & $6 \%$ & $0 \%$ & $93 \%$ & $0 \%$ & $\$ 87$ \\
\hline $\begin{array}{l}\text { Energy } \\
\text { Saved } \\
5,400 T W h\end{array}$ & $3 \%$ & $30 \%$ & $29 \%$ & $3 \%$ & $35 \%$ & $\$ 272$ \\
\hline $\begin{array}{l}\text { Emissions } \\
\text { Reduced } \\
1.8 \mathrm{Gt} \mathrm{CO}_{2} \mathrm{e}\end{array}$ & 0 & $30 \%$ & $22 \%$ & $5 \%$ & $39 \%$ & $\$ 99$ \\
\hline
\end{tabular}

on agricultural productivity would also be significant if data were available for a fuller set of emissions (see Annex C).

\section{Development Project Case Studies}

The case studies below are based on World Bank-financed, subnational development projects, scaled up to estimate their impacts at the national level. Using the analytical framework described above, these projects are analyzed relative to a "no project" baseline to determine the additional benefits (beyond the net present economic value typically calculated in project financial analysis) that would accrue over the life of each project (generally 20 years).

This presentation differs from the results shown in the sector policy case studies. It is intended to present an aggregated view of each project's value over the planning horizon in deciding whether to proceed with a project. While these case studies focus on demonstrating a broader range of benefits during the implementation and analysis phases of development initiatives, it is important to consider these issues during the planning stages so that project designers can adjust plans to optimize a comprehensive range of benefits.

All these case studies should be viewed as simulations that, while based on realistic projects and data, require assumptions for scaling that may or may not be feasible to implement. These simulations are meant to demonstrate the potential for additional benefits beyond what is derived from current project-level economic 
analysis. ${ }^{39}$ (The analytical tools used for these simulations are described in Steps 2 and 3 of the framework (see Chapter 2); the valuation methods are explained at the beginning of this chapter. Finally, see Annex D for more details on these case studies.)

\section{Development Project Case Study 1: Sustainable Transportation in India}

Affordable, low-emissions transport is crucial for development. People need effective transit options for access to jobs, education, and health services; economic activity requires the transport of goods. Well-designed and -enforced bus rapid transit (BRT) is a relatively inexpensive way to get people out of high-emitting vehicles and to reduce traffic congestion and pollution. In 2009, the World Bank approved a sustainable urban transport project for India that included BRT in three pilot cities. The Pimpri-Chinchwad BRT may serve as a model for replication across India; it was analyzed in depth in this case study to establish realistic benefits that can be expected under real-world conditions.

\section{Case Study Interventions}

The results of the Pimpri-Chinchwad BRT analysis and a Ministry of Urban Development (MOUD) study of more than 87 cities across India were used to estimate the length of viable BRT routes that could realistically be developed across India, as well as the per-kilometer costs and benefits of such development. For this case study, the length was estimated at approximately $1,000 \mathrm{~km}$, including more than $422 \mathrm{~km}$ that is already included in government plans. This was contrasted against a "no BRT" scenario. The analysis estimates that investment of $\$ 3-4$ billion would be needed to develop 1,000 km of BRT corridors in about 20 cities across India within 6-12 years.

\section{Case Study Benefits}

Analysis using the TEEMP model shows that large reductions in time, emissions, fuel use, and traffic fatalities can be achieved by shifting passenger traffic away from current transportation patterns to a modern BRT system. The emissions reduction benefits were further analyzed using the TM5-FASST tool, which shows that reductions in black carbon and co-pollutant emissions from the expanded BRT would reduce crop losses and deaths from respiratory illnesses. Capital investments, operation and maintenance costs, fuel savings, and productivity benefits were fed into the Oxford Economics GEIM, which shows further benefits: Investment in India's infrastructure will boost its economy and create jobs, and the switch to mass transit will reduce the overall cost of transport, raising firms' profit margins and households' real incomes.

Results are summarized in Figure 3.7; in Box 3.4 they are compared with the net present value of the project as estimated by current project analysis methods. Here the reduced cost of

\section{Development Project Case Study 1: Sustainable Transportation in India}

This case study includes construction of more than $1,000 \mathrm{~km}$ of new bus rapid transit lines deployed in about 20 large Indian cities to displace more than seven percent of current traffic along the selected routes.

transport per passenger kilometer was scaled up (less project costs). Annual financial flows of all benefits are aggregated through 2033 and discounted at three percent. (See Annex D for a sensitivity analysis to alternative values of the social discount rate.

39 The results of these simulations have not been endorsed by the in-country project counterparts.

\section{Box 3.4: Development Project Case Study 1 Benefits: Sustainable Transportation in India}

Deployment of $1,000 \mathrm{~km}$ of new bus rapid transit lanes in about 20 Indian cities could lead to:

\section{Stated Project Benefits (scaled to the national level)}

NPV of project development objectives: $\$ 9.7$ billion (mostly time savings and reduced operating costs).

\section{Additional Local ${ }^{\star}$ Socioeconomic Benefits ${ }^{\star \star}$}

- $B C$ reduced: 5,000-6,000 tons.

- Lives saved: 27,200-31,200 (from reduced accidents and air pollution), with a value of $\$ 49-\$ 54$ billion.

- Crops saved: more than 28,000 tons, with a value of $\$ 3$ million.

- Jobs created: 44,000-91,000 short-term; more than 128,000 long-term.

- Effect on India's GDP: \$11.5-\$13.5 billion increase between 2013 and 2032.

\section{Global Public Goods**}

$\mathrm{CO}_{2}$ e emissions reduced: $42-49 \mathrm{Mt}$, valued at $\$ 1.3-\$ 1.5$ billion based on the social cost of carbon.

* Local here refers to the national level.

** Net present value of aggregate benefits over 20 years, in 2010

dollars discounted at three percent. 
Figure 3.7: Socioeconomic and climate benefits of sustainable transportation in India

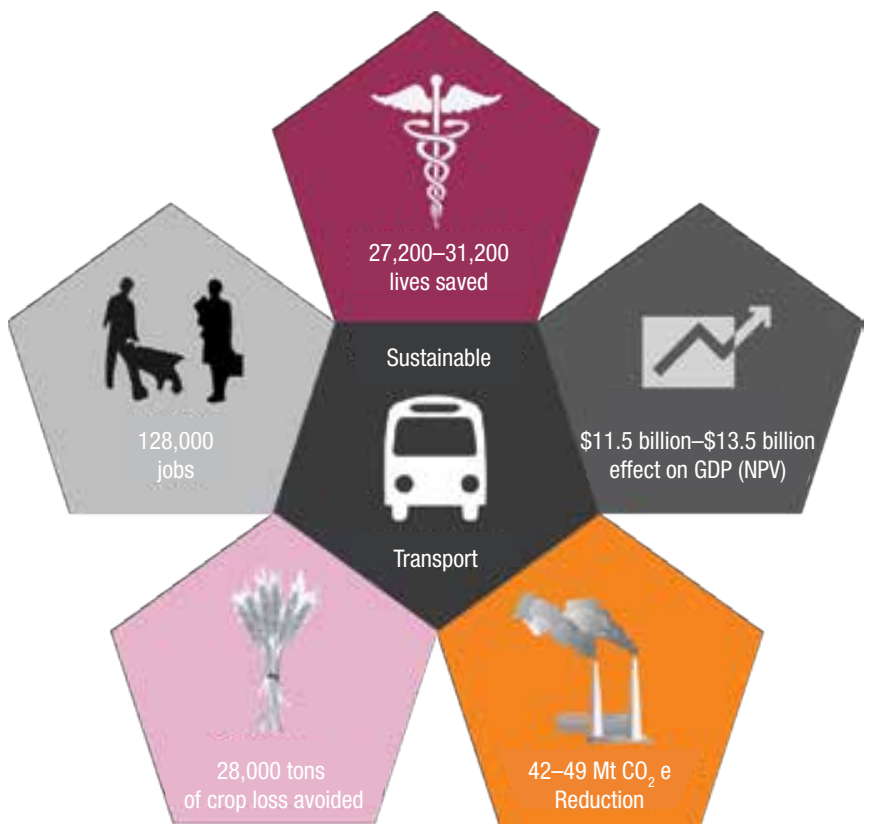

Note: Benefits are scaled to national level and aggregated over project period.

\section{Summary and Conclusions}

A comprehensive value of the project was established by exploring the multiple benefits of expanded BRT systems. As shown above, the benefits include time and fuel savings, reduced environmental impact, and fewer deaths from traffic accidents and air-qualityrelated respiratory illnesses. There would also be significant macroeconomic benefits. In addition to the $\$ 9.7$ billion in NPV that might typically be used to justify such a project, this study has identified more than $\$ 62$ billion in added value, including the social cost of carbon and the welfare benefits of lives saved, crops protected, and GDP growth. In addition, more than 5,000 tons of black carbon emissions would be eliminated, with potentially strong climate benefits. While not all of these benefits can be

\section{Development Project Case Study 2: Integrated Solid Waste Management in Brazil}

National expansion of an existing World Bank integrated solid waste management project with innovative finance mechanisms would enable sanitary disposal of all of Brazil's solid waste through sanitary landfills, composting, and biogas digestionsignificantly reducing methane emissions. directly included in the project's financial analysis, they could be part of the discussion of broader economic benefits that accrue to a country as a result of such a transportation program.

\section{Development Project Case Study 2: Integrated Solid Waste Management in Brazil}

Effective management of municipal solid waste poses "one of the biggest challenges [to] the urban world" (UN-Habitat 2010). In low-income countries, most cities collect less than half of the waste generated, and only half of the collected waste is processed to minimum acceptable environmental and health standards. Properly managing waste to minimize methane emissions offers a variety of local and global benefits. Locally, improper waste management, especially open dumping and open burning, contaminates water, air, and land; attracts disease vectors; and clogs drains, contributing to flooding. At the global scale, burning waste without proper air pollution controls creates toxic pollutants; improper disposal also pollutes the oceans, threatening ecosystems, fisheries, and tourism. Waste is an emerging contributor to climate change, emitting 5 percent of global GHGs and 12 percent of methane (Bogner et al. 2007). Waste has the potential, however, to be a net sink of GHGs when used as a resource, through recycling and reuse (Bogner et al. 2007).

\section{Case Study Interventions}

This case study estimates the emissions reductions from integrated solid waste management in Brazil by a simulated scale-up of one project to the national level. The model project selected is an integrated solid waste management project with an innovative carbon finance platform. The registered carbon finance methodology integrates a seamless payment structure within solid waste management investments, greatly facilitating the sale of credits and the additional benefits that can be captured from those resources. It is a $\$ 50$ million financial intermediary loan for on-lending to borrowers with solid waste subprojects. The project aims to improve the treatment and disposal of municipal solid waste; its success is measured by the number of open dumps closed and the increased volume of waste disposed in sanitary landfills, composted, or recycled. Brazil was selected for scale-up due to the existing strong regulatory structure and finance instruments available in this sector.

Four different policy scenarios for managing Brazil's waste were compared with a reference baseline:

- Baseline: The current state of solid waste management in Brazil, with 58 percent of waste going to sanitary landfills, most of which flare the methane produced; the remainder of the waste is going to open dumps, which simply vent the methane produced. 
- All landfill scale-up: All generated waste ends up in a sanitary landfill (no more open dumping), and 50 percent of landfill gas is collected and flared.

- All landfill with electricity generation: Similar to the previous scenario, but 50 percent of landfill gas is flared and 50 percent is used to generate electricity, displacing natural gas on the electricity grid.

- Anaerobic digestion of organic waste with electricity generation: Seventy-five percent of organic waste is sorted and routed to anaerobic digesters to produce electricity, displacing natural gas on the grid; the resulting compost is used as fertilizer (but no market value is assessed for fertilizer substitutions).

- Composting for organic waste: Seventy-five percent of organic waste is sorted and composted. Again, this compost is not assumed to displace any fertilizer; this underestimates the environmental benefits.

For all of the Brazilian waste scenarios explored, the most relevant result is the difference between the policy scenario at the baseline and at "full implementation." The required investment is estimated at \$1-2 billion per year through 2030 .

\section{Case Study Benefits}

The project will result in reduced methane emissions as well as a variety of other benefits, including improved water quality, improved soil quality, improved public health, and decreased mining of natural resources. The methane reductions were estimated using the EASEWASTE solid waste lifecycle assessment model, using data specific to Brazil for generation rates, composition, electricity grid, and landfill behavior. Generic data was used to model the composting facilities and the anaerobic digesters.

Improved organic waste treatment, through anaerobic digestion and composting, with electricity production offers the greatest potential for methane reduction from solid waste for Brazil (on the order of $15-30$ million metric tons of $\mathrm{CO}_{2}$ e per year). These emissions reductions were input into the FASST tool to estimate additional health and crop benefits from reduced ground-level ozone formation. Each year, these could result in 246 to 468 avoided deaths from respiratory illnesses and 53,000-101,000 tons of avoided crop losses (with a value of \$9.1-17.4 million globally).

These scenarios also yield significant macroeconomic benefits over the 20-year analysis period, including increased GDP in Brazil of \$13.3-\$35.2 billion (net present value in 2010 dollars, using a 3 percent discount rate), with a corresponding growth in jobs of $44,000-110,000$ depending on the scenario. In addition, $0.5-1.1$ percent of national power demand is satisfied as an additional benefit in two of the scenarios. Summaries of the results are shown in Box 3.5 and Figure 3.8.

\section{Box 3.5: Development Project Case Study 2 Benefits: Integrated Solid Waste Management in Brazil}

A project simulation to enable sanitary disposal of all of Brazil's solid waste, through improved collection and sorting, sanitary landfills, composting, and biogas digestion, is estimated to have the following direct benefits:

\section{Stated Project Benefits (scaled to national level)}

NPV of project development objectives: more than $\$ 100$ billion (inclusive of $\$ 1.6-\$ 3.2$ billion carbon finance value).

\section{Additional Local* Socioeconomic Benefits ${ }^{\star *}$}

- Jobs created: 44,000-110,000.

- Energy saved: 0.5-1.1 percent of Brazil's electricity demand.

- Effect on Brazil's GDP: \$13.3-\$35.2 billion increase between 2012 and 2032.

\section{Global Public Goods ${ }^{\star \star}$}

- $\quad \mathrm{CO}_{2}$ e emissions reduced: $158-315 \mathrm{Mt}$, valued at \$4.8-\$9.7 billion based on the social cost of carbon (a social value increment of \$3.2-\$6.5 billion beyond the carbon finance value).

- Lives saved: 2,500-4,900 avoided premature deaths from air pollution, with a monetized value of $\$ 5.5-\$ 10.6$ billion.

- Crops saved: 550,000-1.1 million tons, worth $\$ 61-\$ 120$ million.

* Local here refers to the national level.

** Net present value of aggregate benefits over 20 years, in 2010 USD

discounted at three percent.

The net present value of the project is based on the estimated fees generated if all of Brazil's solid waste is treated in sanitary landfills, less costs drawn from the recent report What a Waste (Hoornweg and Bhada-Tata 2012)—including purchasing, operations, maintenance, and debt service for each of the options explored. Potential program costs have not been considered here.

\section{Summary and Conclusions}

This case study shows that greater emissions reductions can be achieved using an integrated solid waste approach, which considers every step in the waste value chain, than by targeting only one technology (e.g., sanitary landfills). Although methane is emitted only at the point of waste treatment and disposal, efforts to reduce these emissions and manage waste as a resource can occur at every stage: planning, waste generation, collection, treatment, and disposal. Upstream efforts are especially valuable. For example, incentive schemes to reduce waste generation and increase source separation yield two types of SLCP reductions. 
Figure 3.8: Socioeconomic and climate benefits of integrated solid waste management in Brazil

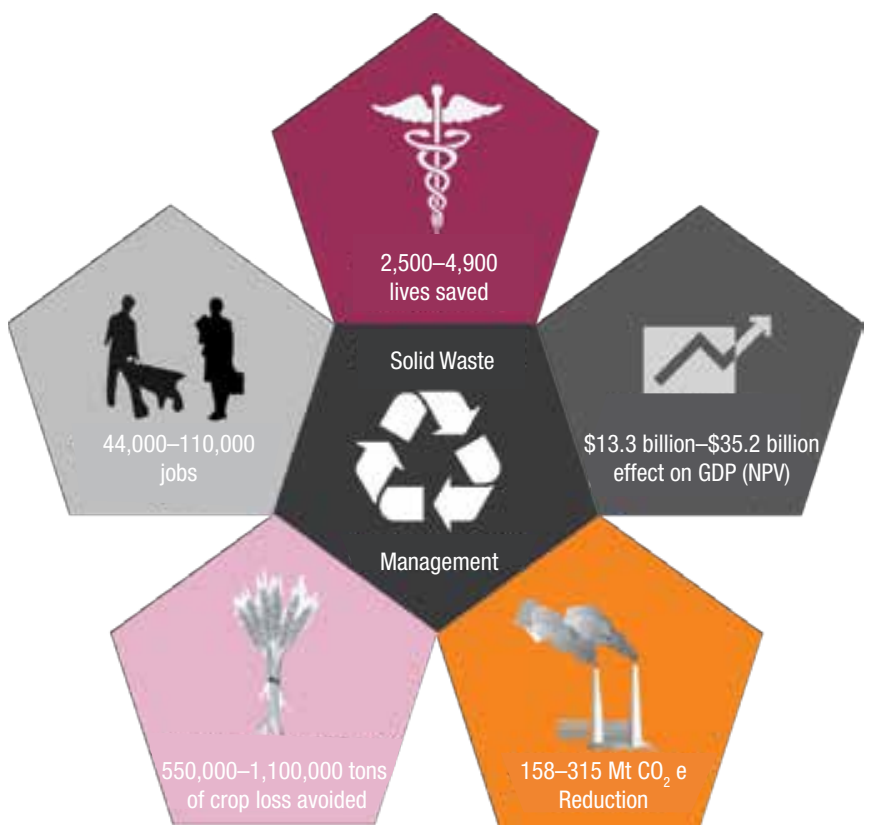

Note: Benefits are scaled to national levels and aggregated over project analysis period.

First, they directly reduce landfill methane (and other downstream GHG) emissions; second, they displace other sources of SLCP (and GHG) emissions (i.e., fertilizers and natural gas).

Large-scale use of these waste-to-resource technologies requires major investments of \$1-\$2 billion per year in upstream waste reduction and source separation. Without separation of waste at the household level, neither composting nor anaerobic digestion is economically feasible. Making these investments, however, would lead to significant economic returns. The NPV of such a project is estimated at approximately $\$ 100$ billion. In addition, between $\$ 22-\$ 52$ billion in additional value stems from increased GDP, the social value of carbon (beyond carbon finance), reduced mortality, and improved crop yields. All these benefits should be considered in the economic analysis of such a project.

\section{Development Project Case Study 3: Cleaner Cookstoves in Rural China}

China has made great strides in expanding energy access and providing cleaner cooking fuels and improved stoves throughout the country. However, about half of China's population still relies on solid fuels (coal and biomass) for cooking and heating, and the International Energy Agency estimates 241 million people in China will continue to do so by 2030 (World Energy Outlook 2013). Household air pollution from solid fuel use is estimated to cause

\section{Development Project Case Study 3: Cleaner Cookstoves in Rural China}

A 20-percent public subsidy in China between 2015 and 2020 for fuel-efficient, lower-emitting cookstoves and solar cookers is assumed to establish a robust, self-sustaining market for these advanced technologies; this would enable all rural poor households that currently use solid fuels for residential cooking to switch to the cleaner stoves by 2030

more than one million premature deaths each year in China (Lim et al. 2012). Switching to modern fuels would be the most effective way to reduce this pollution and health damage; these fuels are more expensive, however, and require more costly stoves and delivery infrastructure. As a result, poorer rural households without access to affordable modern fuels such as liquid petroleum gas and natural gas are unlikely to transition on a large scale. Effective interventions to scale up the dissemination of clean-burning, fuelefficient stoves for household cooking and heating can mitigate the health hazards of burning solid fuels (World Bank 2013c).

\section{Case Study Interventions}

While heating systems and combined cooking and heating stoves also represent important sources of indoor and outdoor air pollution, in order to simplify the analysis, the focus here is only on cleaner cookstoves.

This case study, based on a universal access to clean cooking scenario developed under the China Clean Stove Initiative (World Bank 2013c), assumes ${ }^{40}$ a publicly supported plan to encourage rural households to switch to more fuel-efficient and environmentally friendly cookstoves starting in 2015. For the first five years, the public sector would support a 20 percent subsidy to rural households for the cost of the clean cookstoves in addition to substantial technical assistance funding. This temporary support is assumed to encourage a robust private market that would propel further deployment of cleaner stoves through 2030, with households bearing the full cost. The 20 percent subsidy and program and technical assistance will cost $\$ 400$ million over the program timeframe (2015-2020), supplemented by $\$ 1.2$ billion in private sector investment, which takes into account reduced household spending in other areas in response to increases spending on cookstoves.

This case study assumes that 40 percent of rural poor households relying primarily on solid fuels for cooking will have switched to cleaner stoves by 2020, and all households will have switched by 2030. This is against a backdrop of increasing urbanization

40 Unlike the other case studies based on past investment projects, this analysis is based on a hypothetical scenario. 
and rising household incomes, which have already established a trend toward modern fuels and cleaner stoves.

Based on these assumptions, more than 20 million subsidized stoves (improved biomass and clean-fuel cookstoves and solar cookers) would be deployed between 2015 and 2020, and more than 50 million unsubsidized stoves would be sold between 2020 and 2030, significantly speeding up the naturally occurring transition to cleaner stoves.

\section{Case Study Benefits}

Deploying clean cooking solutions in China would reap many benefits, including improved health, energy savings, and private sector development opportunities. As estimated by the FASST tool, emissions reductions by the year 2030 of more than 480,000 tons

\section{Box 3.6: Development Project Case Study 3 Benefits: Clean Cookstoves in Rural China}

A 20-percent public subsidy in China between 2015 and 2020 for fuel-efficient, lower-emitting cookstoves and solar cookers, and subsequent unsubsidized sales through 2030 , are estimated to have the following benefits:

\section{Stated Project Benefits}

Because this case study is not based on an actual project, but was developed based on the universal access to clean cooking scenario developed under the China Clean Stove Initiative (World Bank, 2013b), the net present value of the project development objectives has not been calculated.

\section{Additional Global Public Goods*}

$\mathrm{CO}_{2}$ e emissions reduced: $49 \mathrm{Mt}$, valued at $\$ 1.5$ billion based on the social cost of carbon of $\$ 34 / \mathrm{tCO}_{2} \mathrm{e}$ in 2010 , rising to $\$ 55 /$ $\mathrm{tCO}_{2} \mathrm{e}$ in 2030 .

\section{Additional Local Socioeconomic Benefits*}

- Lives saved: more than one million from avoided premature deaths due to outdoor air pollution, with a value of $\$ 1.5$ trillion (within China); even more lives would be saved if considering the health impacts from reductions in indoor emissions.

- Jobs created: about 22,000 (near term).

- Energy saved: 545 million gigajoules (GJ) reduced coal use and 5,400 million GJ biomass use.

- Macroeconomic benefits of $\$ 10.7$ billion between 2015-2030 (largely due to the economic impact of fuel savings).

${ }^{*}$ Net present value of aggregate benefits over 20 years, in 2010 dollars discounted at three percent. of $\mathrm{PM}_{2.5}$ would have very significant public health benefits. These include avoiding an estimated 87,900 premature deaths in that year from lung cancer and heart attacks, the majority (more than $85,000)$ in China. By 2030, $\$ 250$ billion $(85,000$ lives times the estimated $\$ 3$ million VSL) in avoided mortality could be realized in that year. These benefits are underestimated, however, because they only account for improvements in outdoor air quality; greater health benefits are expected due to improved household air quality, but tools to quantify these benefits are not available. ${ }^{41}$

The large energy savings, especially from reduced coal use, would add more than $\$ 10$ billion to the Chinese economy over the 20-year analysis period ending in 2033. The combined energy savings from biomass and coal builds by 2030 to nearly 490 million gigajoules (GJ) annually, or about three percent of residential energy use. The increased consumer spending also yields job gains. A summary of the benefits is presented in Box 3.6 and Figure 3.9.

\section{Summary and Conclusions}

A plan to encourage rural households to switch to more fuel-efficient and environmentally friendly cookstoves, by subsidizing and supporting deployment of more than 20 million cookstoves between

41 Tools to estimate the benefits from improvements in household air quality are under development by the University of California Berkeley for the Climate and Clean Air Coalition partner countries; no such tools exist for China at this time.

Figure 3.9: Socioeconomic and climate benefits of cleaner cookstoves in rural China

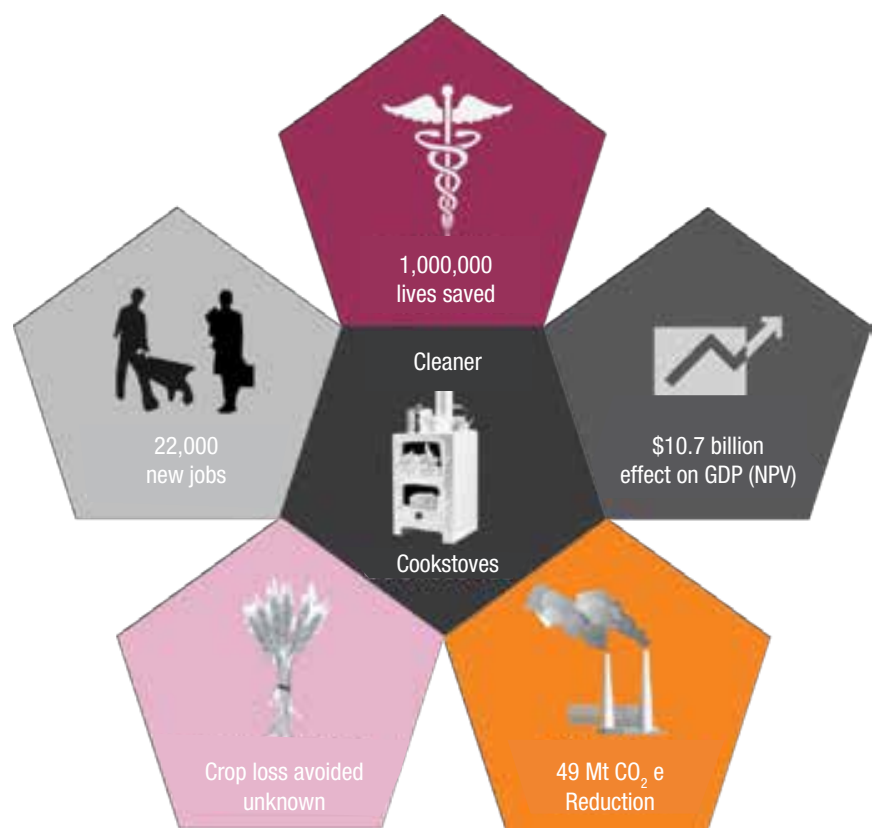

Note: Benefits are aggregated over the project analysis period. 


\section{Development Project Case Study 4: Biogas Digestion and Photovoltaic Systems in Mexican Agriculture}

Given high and increasing demand for co-funding of biodigesters at pig and dairy farms, and PV systems to provide power for chilling systems at dairy farms, this case study assumes additional co-funding to equip 90 percent of Mexico's pig and dairy herds with biodigesters, and 90 percent of dairy farms, with PV systems by 2031.

2015 and 2020, would have large health and energy benefits. It is estimated that more than 85,000 premature deaths from outdoor air pollution could be avoided annually in 2030 (more than one million lives over 20 years) in China alone. The net present value of these health benefits is more than $\$ 1.5$ trillion in 2010 dollars. Recent studies suggest that more than one million premature deaths are attributed to household air pollution each year (Lim et al. 2012); thus the potential health benefits could be higher if household exposure were included. Large energy savings could also reduce energy costs nationwide, resulting in broad economic benefits of more than $\$ 10$ billion over the analysis period. Finally, more than 20,000 new jobs could be created.

\section{Development Project Case Study 4: Biogas Digesters and Photovoltaic Systems in Mexican Agriculture}

According to Mexico's Fifth National Communication to the UN Framework Convention on Climate Change, agriculture continues to be an important source of the country's emissions (12\% of its GHG emissions in 2010 including both methane and nitrous oxide), primarily from land-use changes, tillage, synthetic fertilizers, and anaerobic decomposition of organic materials. To reduce these emissions and improve the agricultural sector's contribution to the overall economy, the government of Mexico has prioritized improvements in the sector's energy efficiency, renewable energy, and biomass practices.

\section{Case Study Interventions}

This case study builds on the successful Mexico Sustainable Rural Development Project, a $\$ 100$ million World Bank loan blended with a $\$ 10.5$ million Global Environment Facility grant, with additional contributions from the Government of Mexico and project beneficiaries. The project supported a number of technologies, including biodigesters at pig and dairy farms. As of May 2013, 303 biodigesters had been installed, half at pig farms and half at dairy farms. These installations are driven by farmer demand, which is expected to grow as biodigester technology becomes more cost-effective and better adapted to different production scales.

While the original project supports a range of energy-efficiency technologies, this case study focuses exclusively on continued deployment of biodigesters at pig and dairy farms, plus motogenerators and photovoltaic systems on dairy farms, where milk-cooling systems favor the added expense of electrical generation add-ons. The case study assumes that public funding is available to continue leveraging private sector investment in these technologies through 2031, when 90 percent of pig and dairy herds (estimated at 15 million head of pig and 3.2 million head of dairy cattle) would have added manure biodigestion capacity, with generators and PV systems included on the dairy farms.

\section{Case Study Benefits}

The project benefits include reduced methane emissions, which lower global background ground-level ozone and related health and agricultural damage. By recovering methane from biodigesters and flaring it or using it to generate electricity, $\mathrm{CO}_{2} \mathrm{e}$ emissions are reduced by 9.4 million tons per year in 2030. Estimated annual benefits include 180 avoided premature deaths from air pollution (but relatively few within Mexico) and 39,000 tons of avoided crop losses worth more than $\$ 6$ million (mostly outside Mexico). Other benefits include new job creation and improved sanitary conditions due to manure treatment.

The net present value of the project is based on the carbon finance value of the reduced methane emissions, equivalent to nine million tons of annual $\mathrm{CO}_{2} \mathrm{e}$ reductions by $2030\left(103 \mathrm{MtCO}_{2} \mathrm{e}\right.$ cumulatively) and worth more than $\$ 1$ billion over the 20-year program (less costs of about $\$ 600$ million). Based on the social cost of carbon, however, this project's emissions reductions are worth $\$ 3.2$ billion ( $\$ 2.2$ billion higher than the carbon finance value). The results are summarized in Box 3.7 and shown in Figure 3.10.

\section{Summary and Conclusions}

Sustained investment that achieves 90 percent penetration of manure biodigesters across all the pig and dairy farms and 90 percent penetration of photovoltaic systems across all dairy farms in Mexico would derive significant economic, public health, agricultural, and environmental benefits. In addition, policy reforms to allow farmers to sell excess electricity generated to the power company could produce even larger benefits.

While the project economic analysis assumes a carbon finance value of more than $\$ 1$ billion, these emissions reductions are more completely represented by the social cost of carbon, which values the reductions at $\$ 3.2$ billion-in other words, an extra $\$ 2.2$ billion in welfare value above the finance value. Increased productivity from energy savings adds an additional $\$ 1.1$ billion in economic benefit; global health and agricultural benefits are monetized 


\section{Box 3.7: Development Project Case Study 4 Benefits: Biogas Digestion and PV in Mexican Agriculture}

Co-funding to equip 90 percent of pig and dairy farms with biodigesters and 90 percent of dairy farms with PV systems by 2031 would have the following benefits:

\section{Stated Project Benefits}

NPV of project development objectives: \$424 million.

\section{Additional Local ${ }^{\star}$ Socioeconomic Benefits**}

- Lives saved in Mexico: relatively few (approximately 15), with a monetized value of $\$ 50$ million.

- Jobs created: 1,400.

- Energy saved: 11 percent of national agricultural electricity demand.

- Effect on Mexico's GDP: increase of $\$ 1.1$ billion between 2013 and 2031.

\section{Global public goods**}

- $\mathrm{CO}_{2}$ e emissions reduced: $103 \mathrm{Mt}$ (as methane), valued at $\$ 3.2$ billion based on the social cost of carbon (a social value increment of $\$ 2.2$ billion beyond the carbon finance value).

- Lives saved outside Mexico: more than 1,900 avoided premature mortalities from air pollution, with a monetized value of $\$ 4.1$ billion.

- Crops saved: more than 410,000 tons, worth $\$ 45$ million (mostly outside Mexico).

* Local here refers to the national level.

${ }^{* *}$ Net present value of aggregate benefits over 20 years in 2010 dollars discounted at three percent.

at about $\$ 4.2$ billion. This suggests that more than 17 times the stated project value is not recognized through current practices.

\section{Lessons and Conclusions from the Case Studies}

This chapter demonstrates the use of an integrated framework to analyze the multiple development benefits of efforts to mitigate climate change and protect air quality. Both regional policy changes and national development projects are analyzed using the framework; the aim is to demonstrate its efficacy as a tool for local and national policymakers, development organizations, philanthropies, analysts, and others.
Figure 3.10: Socioeconomic and climate benefits of biodigesters and $\mathrm{PV}$ in Mexican agriculture

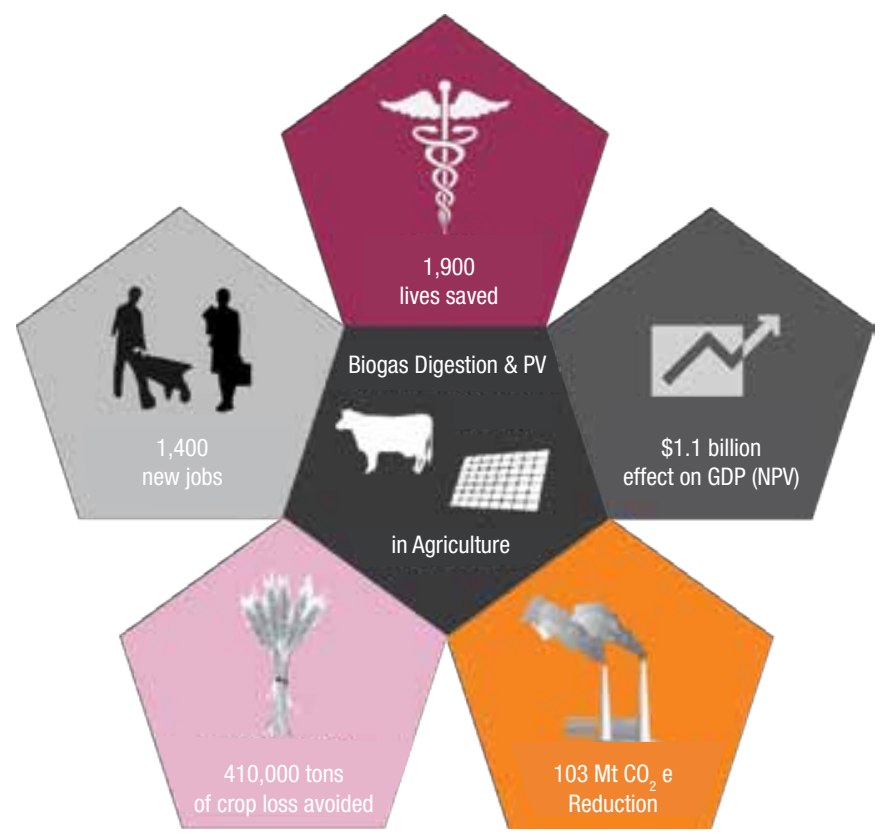

Note: Benefits of manure management and renewable energy deployment are scaled to national levels and aggregated over the project analysis period.

Since the policy-based case studies and the project-based case studies cover different regions and use slightly different metrics, direct comparisons and a summation of benefits are not possible. For instance, the policy interventions are presented in terms of their annual impact in 2030; the project interventions are presented as the aggregate impact over a 20-year assumed life of the project. Either way, a snapshot summary of each case study shows that significant benefits can be realized.

The first three case studies demonstrate the effects of key sector policy interventions and determine the benefits ${ }^{42}$ realized in six regions (the U.S., China, the EU, India, Mexico, and Brazil) and the impact on global GDP. A useful way to view these benefits is to compare them against a similar metric, in this case a metric ton of $\mathrm{CO}_{2}$ e abated in 2030 (see Table 3.1). For example, the transport sector would realize a net return on mitigation of $\$ 169$ per ton of $\mathrm{CO}_{2} \mathrm{e}$, even without accounting for the health or GDP benefits. In the buildings sector, where the interventions have the highest costs among the three sectors, the health and GDP benefits are substantial enough to cover the costs. The industrial sector is the most promising in terms of benefits compared with abatement

\footnotetext{
42 Since the policy case studies covered a limited number of pollutants (methane and $\mathrm{BC}$, and no co-pollutants), the health and agricultural benefits are underestimated. Even with the limited emissions data included in this study, the resulting benefits can be significant.
} 
Table 3.1: Sector policy case studies: Comparison of costs and benefits per metric ton of $\mathrm{CO}_{2}$ e abated ${ }^{\mathrm{a}}$

\begin{tabular}{|c|c|c|c|}
\hline 2030 Costs & Transportation & Industry & Buildings \\
\hline $\mathrm{CO}_{2}$ e mitigated & $2.4 \mathrm{Gt} / \mathrm{yr}$ & $4.3 \mathrm{Gt} / \mathrm{yr}$ & $1.8 \mathrm{Gt} / \mathrm{yr}$ \\
\hline Mitigation Costs & $-\$ 169 / \mathrm{tCO}_{2} \mathrm{e}$ & $\$ 7 / \mathrm{tCO}_{2} \mathrm{e}$ & $\$ 36 / \mathrm{tCO}_{2} \mathrm{e}$ \\
\hline Health Benefit & $\$ 36 / \mathrm{tCO}_{2} \mathrm{e}$ & $\$ 56 / \mathrm{tCO}_{2} \mathrm{e}$ & $\$ 56 / \mathrm{tCO}_{2} \mathrm{e}$ \\
\hline Crop Benefit & NA & $\begin{array}{l}3.8 \text { million } \\
\text { additional people } \\
\text { fed }\end{array}$ & NA \\
\hline $\begin{array}{l}\text { Global GDP } \\
\text { increase }\end{array}$ & $\begin{array}{l}\$ 250-\$ 400 / \\
\mathrm{tCO}_{2} \mathrm{e}\end{array}$ & $\$ 280-336 / \mathrm{tCO}_{2} \mathrm{e}$ & $\$ 0-134 / \mathrm{CO}_{2} \mathrm{e}$ \\
\hline
\end{tabular}

Note: Values shown are for the six focus regions unless otherwise indicated. a Short-lived climate pollutants are not accurately gauged in terms of equivalence to $\mathrm{CO}_{2}$ based on their 100-year global warming potential. New metrics are needed that account for the fact that many SLCPs are thousands of times more potent than $\mathrm{CO}_{2}$ for a short time, yet compare more modestly to the 100-year global warming potential of $\mathrm{CO}_{2}$ because it continues to warm during the entire 100 years.

costs. Although crop benefits are not included for transportation or buildings, these benefits would be substantial if a wider suite of emissions data were available (see footnote 51 in Annex C).

Translating the aggregated health, agriculture, and energy benefits for all sector policies into monetary values yields the results shown in Table 3.2 .

The project-based case studies examine several sub-national development projects, scaled up to the national level. A sampling of the benefits of these projects is shown in Table 3.3. A striking result of this analysis is that these projects have significant additional value well beyond the already significant stated project benefits.

Table 3.2: Sector policy case studies: Monetized health, agricultural, and energy benefits in 2030

\begin{tabular}{l|c|c|c}
\hline Regions & Health & Agriculture & Energy Savings \\
\hline China & $\$ 66$ billion & \$69 million & \$311 billion \\
\hline India & \$293 billion & \$14 million & $\$ 75$ billion \\
\hline US & $\$ 8$ billion & $\$ 48$ million & $\$ 186$ billion \\
\hline EU & $\$ 8$ billion & $\$ 82$ million & $\$ 181$ billion \\
\hline Brazil \& Mexico & $\$ 53$ billion & $\$ 3$ million & $\$ 45$ billion \\
\hline Total & $\$ 429$ billion & $\$ 216$ million & $\$ 798$ billion \\
\hline
\end{tabular}

Note: Estimated avoided premature mortality and increased crop yields from abatement measures undertaken in each sector (transport, industry, and buildings) are monetized and aggregated by region. The values ${ }^{a}$ of energy savings are also shown. Figures are denoted in 2010 dollars.

a The monetized values for energy savings are obtained by assuming a price of oil at $\$ 80 /$ barrel in 2010 dollars in accordance with the scenario assumptions of MACC 3.0 (see Appendix C) and applying the following equivalences: $1 \mathrm{GWh}=8.6 \mathrm{e}^{-5}$ Mtoe, and $1 \mathrm{Mtoe}=7.33 \mathrm{Mboe}$ (source: IEA, BP). This is a rather crude, imprecise estimate, but nonetheless useful to provide an order of magnitude of the monetary savings associated with the emissions reductions specified in each case study.
Added value provides a useful rationale for improving economic analysis, but it may not be the most important way to view the multiple benefits derived by the project-based case studies. Table 3.4 provides an alternative view of the same benefits, categorized as global public goods or local socioeconomic benefits. As the table shows, interventions that reduce methane lead to large global public goods with respect to $\mathrm{CO}_{2}$ e reductions, health, and agriculture, whereas measures that reduce particulate matter and black carbon have larger local health benefits. All lead to positive economic benefits over the 20-year investment period examined in this analysis.

Grouping the multiple benefits this way makes it easier to recognize the contributions countries can make to greening their own growth in addition to benefits that accrue to the rest of the World.

None of the case studies includes the value of reduced climate change impacts, such as damage caused by more-intense storms, higher storm surges and sea levels, and damaged ecosystems.

While these results may indicate significant costs or benefits in one sector or region versus another, they do not show the integrated impact of all the emissions reduction measures available across sectors and the corresponding inter-sectoral interactions. A more integrated analysis would allow a better understanding of how savings in one sector can be reinvested to cover costs in other sectors to yield overall economic growth. Such synergistic benefits could be greater than the sum of the individual benefits. ${ }^{43}$

In addition, the full benefits of reduced emissions are not captured in this study due to the limited data in the MACC model (see Annex $\mathrm{C}$ for a discussion of the significantly underestimated benefits, based on recent research). As a result, the labor and agricultural productivity benefits (from greater longevity, fewer work days lost to illness, and reduced crop damage) were not included in the macroeconomic analyses because of their small size relative to the impact across the overall workforce. A recent analysis by Sanderson et al. (2013) demonstrates that such effects can be large enough to recoup the entire cost of mitigation. These types of integrated scenarios using a systems approach with additional macroeconomic linkages should be investigated in future work.

\footnotetext{
43 This has been demonstrated in prior multi-pollutant, multi-sector analyses in the U.S., where simultaneous implementation of seven major mitigation actions resulted in greater economic benefits than the sum of assessed benefits from the individual measures (MDE 2013).
} 
Table 3.3: Development project case studies summary

\begin{tabular}{|c|c|c|c|c|c|c|c|c|}
\hline \multirow[b]{2}{*}{$\begin{array}{l}\text { Projects } \\
\text { Pro }\end{array}$} & $\begin{array}{l}\text { Reduced } \\
\text { Op Cost }\end{array}$ & $\begin{array}{l}\text { Income } \\
\text { Generated }\end{array}$ & $\begin{array}{c}\text { Carbon Finance } \\
\text { Benefit }\left(\mathrm{CO}_{2}\right)\end{array}$ & $\begin{array}{l}\text { Social Cost Of } \\
\mathrm{CO}_{2} \mathrm{e}\end{array}$ & Lives Saved & $\begin{array}{l}\text { Crop Loss } \\
\text { Avoided }\end{array}$ & Jobs Created & $\begin{array}{l}\text { Effect on } \\
\text { GDP (NPV) }\end{array}$ \\
\hline & \multicolumn{3}{|c|}{$\begin{array}{l}\text { Estimated NPV of scaled project based on } \\
\text { stated project benefits }\end{array}$} & \multicolumn{5}{|c|}{ Additional added value aggregated over 20 years } \\
\hline $\mathrm{P} 1$ & $\$ 9.7$ bn & - & - & $\begin{array}{l}\text { 42-49 Mt value } \\
\text { of } \$ 1.3-1.5 \mathrm{bn}\end{array}$ & $\begin{array}{c}27,200-31,200 \\
(\$ 49-54 \mathrm{bn})\end{array}$ & $\begin{array}{l}28,000 \text { tons }(\$ 3 \\
\mathrm{mn})\end{array}$ & $\begin{array}{c}\text { 44,0000-91,000 temp, } \\
128,000 \text { long-term }\end{array}$ & $\$ 11.5-13.5 b n$ \\
\hline P2 & - & $\$ 97-98$ bn & $\begin{array}{l}158-315 \mathrm{Mt} \\
(@ \$ 16 / \mathrm{ton}= \\
\$ 1.6-3.2 \mathrm{bn})\end{array}$ & $\begin{array}{c}158-315 \mathrm{Mt} \\
\text { additional value } \\
\text { of } \$ 3.2-6.5 \mathrm{bn}\end{array}$ & $\begin{array}{c}2,500-4,900 \\
(\$ 5.5-10.6 \mathrm{bn})\end{array}$ & $\begin{array}{c}550,000-1.1 \\
m n \text { tons } \\
(\$ 61-120 \mathrm{mn})\end{array}$ & $44,000-110,000$ & $\$ 13.3-35.2 \mathrm{bn}$ \\
\hline P3 & - & - & - & $\begin{array}{l}49 \text { Mt value of } \\
\$ 1.5 \mathrm{bn}\end{array}$ & $\begin{array}{c}>1,000,000 \\
(>\$ 1.5 \mathrm{tn})\end{array}$ & - & 22,000 & $\$ 10.7$ bn \\
\hline P4 & - & $N P V:^{*} \$ 424 m n$ & $\begin{array}{c}103 \mathrm{Mt}(@ \$ 16 / \text { ton } \\
=\$ 1 \mathrm{bn})\end{array}$ & $\begin{array}{l}103 \mathrm{Mt} \text { additional } \\
\text { value of } \$ 2.2 \mathrm{bn}\end{array}$ & $\begin{array}{l}1,900(\$ 4.1 \\
\mathrm{bn})\end{array}$ & $\begin{array}{l}410,000 \text { tons } \\
(\$ 45 \mathrm{mn})\end{array}$ & 1,400 & $\$ 1.1 \mathrm{bn}$ \\
\hline
\end{tabular}

Notes:

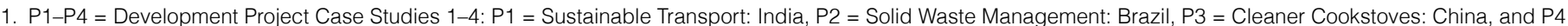
= Biogas Digestion and PV in Agriculture: Mexico; $\mathrm{mn}=$ million, bn =billion, and $\mathrm{tn}=$ trillion.

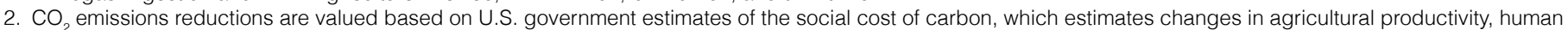
health, and property damage from increased flood risks.

3. Using methods recommended by the OECD (2011) for OECD countries and published estimates of the value of statistical life (VSL) for non-OECD countries and adjusting for differences in income and purchasing power, the following VSLs for avoided mortality were established (all reported in 2010 dollars). China: $\$ 700,635$; India: \$997,093; Mexico: \$1,379,804; Brazil: \$1,555,800; the EU: \$6,375,400; and the U.S.: \$7,887,510.

4. Crops are valued at $\$ 171 /$ ton based on 2010 grain prices from data.worldbank.org.

5. Unlike other case studies, P3 is not based on an actual project, but was developed based on the recently announced joint World Bank/Chinese government China Clean Stove Initiative (World Bank 2013b). As a result, there are no stated project benefits.

6. Net present values (NPVs) are calculated using a 3-percent social discount rate; results have also been calculated using 2.5 and five percent discount rates. All values are provided in Annex D.

* $\$ 622$ million in costs are subtracted from the $\$ 1$ billion in carbon finance value to arrive at a net present value of $\$ 424$ million in 2010 dollars. 
Table 3.4: Development project case studies: summary of global and local benefits

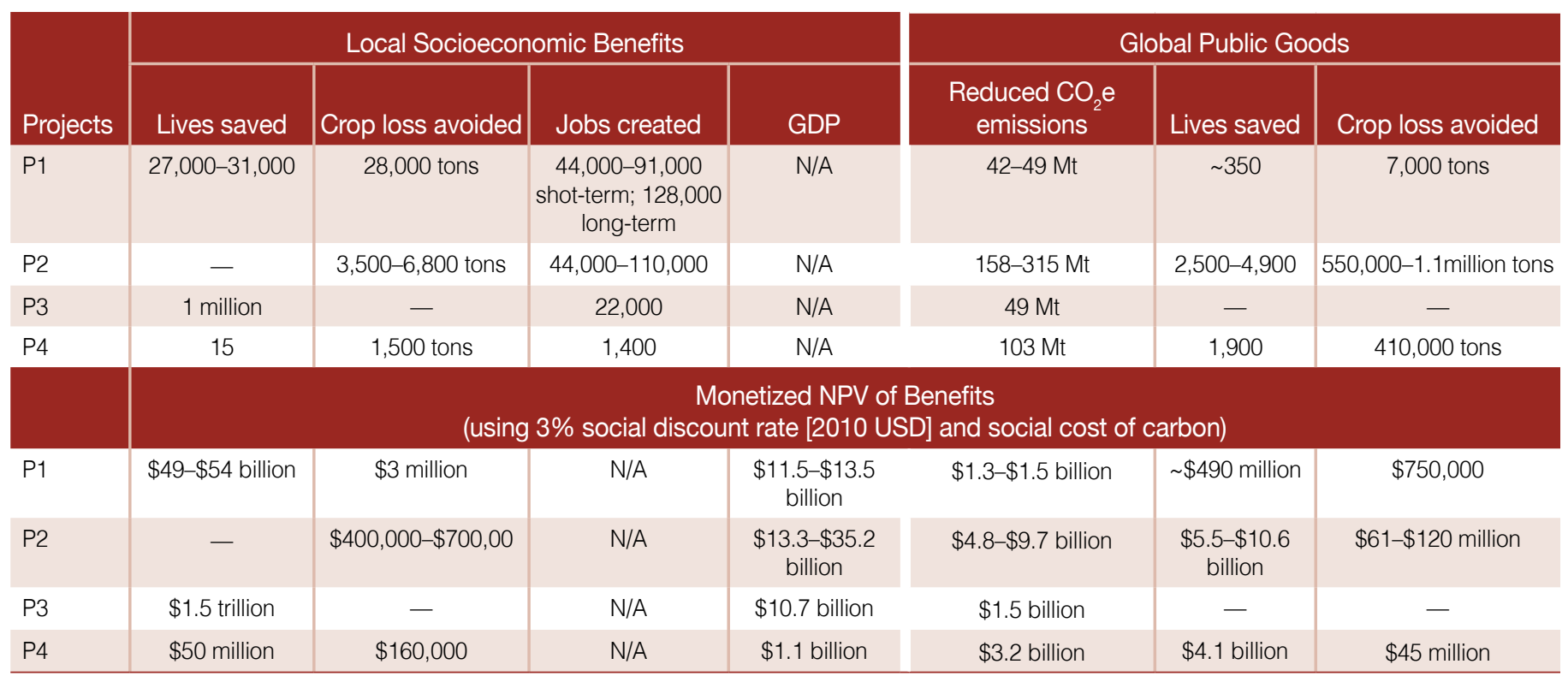

Notes:

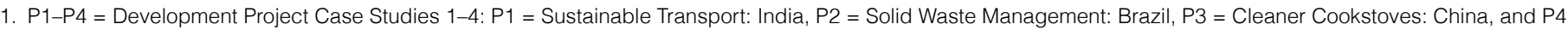
= Biogas Digestion and PV in Agriculture: Mexico; $\mathrm{mn}=$ million, bn =billion, and $\mathrm{tn}=$ trillion.

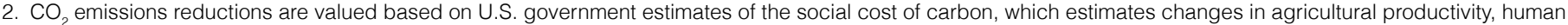
health, and property damage from increased flood risks.

3. Using methods recommended by the OECD (2011) for OECD countries and published estimates of the value of statistical life (VSL) for non-OECD countries and adjusting for differences in income and purchasing power, the following VSLs for avoided mortality were established (all reported in 2010 dollars). China: $\$ 700,635$; India: $\$ 997,093$; Mexico: $\$ 1,379,804$; Brazil: $\$ 1,555,800$; the EU: $\$ 6,375,400$; and the U.S.: $\$ 7,887,510$.

4. Crops are valued at $\$ 171 /$ ton based on 2010 grain prices from data.worldbank.org.

5. Unlike other case studies, P3 is not based on an actual project, but was developed based on the recently announced joint World Bank/Chinese government China Clean Stove Initiative (World Bank 2013b). As a result, there are no stated project benefits.

6. Net present values (NPVs) are calculated using a 3-percent social discount rate; results have also been calculated using 2.5 and five percent discount rates. All values are provided in Annex D. 


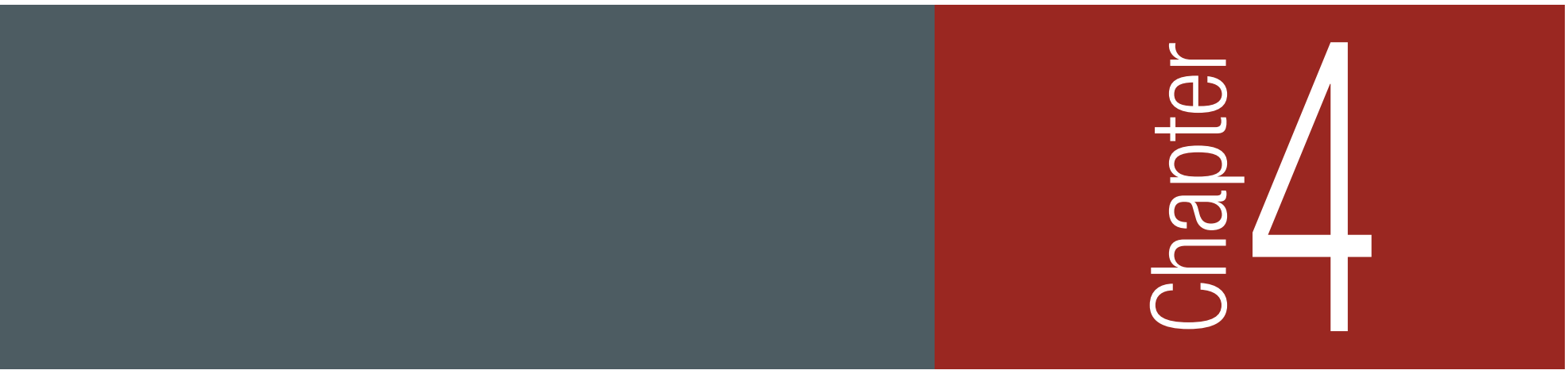

\section{Conclusions and Next Steps}

The growing cost of environmental degradation in many developing countries is impeding progress toward achieving the World Bank's twin goals of reducing poverty and boosting shared prosperity. According to a recent study, 5.7 percent of India's GDP in 2009 was lost to environmental degradation, with almost 3.3 percent attributed to air pollution emissions (World Bank 2013b). In China, serious air pollution has become a restricting bottleneck for regional socioeconomic development (CAAC 2013). Developing countries like India and China recognize the concurrent need to reduce air pollution, improve access to affordable energy and convenient transportation, address climate change, and grow their economies. China's " 12 th Five-Year Plan on Air Pollution Prevention and Control in Key Regions” places economic development at the center of its air quality management plans; India's 12th Five-Year Plan (Planning Commission, Government of India, 2013) acknowledges a need to establish "green national accounts" to measure the true costs of environmental degradation and to acknowledge the full benefits of reduced emissions.

As international development organizations, philanthropies, and others support developing countries in prioritizing climate project and policy interventions to close the greenhouse gas "emissions gap," improved analysis is needed to identify ways to leverage synergies among interventions, reduce costs, and maximize local socioeconomic benefits.

This report puts forth a holistic framework to estimate the multiple benefits of reduced emissions of several pollutants. Including the value of these benefits in economic analysis provides a fuller accounting of the true value of policies and programs and makes a stronger case for coordinated climate and development action. Further, it demonstrates the application of the framework using sectoral case studies at the policy and project level and at national and regional scales. By doing so, the report shows that national and international policymakers, finance organizations, and others can strengthen their estimation of the multiple benefits of such policies and projects. Furthermore, quantifying the benefits can facilitate support from different constituencies, including those interested in public health and food and energy security. Such improved analyses can also advance international discussions on the most effective ways to avoid the risks of a $4^{\circ} \mathrm{C}$ warmer world.

The framework presented in this report, like most first time efforts, has some limitations: the framework uses a patchwork of tools that were not designed to seamlessly integrate with one another; it does not account for behavioral issues, such as modal choice in public transit; and it does not explicitly account for the costs of the climate change impacts of these emissions. In addition to addressing these limitations, the framework could be strengthened through additional work:

- Further benefits assessments based on more comprehensive emissions data.

- Macroeconomic analysis to reflect the benefits of green versus non-green investment options.

- Better assessment of tradeoffs, such as between higher costs and productivity gains.

- Better assessment of risks to avoid locking-in development on the wrong path.

- Inclusion of welfare gains and other non-quantifiable benefits (such as equity and inclusion) in macroeconomic analysis.

Making the framework functional at the sub-national project level faces additional challenges. For example, integrating health 
and agriculture benefits into the economic analysis of individual projects (rather than using the global macroeconomic model as has been done in this report) may require a more tailored approach. Local benefits-such as time savings, gender equality, and social inclusion-may also need to be incorporated. Because not all these benefits are quantifiable, a hybrid approach may be needed. These challenges can be overcome if sub-national project teams start testing this framework in partnership with local counterparts to refine it.
Finally, the preparation of this report included consultative workshops in China and India where the demand for such a framework was strongly articulated by local policy makers and other stakeholders. The consultations identified the need for decision makers at the national and sub-national level to be sensitized to the idea of a framework that can help quantify multiple benefits so that they can consider using it as part of their economic rationale for policies and projects. 


\section{References}

Alberani, Cropper, Simon, and Arora (1999). Valuing Mortality Reductions in India: A Study of Compensating Wage Differentials. Policy Research Working Papers, The World Bank: http:// dx.doi.org/10.1596/1813-9450-2078.

Amann, M. et al. (2011). "Cost-effective Control of Air Quality and Greenhouse Gases in Europe: Modeling and Policy Applications." Environmental Modelling \& Software, 26 (2011) 1489-1501.

Avnery S, D. Mauzerall, J. Liu, and L.W. Horowitz (2011). “Global Crop Yield Reductions due to Surface Ozone Exposure” and "Year 2030 Potential Crop Production Losses and Economic Damage under Two Scenarios of $\mathrm{O}_{3}$ Pollution." Atmospheric Environment, 45, 2297-2309.

Avnery S, D. Mauzerall, and A.M. Fiore (2013). "Increasing Global Agricultural Production by Reducing Ozone Damages via Methane Emission Controls and Ozone-resistant Cultivar Selection.” Global Change Biology, 19, 1285-1299, doi:10.1111/ gcb. 12118 .

Belli, P. et al. (1998). Handbook on Economic Analysis of Investment Operations. The World Bank, January 1998.

Bollen, J.C., C.J. Brink, H.C. Eerens, A.J.G. Manders (2009). “Cobenefits of climate policy” PBL Report no. 500116005, February 2009 (available online at: http://www.unep.org/transport/ gfei/autotool/understanding_the_problem/Netherlands $\% 20$ Environment\%20Agency.pdf

Bollen, Johannes, Sebastiaan Hers, Bobvander Zwaan (2010). "An integrated assessment of climate change, air pollution and energy security policy”, Energy Policy 38 (2010) 4021-4030.
Bogner, J. et al. (2007). Waste Management. In: Metz B, Davidson OR, Bosch PR, Dave R, Meyer LA, editors. Climate Change 2007: Mitigation. Contribution of Working Group III to the Fourth Assessment Report of the Intergovernmental Panel on Climate Change. Cambridge, United Kingdom and New York, NY, USA: Cambridge University Press, 2007.

Bond, T. et al. (2013). "Bounding the Role of Black Carbon in the Climate System: A Scientific Assessment,” Journal of Geophysical Research, Atmospheres, doi: 10.1002/jgrd.50171, January. Bussolo, M. and O'Connor, D. (2001). Clearing the Air in India: The Economics of Climate Policy with Ancillary Benefits. Int. Development Centre Working Paper 182, CD/DOC 14, OECD.

CAAC (2013). China Clean Air Policy Briefing No. 1, "Twelfth Five-Year Plan" on Air Pollution Prevention and Control in Key Regions. English Translation of original document issued by the Ministry of Environmental Protection (MEP), National Development and Reform Commission (NDRC), and Ministry of Finance, December 2012. Clean Air Alliance of China, April, 2013.

Cassidy, Emily S., Paul C. West, James S. Gerber, and Jonathan A. Foley (2013). Redefining Agricultural Yields: From Tonnes to People Nourished per Hectare. Environ. Res. Lett. 8 (2013) 034015 (8pp).

Chen, Y., A. Abestein, and M. Greenstone and H. Li (2013). "Evidence on the Impact of Sustained Exposure to Air Pollution on Life Expectancy from China's Huai River Policy”, Proceedings of the National Academy of Sciences of the United States, vol. 110 no. 32 (2013), 12936-12941. 
Clarke, L. et al. (2008). $\mathrm{CO}_{2}$ Emissions Mitigation and Technological Advance: An Updated Analysis of Advanced Technology Scenarios. Pacific Northwest National Laboratory, Richland, WA.

Dinkel, J. et al. 2011: Abatement Opportunities for Non- $\mathrm{CO}_{2}$ Climate Forcers. Report for ClimateWorks Foundation and European Climate Foundation.

Enkvist, P. A., J. Dinkel, and C. Lin (2009). Impact of the Financial Crisis on Carbon Economics: Version 2.1 of the Global Greenhouse Gas Abatement Cost Curve. McKinsey and Company.

ESCAP (United Nations Economic and Social Commission for Asia and the Pacific) (2007). Sustainable Infrastructure in Asia: Overview and Proceedings. Seoul, Korea: Seoul Initiative Policy Forum on Sustainable Infrastructure. September 6-8, 2006.

Fang, Y., V. Naik, L.W. Horowitz, and D. L. Mauzerall (2013). “Air pollution and associated human mortality: the role of air pollutant emissions, climate change and methane concentration increases from the preindustrial period to present", Atmospheric Chemistry and Physics, 13, 1377-1394, 2013.

Florida, R. (2000). Competing in the Age of Talent: Quality of Place and the New Economy. Report prepared for the R.K. Mellon Foundation (Heinz Endowments and Sustainable Pittsburgh).

GEF (Michael Repogle). Manual for Calculating Greenhouse Gas Benefits for Global Environment Facility Transportation Projects. GEF/C.39/Inf.16. October 2010, pp. 20 ff.

Giusti., L. (2009). "A Review of Waste Management Practices and their Impact on Human Health.” Waste Management 29 (8) (August): 2227-2239. doi:10.1016/j.wasman.2009.03.028.

Hammit and Zhou (2006) "The Economic Value of Air Pollution Related Health Risks in China: A Contingent Valuation Study.” Environ. \& Resource Econ. 33: 399-423.

Hoornweg and Bhada-Tata (2012). "What a Waste: Waste Management around the World." The World Bank, Washington DC.

Hu, A., Y. Xu, C. Tebaldi, W. M. Washington, and V. Ramanathan (2013). "Mitigation of Short-lived Climate Pollutants Slows Sea-level Rise.” Nature Climate Change, doi:10.1038/ nclimate1869.

IDB (2013). Mitigation Strategies and Accounting Methods for Greenhouse Gas Emissions for Transportation. Inter-American Development Bank, Washington DC, June, 2013.

IPCC (2007). Climate Change 2007: Synthesis Report. Contribution of Working Groups I, II and III to the Fourth Assessment Report of the Intergovernmental Panel on Climate Change [Core Writing Team, Pachauri, R.K and Reisinger, A. (eds.)]. IPCC, Geneva, Switzerland, $104 \mathrm{pp}$.

Kirkeby, J. et al. (2008). "Environmental Assessment of Waste Incineration in a Life-cycle-perspective (EASEWASTE)," Waste Manag. Res., February 1, 2008 26: 96-103.

Law et al. (2010). Plastic Accumulation in the North Atlantic Subtropical Gyre. Science, 329(5966): 1185-1188. DOI: 10.1126/ science. 1192321.
Liu, W. G. and S. C. Zhao (2011). The Value of a Statistical Life in Road Safety: Findings from a Contingent Valuation Study in Dalian, China. ICTIS 2011: pp. 1061-1067.doi: 10.1061/41177(415)134. First International Conference on Transportation Information and Safety (ICTIS) Wuhan, China, June 30-July 2, 2011.

Lim, S. S., et al. (2012). "A Comparative Risk Assessment of Burden of Disease and Injury Attributable to 67 Risk Factors and Risk Factor Clusters in 21 Regions, 1990-2010: A Systematic Analysis for the Global Burden of Disease Study 2010." Lancet 380 (9859): 2224-60.

Madheswaran, S. (2007). "Measuring the Value of Statistical Life: Estimating Compensating Wage Differentials among Workers in India.” Social Indicators Research, 84:83-96, Oct. 2007.

Markandya (1998). The Valuation of Health Impacts in Developing Countries. Institute of Applied Economic Research, Brazil. MDE (2013). Maryland's Greenhouse Gas Reduction Plan. Maryland Department of the Environment, Baltimore, Maryland, July, 2013. Available at: http://www.climatechangemaryland.org/plan/.

Molina et al. (2009). "Reducing Abrupt Climate Change Risk Using the Montreal Protocol and Other Regulatory Actions to Complement Cuts in $\mathrm{CO}_{2}$ Emissions." Proceedings of the National Academy of Science, 10.1073/pnas.0902568106.

Naucler, T. and Enkvist, P. A. (2009). Pathways to a Low Carbon Economy. Version 2 of the Global Greenhouse Gas Abatement Cost Curve. McKinsey and Company.

Nellemann, C., M. MacDevette, T. Manders, B. Eickhout, B. Svihus, A.G. Prins, and B.P. Kaltenborn, (Eds) (2009). The Environmental Food Crisis - The Environment's Role in Averting Future Food Crises. A UNEP Rapid Response Assessment. United Nations Environment Programme, GRID-Arendal, www. grida.no (ISBN: 978-82-7701-054-0).

NYSERDA (2012). Applying the Multi-Pollutant Policy Analysis Framework to New York: An Integrated Approach to Future Air Quality Management, Prepared by Gary Kleiman and Leah Weiss for the New York State Energy Research and Development Authority, Report 12-10, Albany, NY, May, 2012.

OECD (2011). "Valuing Mortality Risk Reductions in Regulatory Analysis of Environmental, Health, and Transport Policies: Policy Implications." OECD, Paris: www.oecd.org/env/policies/vsl. Ortiz, Ramon Arigoni, Anil Markandya, and Alistair Hunt (2009). "Willingness to Pay for Mortality Risk Reduction Associated with Air Pollution in São Paulo.” Rev. Bras. Econ. vol.63, no.1, Rio de Janeiro Jan./Mar. 2009.

Paltsev and Capros (2013). "Cost Concepts for Climate Change Mitigation.” Climate Change Economics, 4, S1, 1340003-1.

Planning Commission, Government of India (2013). $12^{\text {th }}$ Five Year Plan (2012-2017): Faster, More Inclusive, and Sustainable Growth. Planning Commission, Government of India, SAGE Publishing, New Delhi, India. 
Qin, X., L. Li, and Y. Liu (2000). The Value of Life and Its Regional Difference in China.

Sanderson, W. et al. (2013). "Effects on Well-Being of Investing in Cleaner Air in India.” Environ. Sci. Technol., accepted Oct. 21, 2013: dx.doi.org/10.1021/es402867r.

Serôa Da Motta, Ronaldo, Ramon Arigoni Ortiz, and Sandro De Freitas Ferreira (1997). Health and Economic Values for Mortality and Morbidity Cases Associated With Air Pollution in Brazil. OECD Working Paper.

Shanmugam K.R. (1997). The Value of Life: Estimates From Indian Labour Market. The Indian Economic Journal, 105-114.

Shindell et al. (2012). "Simultaneously Mitigating Near-term Climate Change and Improving Human Health and Food Security." Science, 335, pg. 183.

Spiegel, A., Bresch, D (2013). Building a Sustainable Energy Future: Risks and Opportunities. Swiss Re: http://www.swissre.com/ rethinking/sustainable_energy/Building_a_sustainable_energy_future_risks_and_opportunities.html.

UNEP (2011a). Near-term Climate Protection and Clean Air Benefits: Actions for Controlling Short-Lived Climate Forcers. Nairobi, Kenya: United Nations Environment Programme (UNEP).

(2011b). HFCs: A Critical Link in Protecting Climate and the Ozone Layer. Nairobi: United Nations Environment Programme (UNEP).

(2011c). Towards a Green Economy: Pathways to Sustainable Development and Poverty Eradication. Nairobi: UNEP.

(2013). The Emissions Gap Report 2013. United Nations Environment Programme (UNEP), Nairobi.

UNEP/WMO (2011). Integrated Assessment of Black Carbon and Tropospheric Ozone: Summary for Decision Makers. UNON/ Publishing Services Section/Nairobi, ISO 14001:2004.

UN-Habitat(2010). Solid Waste Management In the World's Cities. United Nations Human Settlements Programme. London.

U.S. Environmental Protection Agency Guidance (2000): http:// yosemite1.epa.gov/ee/epa/eed.nsf/pages/MortalityRiskValuation.html\#top.

U.S. Interagency Working Group on Social Cost of Carbon (2013). Technical Support Document: Technical Update of the Social Cost of Carbon for Regulatory Impact Analysis Under Executive Order 12866.
Van Dingenen, R. et al. (2009). "The Global Impact of Ozone on Agricultural Crop Yields under Current and Future Air Quality Legislation," Atmos. Environ.43, 604-618.

Wagner, F. et al. (2013). GHG Mitigation Potentials for China and India from the GAINS Model for 2020. IIASA report to ClimateWorks, ClimateWorks Foundation, San Francisco, CA.

Wang and He (2010). The Value of a Statistical Life: A Contingent Investigation in China. World Bank Policy Research Working Paper 5421, September 2010.

Weiss, L. et al. (2007). "Building Momentum for Integrated Multi-pollutant Planning: A Northeast States' Perspective.” EM magazine, Air and Waste Management Association, pp. 25-29, May, 2007.

World Bank (2011). Black Carbon and Climate Change, Considerations for International Development Agencies. Washington, DC: World Bank Environment Department.

(2012a). Turn Down The Heat: Why a $4^{\circ} \mathrm{C}$ Warmer World Must be Avoided. The World Bank, Washington DC, November, 2012. (2012b). Inclusive Green Growth: The Pathway to Sustainable Development. The World Bank, Washington, DC.

(2013a). Integration of Short-lived Climate Pollutants in World Bank Activities. Climate Policy and Finance Department, The World Bank, Washington, DC.

(2013b). India: A Diagnostic Assessment of Select Environmental Challenges; An Analysis of Physical and Monetary Losses of Environmental Health and Natural Resources. South Asia Disaster Management and Climate Change Unit, The World Bank, Washington, DC.

(2013c). China: Accelerating Household Access to Clean Cooking and Heating. Asia Sustainable and Alternative Energy Program, The World Bank

(2013d). On Thin Ice: How Cutting Pollution Can Slow Warming and Save Lives. The World Bank, Washington, DC, and the International Cryosphere Climate Initiative, Charlotte, VT.

World Energy Outlook (2013). Available at http://www. worldenergyoutlook.org/resources/energydevelopment/ energyaccessprojectionsto2030/.

Zhang, X. (1999). Valuing Mortality Risk Reductions Using the Contingent Valuation Method: Evidence from a Survey of Beijing Residents in 1999. Paper for the Second World Congress of Environmental Economics. 



\section{Annex A: Summary of Health, Agricultural, and Climate Benefits from Emissions Reduction}

In a development context, the local benefits of reducing incomplete combustion of biomass and fossil fuels and eliminating other air pollutants are clear. In many cases, the development benefits of improved local environmental quality far exceed the potential climate benefits of reducing these emissions. For example, BC from incomplete combustion of diesel in vehicles is a toxic air pollutant. Diesel exhaust is a risk factor for cardiopulmonary disease and can trigger asthma and heart attacks, leading to hospital visits and premature deaths (World Bank 2011). Methane is released as a fugitive emission from oil and gas production and distribution, biogas production, agricultural production (including livestock and rice farming), decomposition of municipal solid waste, and other activities (e.g., coal mining). In the atmosphere, methane leads to the formation of tropospheric ozone, a component of smog. These pollutants can cause significant crop damage, lowering agricultural yields (UNEP 2011a).

The last global burden of disease report (Lim et al. 2012) estimated that in 2010 there were 3.5 million premature deaths from indoor smoke from solid fuels and another three million deaths from urban air pollution. Both forms of air pollution include black carbon. These statistics provide a strong impetus for taking quick action to reduce $\mathrm{BC}$ emissions.

Fang et al (2013) studied the human health effects of air pollution, climate change, and increased methane concentrations from the pre-industrial period to the present. They found that global changes in $\mathrm{PM}_{2.5}$ are associated with 1.5 million cardiopulmonary deaths and 95,000 lung cancer deaths annually, and ozone changes are associated with 375,000 respiratory deaths annually. Most air pollution mortality is driven by increased emissions of fine particles and smog (95 percent and 85 percent of mortalities from $\mathrm{PM}_{2.5}$ and ozone, respectively). These include $\mathrm{BC}$ and tropospheric ozone formed from methane. Changing climate and increasing methane concentrations also contribute to global premature mortality (by up to 5 and 15 percent, respectively). This study also found that, in some regions, climate change and increased methane together are responsible for more than 20 percent of the respiratory mortality associated with ozone exposure.

Chen et al. (2013) analyzed the impact on life expectancy of sustained exposure to air pollution, using a wide range of data sources generated by a central government policy to provide free winter heating to homes and offices in the period of 1950-1980 in cities north of the Huai River. The researchers found air pollution was 55 percent higher in the north between 1981-2000, resulting in life expectancies about 5.5 years lower than in the south, where heating was not legally required and promoted. In other words, air pollution had resulted in 500 million residents of Northern China to lose more than 2.5 billion life years of life expectancy. More generally, the analysis suggests that long-term exposure to an additional $100 \mu \mathrm{g} / \mathrm{m}^{344}$ of TSPs is associated with a reduction in life expectancy of about three years.

In a recent paper, Avnery et al. (2013) examined the potential benefits of a strategy to mitigate surface ozone by gradually reducing emissions of methane, an important greenhouse gas and tropospheric ozone precursor. Because ozone has a significant negative impact on crop yields, reducing ozone-induced agricultural losses would allow the world to meet the projected 50 percent increase in global grain demand by 2030 without further environmental

44 Micrograms (one-millionth of a gram) per cubic meter of air. 
degradation. The study finds that a specific set of methane emissions reduction strategies-if fully implemented-would increase global production of soybean, maize, and wheat by 23-102 Mt in 2030 , equivalent to an approximately $2-8$ percent increase relative to year 2000 production and worth $\$ 3.5-15$ billion worldwide (in 2000 dollars), increasing the cost effectiveness of this methane mitigation policy.

Bollen et al. (2010) went a step further and demonstrated multiple possible synergies that can be exploited by combining climate change, air pollution, and energy security policies. The benefits of coordinated policies can be large: in Europe, for example, the achievable reductions in $\mathrm{CO}_{2}$ emissions and oil consumption are significantly deeper for integrated policies than when one of the policies is omitted. Integrated optimal energy policy can reduce the number of premature deaths from air pollution by about 14,000 annually in Europe and over three million per year globally by lowering people's chronic exposure to ambient particulate matter.

Along the same lines, Shindell et al. (2012) considered a large number of emissions control measures to reduce emissions of tropospheric ozone and black carbon, pollutants that contribute to degraded air quality and global warming. The study identifies a subset of specific measures targeting methane and $\mathrm{BC}$ emissions that could reduce projected global mean warming by approximately $0.5^{\circ} \mathrm{C}$ by 2050 , avoid $700,000-4.7$ million annual premature deaths from outdoor air pollution, and increase annual crop yields by $30-135$ million metric tons due to ozone reductions in 2030 and beyond. The study also quantifies the net benefits of methane emissions reductions, estimated at $\$ 700-5,000$ per metric ton, well above average marginal abatement costs (about $\$ 250 / \mathrm{t}$ ).

Other reports published by multilateral institutions arrive at the same conclusion. A study commissioned by the OECD and conducted by the Netherlands Environmental Assessment Agency (Bollen et al., 2009) found that a stringent global climate policy will lead to considerable improvements in local air quality and, consequently, improved health. The analysis showed that measures to reduce emissions of greenhouse gases to 50 percent of 2005 levels by 2050 can reduce the number of premature deaths from chronic exposure to air pollution by $20-40$ percent. The policy implications are, however, different for emerging economies and developed countries. Whereas climate policy will generate air quality improvements in the OECD countries (particularly in the U.S.) in the mid-term, in emerging economies these benefits will only become significant in the longer run.
In China, for example, the Bollen (2009) analysis suggests that the costs of reducing greenhouse gas emissions by 80 percent from the baseline would amount to 6.5 percent of the country's GDP, while the benefits would be equivalent to 4.5 percent of GDP. These same benefits could also be achieved, however, through a more targeted air quality policy at a cost of 1.8 percent of GDP. On the flip side, stringent air quality policy can lead to significant reductions in greenhouse gas emissions. Again using China as an example, the authors find that stringent air policy to reduce the number of premature deaths from chronic exposure to outdoor air pollution by 70 percent by 2050 (compared with the baseline) would lower GDP in 2050 by 7 percent; the air quality benefits would be equivalent to 7.5 percent of GDP and greenhouse gas emissions would be 40 percent lower.

A 2011 synthesis report published by UNEP found that reducing atmospheric concentrations of short-lived climate pollutants, specifically black carbon, tropospheric ozone, and methane, offers a real opportunity to improve public health, reduce crop yield losses, and slow the rate of near-term climate change, thereby aiding sustainable development. Crucially, the health benefits from implementing black carbon mitigation measures (especially by controlling emissions from biomass cookstoves and transport in Asia and Africa) would be realized immediately and almost entirely in the regions that reduce their emissions. More specifically, the reductions in outdoor particulate air pollution (from black carbon measures) would avoid an estimated 2.4 million premature deaths annually by 2030 while also greatly reducing the health impacts from indoor exposure. Controlling emissions of methane and other ozone precursors by implementing black carbon measures (by reducing emissions from coal mines in Northeast Asia, South East Asia, and the Pacific; oil and gas production in all regions; and long-distance natural gas transmission pipelines in North America and Europe; and by implementing Euro VI standards more widely) would avoid annual losses from four major crops of about $32 \mathrm{Mt}$ each year after 2030. Finally, reducing these short-lived climate pollutants offers a realistic opportunity to significantly reduce the rate of global warming (by about $0.4^{\circ} \mathrm{C}$ ) between $2010-2040$.

In addition to the impacts described here, SLCPs cause serious damage to non-crop flora and fauna (wild forests and wildlife); this has not as yet been as rigorously studied. It is clear that the ecosystem services supported by biodiversity, watersheds, and climate-regulating systems have significant economic value (World Bank 2012b), including nature-based tourism. Efforts to properly value these aspects of natural capital will be integrated into future analyses on the multiple benefits of reducing emissions. 


\section{Annex B: Detailed Description of the Models}

This report uses recently developed emissions modeling and assessment tools and an integrated macroeconomic model. Two innovative programs helped usher in these modern, synergistic, multi-pollutant air quality and energy planning tools. The programs, the European Convention on Long-Range Transboundary Air Pollution and the U.S. market-based approach to control acid rain under the Clean Air Act, advanced economic efficiency as a major driver of the design of air quality management programs.

\section{Box B.1: Examples of Integrated Planning Approaches}

\section{Europe: The Convention on Long-Range Transboundary Air Pollution}

The innovative Regional Air Pollution Information and Simulation (RAINS) model was the predecessor to today's Greenhouse Gas and Air Pollution Interactions and Synergies (GAINS) model. Maintained by the International Institute for Applied Systems Analysis, RAINS informed national emission caps that employed cost-effectiveness as the rationale for differentiated obligations. The model had to quantify the costs of the entire range of emissions reduction possibilities and ensure that the desired environmental outcomes were achieved across an entire geographic area. By putting all measures into a broader context, RAINS helped decisionmakers identify strategies that maximize synergies between different measures, ensure attainment of all environmental goals, and minimize costs (Amann et al. 2011).

\section{United States: Multi-pollutant Planning under the Clean Air Act}

Implementation of air quality protection under the Clean Air Act is complicated by the act's pollutant-by-pollutant approach; the many challenges that followed spurred development of tools that attempt to deal with multiple air quality issues simultaneously. Integrated multi-pollutant planning has been shown to be a more economical way to address environmental and public health issues than traditional single-pollutant approaches (Weiss et al. 2007; NYSERDA 2012). By concurrently looking at multiple air quality goals and potential controls and their environmental, public health, energy, and economic impacts, a more complex set of policy questions emerges that can then be addressed. Multi-pollutant approaches identify the tradeoffs of implementing one strategy over another, help set priorities and appropriate planning horizons, and identify the optimal mix of policies and controls that will result in greater synergistic benefits than discrete policies covering individual pollutants. 


\section{McKinsey's MACC Model}

The marginal abatement cost curve (MACC) model used in this report to analyze several sector-wide policies was developed by McKinsey \& Co. in 2011-2012. This version, v.3.0, builds on previous modeling and simulation exercises McKinsey conducted for several clients, including the ClimateWorks Foundation, starting in 2007. Subsequent updates took into account changing economic circumstances (such as the 2008-2009 financial crisis) and technology costs (such as the rapidly declining cost of renewable technology and the stalled development of carbon capture and storage).

In graphic representations of MACCs (Figure B.1), policy levers are typically sorted by increasing cost of emissions reduction opportunities in a given year (merit order). The width of each bar represents the potential GHG emissions reduction from that specific intervention (such as a suite of fuel efficiency improvements to the internal combustion engine). This abatement potential is defined as the volume difference between the emissions baseline and the emissions after the lever is applied. To ensure comparability across different sectors and emissions sources, all emissions and sinks (storage) are measured in metric tons of $\mathrm{CO}_{2} \mathrm{e}$. The height of each bar represents the average annual cost for each abatement opportunity of avoiding one metric ton of $\mathrm{CO}_{2}$.

Abatement costs are defined as the incremental cost of a low-emissions technology compared with the reference case, measured on $\$ / \mathrm{tCO}_{2}$ e. These costs include two key components: the annualized repayments for capital expenditure (CapEx) - in other words, the additional investments in new technology or replacement infrastructure necessary to achieve those GHG emission reductions-and the operational costs or savings (OpEx), fuel- and non-fuel-related, associated with each specific abatement opportunity. The repayment period is the functional life of the equipment, and the interest rate is the long-term government bond rate. The abatement costs can therefore be interpreted as pure project costs incurred to install and operate each specific low-emitting technology. Capital availability is not considered a constraint. Other key elements are deliberately excluded from cost calculations: transaction costs, communication/information costs, subsidies or explicit $\mathrm{CO}_{2}$ costs, taxes, and the consequential economic impacts of significantly investing in low-emitting technology (such as advantages from technology leadership).

MACCs can be interpreted as a supply curve of abatement opportunities, independent of abatement targets, which could in

Figure B.1: Global carbon abatement cost curve, 2030

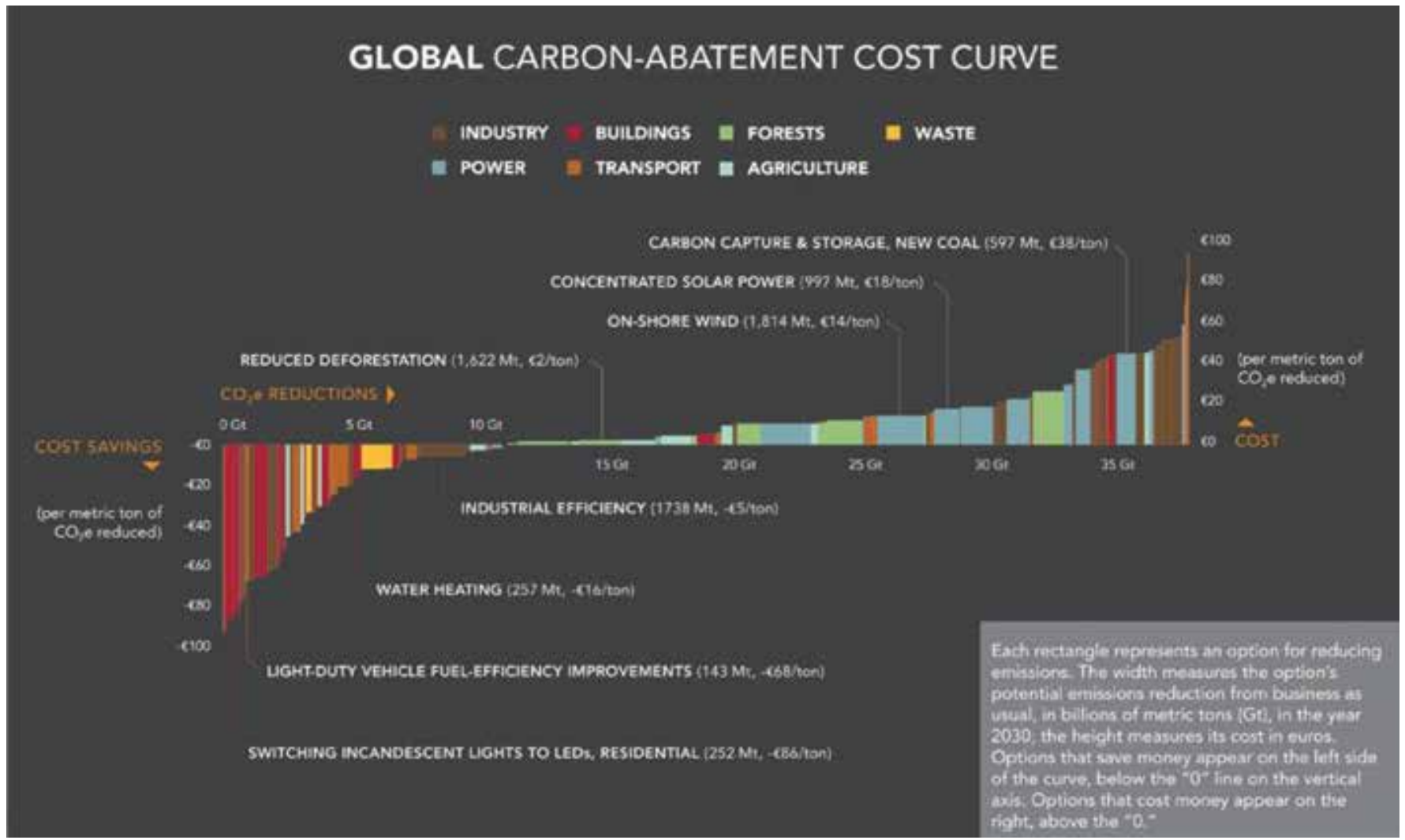


turn be interpreted as a demand curve for abatement. The cost curve representation used for this study takes a societal perspective, rather than that of an individual investor or consumer, to illustrate the cost requirements to the society as a whole. This is clearly an abstraction; policy options are not selected by a single worldwide decision maker. This representation is useful for comparison, however, and to provide a globally consistent indication of available abatement opportunities and associated costs. Given the long time horizon of the analysis, all the results are subject to significant uncertainties. In addition, as mentioned earlier, some key assumptions may significantly affect the analysis, particularly the exclusion of transaction costs (all costs above and beyond the technical project costs incurred in making an economic exchange) and behavioral changes driven by price and non-price factors (including those addressed by specific policies). The MACC model "merit order" typically starts with energy efficiency measures in the industry and building sectors, moves on to address measures in the transport and forests/land use sectors, and ends with the power sector. The model is based on a split of 21 regions (G8 +5, and other major geopolitical regions).

\section{TM5-FASST Model}

The TM5-FASST model is a reduced-form air quality source-receptor matrix (AQ-SRM) developed by the European Commission's Joint Research Center in Ispra, Italy. It covers 56 source regions, including major countries and aggregations of several smaller nations. TM5-FASST can analyze emissions of $\mathrm{SO}_{2}, \mathrm{NOx}, \mathrm{NH}_{3}, \mathrm{CO}$, NMVOC, elemental carbon, primary organic matter, $\mathrm{PM}_{2.5}$, and $\mathrm{CH}_{4}{ }^{45}$ The relation between the emissions of compound $i$ from source $x$ and resulting pollutant $j$ concentration (where $j=i$ in case of a primary component) at receptor $y$ is expressed by a simple functional relation that mimics the underlying meteorological and chemical processes (Van Dingenen et al. 2009). In the current version of TM5-FASST, the function is a simple linear relation:

$$
C_{i \rightarrow j, y, x}=C_{0}+A_{i \rightarrow j, x, y} E_{i, x}
$$

where $C_{i \rightarrow j, y, x}$ is the concentration of species $j$ at receptor $y$ formed from precursor $i$ emitted at source $x, C_{0}$ is a constant, $A_{i \rightarrow j, x, y}$ is the so-called source-receptor coefficient (SRC) between $x$ and $y$ for $(i \rightarrow j)$, and $E_{i, x}$ is the emission rate $(\mathrm{kg} / \mathrm{yr})$ of precursor $i$ at source $x$. The SRCs are stored as matrices with dimension $[\mathrm{x}, \mathrm{y}]$ at the $1^{\circ} \times 1^{\circ}$ resolution of the native TM5-CTM model (in other words, there is one $1^{\circ} \times 1^{\circ}$ SRC map for each of the 56 source regions and for each precursor component) and, in principle, can be aggregated into any customized receptor region.

One particularly useful aggregation scheme is to combine the receptor grids into the 56 defined source regions; hence the
SRCs are stored into 56x56 matrices between identical source and receptor regions. On the other hand, the $1^{\circ} \mathrm{x} 1^{\circ}$ resolution SRC maps allow for calculation of the resulting concentration in each individual grid point and are therefore useful in creating global concentration and impact maps or in constructing customized receptor regions for studies with specific targets.

The resulting air pollutant concentrations, and their specific spatial distribution, are then further processed into impacts, such as the effect of PM on human health (e.g., mortalities, reduction of statistical life expectancy), the impact of $\mathrm{O}_{3}$ on vegetation and crop damage, and damage caused by deposition of eutrophying or acidifying components in sensitive ecosystems. Most of these calculations are based on simple empirical dose-response functions, but they require that additional data be overlaid with the pollutant concentration (or derived metric) in order to properly calculate the exposure (using maps of populations, crops and vegetation, sensitive ecosystems, and so forth).

\section{Oxford Economics' GEIM}

Economic analyses of climate policies are often based on partial equilibrium models, which are typically used to assess the impact of an economic or policy shock affecting two or more interconnected markets, assuming the rest of the economy remains fixed (ceteris-paribus condition). This is a very effective approach when the effects of the policy shock are expected to be limited to specific sectors/markets. However, when the economic or policy shock to be evaluated is complex, expected to be transmitted through different channels and have significant impacts throughout the economy, and may take place in several stages, economists consider general equilibrium models to be the best choice. General equilibrium analysis performs well when evaluating fiscal policies, trade policies, climate change shocks, shocks in international prices, and other shocks.

Oxford Economics' Global Energy Industry Model (GEIM) is a structural, econometric, general equilibrium model of the global economy. McKinsey used GEIM to develop and quantify integrated climate, energy, and economic scenarios for the most recent version of its global GHG abatement cost curve (the MACC v.3.0 described above), linking emissions scenarios with global and regional macroeconomic performance. One of the reasons Oxford Economics' model was chosen to perform the scenario analysis in this report is that its energy module is more detailed and sophisticated than other similar tools.

45 Sulfur dioxide, nitrogen oxides, ammonia, carbon monoxide, non-methane volatile organic compounds, elemental carbon, primary organic matter, particulate matter with a diameter of 2.5 microns or less, and methane. 


\section{GEIM country coverage}

- Developed economies: The U.S., Japan, the Eurozone, Germany, France, Italy, the UK, Canada, Austria, Australia, Spain, Denmark, Finland, Norway, Netherlands, Belgium, Portugal, Ireland, Sweden, Austria, Switzerland.

- Emerging markets: China, Taiwan, China, South Korea, Hong Kong SAR, China, Thailand, Malaysia, Philippines, Indonesia, Singapore, Mexico, Brazil, Argentina, Chile, Poland, Czech Rep., Hungary, Russia, Bulgaria, Croatia, Slovakia, Romania, South Africa, Turkey, India, UAE.

- Six trading blocs: OPEC, Eastern Europe, Africa, Latin America, rest of OECD, rest of world.

As in all general equilibrium models, GEIM's individual country models are fully linked through global assumptions about trade, exchange rates, competitiveness, capital markets, interest rates, commodity prices, and internationally traded goods and services. The level of detail in the model varies depending on availability of reliable data. GEIM examines 46 economies in detail. G7 country models include over 400 variables; other OECD countries' models typically include about 300 variables; and models for emerging markets include about 200. The rest of world is covered by six trading blocs, with headline indicators for 30 countries, so that global GDP and trade are fully modeled. This geographical resolution was ideal for the purpose of this study given the close connection between the size of a country's economy and its relative importance as a GHG emitter.

Figure B.2: Main transmission channels in oxford economics' GEIM model

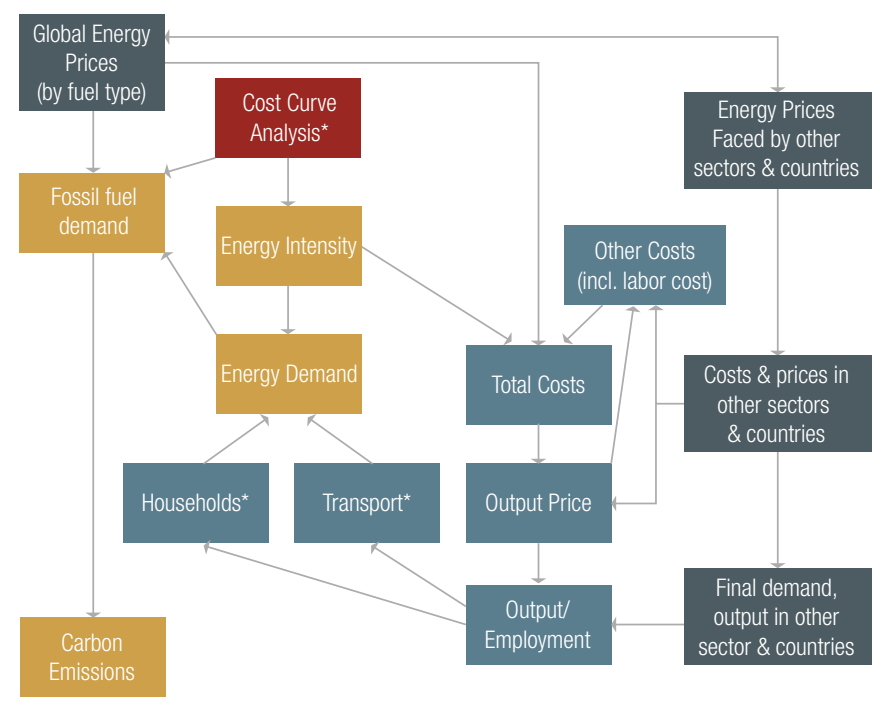

* Cost curve analysis also feeds into households' income and transport energy consumption.
GEIM could be defined as Keynesian in the short run and monetarist in the long run. This means that, while increased demand will initially lead to higher output and employment, shock will feed through into higher wages and prices. Given an inflation target, interest rates will have to rise, reducing demand (known as "crowding out"). In the long run, output and employment are determined by supply-side factors. Figure B.2 presents an overview of the model's main transmission channels.

GEIM operates on the following assumptions:

- Consumption is a function of real income, wealth, and interest rates.

- Investment follows a "q" formulation with accelerator terms.

- Exports depend on world demand and relative unit labor costs.

- Imports depend on total final expenditure and competitiveness.

- Real wages depend on productivity and unemployment relative to the non-accelerating inflation rate of unemployment (NAIRU).

- Prices are a mark-up of unit costs, with profit margins a function of the output gap.

- Monetary policy is endogenized.

- Exchange rates are determined by uncovered interest parity (UIP).

- Expectations are adaptive.

GEIM can model several linkages between different country models, including:

- Trade: World trade for each country is a weighted average of the growth in total goods imports (excluding oil) of all other countries. The weights are thus the relevant coefficients in the trade matrix.

- Competitiveness: Where available, the model uses relative unit labor cost data provided by the IMF (and relative prices elsewhere).

- Interest rates and exchange rates: These are endogenous and are constructed using a Taylor Rule formulation that approximates central banks' response to shifts in the economy and relates movements in interest rates (the standard tool used in monetary policy) to the rate of inflation relative to a predefined target and the level of actual output relative to potential output.

- Commodity prices: The price of oil depends on supply/demand balance, while metal prices depend on industrial growth.

- World price of manufactured goods: These include sectoral outputs such as fuel extraction, iron and steel, transport equipment, computers and office equipment, and so on; prices are determined by change in competiveness, trade environment, and domestic final demand.

- Capital flows: Bilateral capital flows for major blocs are taken into account. 
Oil prices are determined by the interaction of supply and demand in the global market. In the model, oil demand is linked to economic growth, and relative oil prices are fully integrated with the rest of the model. Gas and coal prices are modeled in a similar way.

Despite the relatively strong performance of the model, the global financial crisis highlighted areas where it could be improved:

- Interest rates: Expand coverage to include key corporate and consumer lending rates as well as interbank rates and bond yields.
- Credit conditions: Introduce levers to account for the tightness/looseness of bank lending that is not reflected in interest rates (analysis based on research by John Muellbauer of Oxford University).

- Balance sheet coverage: Expand to cover financial and nonfinancial corporations as well as households and governments.

- Credit ratings: Reflect the impact of sovereign debt ratings on interest rate spreads for government bonds.

- Feedback effects: Include the impacts of unemployment/ insolvencies on credit conditions. 



\section{Annex C: Details and Data for Sector Policy Case Studies}

The first three case studies presented in Chapter 3 analyzed the impacts of key sector policy interventions-including regulations, incentives, and taxes-to stimulate specific measures to cut emissions from three sectors: transportation, industry, and buildings. The ClimateWorks Foundation analyzed the impacts in six regions-China, India, the EU, the U.S., Mexico, and Brazil-plus the impact on global GDP.

\section{"Policy Consensus" Scenario}

The sector policy case studies presented in Chapter 3 are based on certain carbon mitigation assumptions derived from McKinsey's MACCv.3.0. More specifically, they use McKinsey's "Policy Consensus" scenario, in which policy is the main driver of a transition to a clean economy. Amongst the six scenarios considered in MACC $\mathrm{v}$ 3.0, this is the most optimistic scenario. In this scenario, total emissions for all sectors and all regions of the world result in about 45 $\mathrm{GtCO}_{2}$ e emitted per year in 2030. At the other end of the spectrum is the most pessimistic scenario where GHG emission reductions are not pursued. In this scenario, total global emissions result in about $60 \mathrm{GtCO}_{2}$ e emitted per year in 2030. To limit emissions to $45 \mathrm{GtCO}_{2}$ e per year for the policy consensus scenario, the energy system would require a global capital expenditure of about $\$ 6.1$ trillion per year in 2030 (Spiegel and Bresch 2013). This is about $\$ 1.5$ trillion more than in the scenario where GHG reductions are not pursued. In 2010, the global capital expenditure for similar investments was about $\$ 4.3$ trillion.
The policy consensus scenario assumes a recovering economy and a strong greenhouse gas policy agreement among the major economies of the world (strict policies agreed to by 2015 and effective by 2020, as laid out at the COP17 meeting in Durban); this clear policy signal also spurs major investment in clean, efficient technologies well before 2020. In addition, non-energy-related forestry and agriculture $\mathrm{CO}_{2}$ emissions, non- $\mathrm{CO}_{2}$ greenhouse gases, and CCS are addressed forcefully. This is also reflected in fossil-fuel prices, which are an important driver for economic growth projections considered in the scenarios. Figure C. 1 shows the difference in oil prices between the policy consensus scenario and a baseline scenario in which GHG emissions reductions are not pursued. As a consequence of the dramatic decrease in fossil fuel use in the policy consensus scenario, demand for oil decreases and prices remain relatively stable over the $2010-2050$ period, as opposed to a scenario in which fossil fuel use remains dominant and GHG emissions continue to grow as does the demand and price of oil. This is consistent with most other energy models' forecasted trajectories through $2030 .{ }^{46}$ The figure also shows the oil price trajectories for all policy case study simulations.

More details on the assumptions used for the policy consensus scenario is described below. For details on assumptions behind other scenarios, refer to Spiegel and Bresch (2013).

46 See, for example, http://www.eia.gov/pressroom/presentations/howard_04162012. pdf, page 6 . 
Table C.1. Policy Consensus Around Climate Change

\section{0-20: Real climate change policy \\ 2020-30: Global deal reached}

- The economy recovers and grows strongly at the end of the decade (2-3\% OECD, 7-8\% BRIC, 3-4\% RoW)

- More extreme weather events and successful communication campaigns increases public awareness, "clean" consumption and put pressure on politicians. Green voting becomes mainstream and bipartisan

- Increasing consensus in 2015 among policy makers result in national and regional abatement policies (a high implicit $\mathrm{CO}_{2}$ price) on most OECD and BRIC countries by 2020 (not necessarily in the form of a "global deal")

- A clear policy debate makes future international agreement on GHG emissions more likely

- $\quad$ Clean tech roll-out quick with support from a strong economy and policies, with cost trajectory following expectations

- $\quad$ Fossil fuel supplies keep up with demand due to widespread shale gas exploration in US and China
- $\quad$ The economy grows at high growth rates ( 2\% OECD, 6-7\% BRIC, 3-4\% RoW), especially in countries that are early adopters of green tech benefitting on green wave

- Global deal on climate is reached and agreed in 2022

- International cooperation on GHG emissions (high $\mathrm{CO}_{2}$ prices)

- $\quad$ Comprehensive targets on EE

- Non-energy climate forcers also addressed, e.g. Forestry and Agriculture

- $\quad$ Oil demand growth slows significantly.

- Resource holders respond by cutting back production

- $\quad$ Countries that have not diversified energy supply suffer. This also pushes unconventional gas further

- A few countries take the lead in clean tech development, others are followers - green growth benefits early adopters

- Tech driven by private sector and high competition reduces prices more quickly than expected. In parallel, electrification of transport and industrial processes is rolled out in the US and EU
2030-50: Long-term reductions

- $\quad$ Green growth benefits of new industrial revolution underpin continued growth ( 2\% OECD, 4-6\% BRIC, 3-4\% RoW)

- Demand for oil \& coal, less so for gas, gradually decreases leading to reduced prices. But the technology shift means clean energy infrastructure is solidly in place

- $\quad$ Strict ETS system with mandates in non- ETS sectors (high $\mathrm{CO}_{2}$ price and widespread mandates and targets on EE and non-energy climate forcers)

- Thanks to global cooperation and strong growth, an adequate adaptation fund covers risk management for poorer countries

- Impact of climate change not as severe as expected, but clear effects are visible

Note: The global economy recovers (e.g. driven by strong Asian demand), and through a series of observable climate events/trends and scientific advancements until 2020, the broad public starts to agree that global warming is for real. As a result, strong mitigation legislation is established in the major economies between 2020 and 2025.

\section{Sector Policy Case Study 1: Shift to Clean Transport}

Road transport accounted for $6.6 \mathrm{Gt}$ of $\mathrm{CO}_{2} \mathrm{e}$ or approximately 80 percent of all global transport emissions in 2010 (15 percent is

Figure C.1: Oil prices in 2010 USD for Baseline, Policy Consensus and all policy case study scenarios

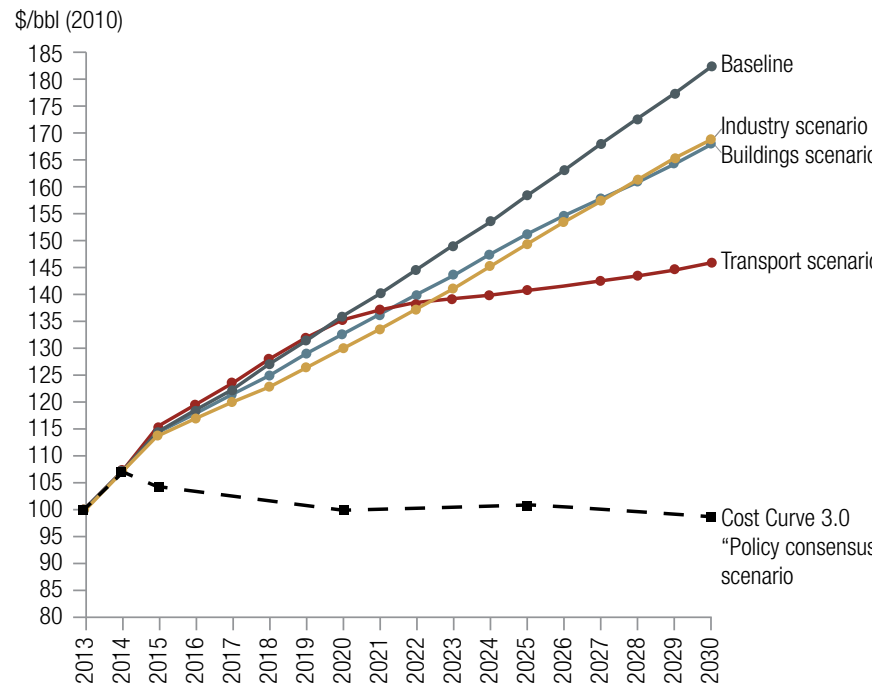

from oil production and refining). About 50 percent of global road transport emissions originate from North America and Western Europe; all emissions currently originate from combustion of liquid fuels (largely fossil), and there is no significant use of indirect energy (i.e., electricity).

\section{Key Assumptions}

This case study assumes a business-as-usual (BAU) growth of global distances traveled of 106 percent for light-duty vehicles (LDVs) from 2010-2030, 57 percent for medium-duty vehicles (MDVs), and 60 percent for heavy-duty vehicles (HDVs). This implies that global emissions will grow by approximately 100 percent until 2030 without reference case efficiency improvements, largely driven by increased vehicle sales in China and other emerging economies. Including reference case efficiency improvements, emissions will grow by about 29 percent to 2030 (to approximately $8.5 \mathrm{Gt} \mathrm{CO}_{2} \mathrm{e}$ ).

The abatement opportunities in the case study include a 30-45 percent improvement in the fuel efficiency of internal combustion engine (ICE) vehicles; aggressive penetration of alternative vehicles, with hybrid vehicles representing up to 60 percent and fully electric vehicles making up 8-12 percent of new vehicle sales; a mode shift of passengers to public transit (2 percent metro, 8 percent buses, and 10 percent BRT); and a shift of freight traffic from trucks to trains (20 percent) and ships (5 percent) in 2030. These improvements could bring down emissions by approximately 35 percent in 2030 compared with the BAU. If all measures at a 
cost of $<\$ 330(€ 250) / \mathrm{tCO}_{2} \mathrm{e}$ were implemented, 2030 emissions would drop to 2010 levels. In this study, the potential from biofuels is limited to gasoline replacement by bioethanol from sugarcane and second-generation lignocellulosic feedstock, with an 11 percent compound annual growth rate (CAGR) in ethanol production required to meet 2030 demand. ${ }^{47}$ Finally, this scenario assumes very limited technical potential for commercial vehicles (due to their higher relative efficiencies and BAU improvements).

The abatement cost for society, in particular for conventional ICE improvements, is negative for many levers; in other words, these improvements have a positive payback over the lifetime of the vehicle because the fuel cost savings are greater than the initial additional investment for the advanced vehicle technology. The marginal abatement cost curve for the six focus regions (China, India, the U.S., EU, Mexico, and Brazil) is presented in Figure C.2.

For implementation of the policy levers in the MACC model, the cumulative investment (CapEx) is $\$ 447$ billion from 2011-2030, offset by cumulative OpEx savings of approximately $\$ 305$ billion. These are pure project costs as defined in Annex B. The capital and operating expenditures by region are shown in Table C.2.

Fuel savings would be substantial in the transport scenario modeled. The two key drivers of reduced fuel consumption are the transition from ICE vehicles to electric vehicles and hybrids (hybrids are assumed to run on electricity 75 percent of the time) and the improvement in fuel efficiency of the remaining ICE vehicles. Since the MACC model tends to be skewed toward underestimating the penetration of hybrids and overestimating the penetration of EVs in the BAU scenario, this results in a slight overstatement of both CapEx and OpEx for the abatement scenario considered in the simulation (Table C.2). This in turn means that both the mitigation potential and abatement costs for the transport sector presented in Figure C.2 may be slightly overestimated (specifically, the levers grouped under the "alternative vehicles" label). The total effect on simulated outcomes in terms of GDP, however, is likely to be negligible. For this analysis, both fuel savings and mode shift toward non-motorized transport, included in the form of avoided trips, were considered when evaluating technology choices.

Table C.2: Transportation: Changes in CapEx and OpEx

\begin{tabular}{l|c|c|}
\multicolumn{3}{|c}{ Change in capital expenditure vs. BAU (in millions, 2010 USD) } \\
\hline & 2020 & 2030 \\
\hline Brazil & $\$ 12,876$ & $\$ 21,483$ \\
\hline China & $\$ 35,176$ & $\$ 75,019$ \\
\hline EU & $\$ 49,973$ & $\$ 63,793$ \\
\hline India & $\$ 13,833$ & $\$ 22,738$ \\
\hline Mexico & $\$ 5,649$ & $\$ 9,303$ \\
\hline United States & $\$ 46,984$ & $\$ 64,556$ \\
\hline
\end{tabular}

Figure C.2: Road transport marginal abatement cost curve, 2030 (six focus regions)

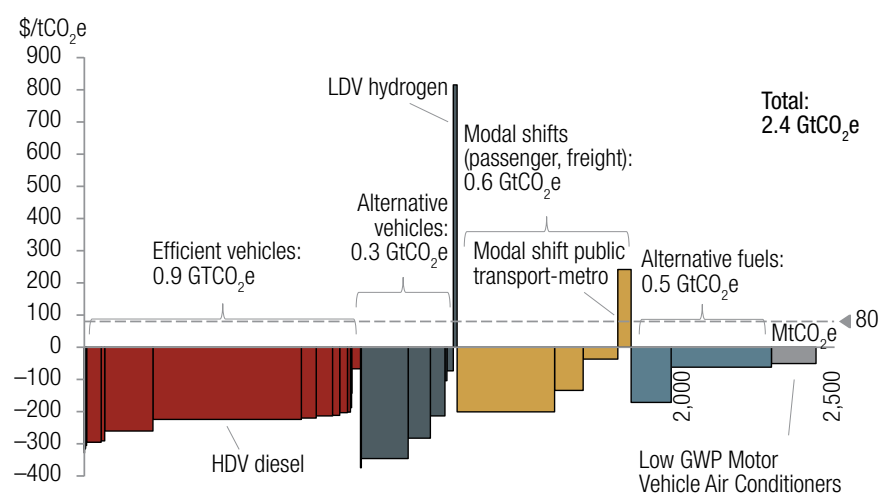

This case study assumes that the ICE transition is dramatic and relatively rapid in all countries (see Figure C.3). In this scenario electric vehicles will reduce tailpipe emissions but will increase emissions from power plants by approximately $80 \mathrm{gCO}_{2} \mathrm{e} / \mathrm{km}$ of distance traveled; this is assumed to be high-emitting electricity. The $\mathrm{CO}_{2}$ emissions reductions included in the analysis already account for these effects, but the full breakdown of other pollutants (including black carbon) is not available and hence is not included (as is the case for all other scenarios). The underlying assumptions on fuel and costs are presented in Tables C.3 and C.4. The analysis does not use a demand model to examine modal

47 The MACC model builds on an analysis of land availability/land use in 2030 that arrives at a potential production volume of 160 billion gallons of biofuel. This analysis only considered the availability of land as constraint for biofuels production and did not take into account other (environmental) factors like water availability or impact on water resources. The model also assumes that the biofuel needed for consumption need not be produced locally. In addition, the cost of abatement through biofuels reflects the cost of production, not an opportunity cost of alternative land uses (for example, the model does not consider the impact of higher sugar prices on the abatement potential and cost of bioethanol).

\begin{tabular}{l|c|c|}
\hline \multicolumn{3}{|c|}{ Change in operating expenditure vs. BAU (in millions, 2010 USD) } \\
\hline & 2020 & 2030 \\
\hline Brazil & $-\$ 616$ & $-\$ 1,738$ \\
\hline China & $-\$ 1,896$ & $-\$ 6,232$ \\
\hline EU & $-\$ 4,371$ & $-\$ 11,565$ \\
\hline India & $-\$ 749$ & $-\$ 2,232$ \\
\hline Mexico & $-\$ 190$ & $-\$ 549$ \\
\hline United States & $-\$ 1,800$ & $-\$ 4,109$ \\
\hline
\end{tabular}


Figure C3: Conventional passenger vehicle efficiency by region, BAU vs. case study

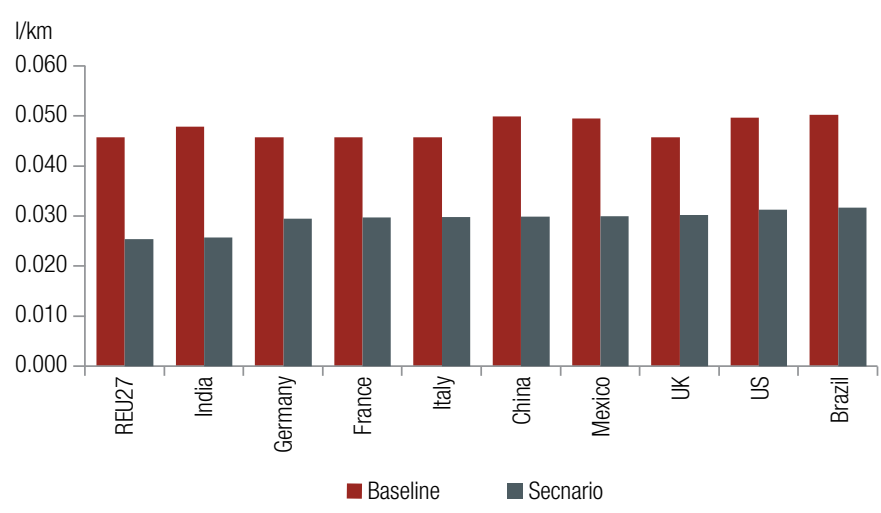

shifts and consumer choices; rather, it presents a supply model mandating change through policy interventions that yield a predetermined amount of emissions reductions. This could lead to a neglect of fixed costs of technology adoption and the risks of a lock-in into high-emissions transport systems.

\section{Case Study Impacts}

The MACC model shows that the interventions described above require significant increases in capital expenditures and result in significant reductions in operating expenditures. The FASST tool shows that the reductions in emissions considered here (primarily $\mathrm{BC}$ ) result in reduced deaths from respiratory illnesses. The GEIM analysis provides the multiple economic impacts. For example, because households and firms would have to buy less fuel, they

Table C.3: Underlying scenario fuel price assumptions by region

\begin{tabular}{|l|l|c|c|}
\hline & Region & 2020 & 2030 \\
\hline Price of Electricity & Brazil & 0.09 & 0.10 \\
\hline (USD/KWh) & China & 0.12 & 0.13 \\
\hline & France & 0.05 & 0.05 \\
\hline & Germany & 0.05 & 0.05 \\
\hline & India & 0.11 & 0.12 \\
\hline & Italy & 0.05 & 0.05 \\
\hline & Mexico & 0.09 & 0.10 \\
\hline Price of Crude Oil (USD/bbl) & Global & 0.05 & 0.06 \\
\hline Price of Gasoline (USD/liter) & Global & 0.81 & 0.09 \\
\hline Price of Diesel (USD/liter) & Global & 0.80 & 0.09 \\
\hline
\end{tabular}

Figure C4: Underlying global scenario power mix (2030)

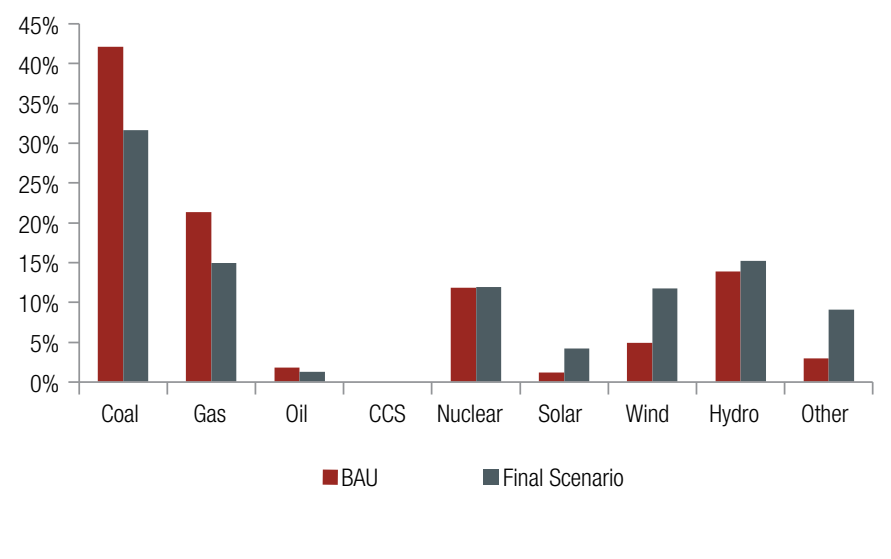

would have more money to spend on other goods and services; in addition, the reduced demand for oil would lower oil prices, providing a boost to the economy. The power sector, however, would need to make investments to meet the increased electricity demand from electric vehicles; the cost of this investment would ultimately be paid by consumers.

Overall, the two clean transport scenarios increase global GDP by $0.5-0.8$ percent ( $\$ 600$ billion $-\$ 1.0$ trillion in 2010 dollars)

Table C.4: Underlying assumptions on incremental costs of plug-in hybrid and electric vehicles

\begin{tabular}{|l|l|c|}
\hline $\begin{array}{l}\text { Incremental cost of plug-in } \\
\text { hybrid/electric vehicles in } 2030 \\
\text { (USD) }\end{array}$ & Region & \\
\hline LDV diesel plug-in hybrid & Brazil & $3,977.18$ \\
\hline & China & $3,471.52$ \\
\hline & India & $3,471.52$ \\
\hline LDV gasoline plug-in hybrid & Mexico & $3,716.16$ \\
\hline & EU & $4,222.85$ \\
\hline & US & $4,222.91$ \\
\hline & Brazil & $3,527.40$ \\
\hline China & $3,079.98$ \\
\hline LDV electric & India & $3,079.98$ \\
\hline & Mexico & $3,297.30$ \\
\hline & EU & $3,746.94$ \\
\hline & US & $3,746.93$ \\
\hline & Brazil & $3,420.11$ \\
\hline & China & $2,999.43$ \\
\hline & India & $2,999.43$ \\
\hline & Mexico & $3,203.76$ \\
\hline & EU & $3,641.31$ \\
\hline & US & $3,640.64$ \\
\hline
\end{tabular}


from the baseline scenario in 2030. However, the impact of the scenarios is not homogenous across countries. Scenario 1 , which assumes that developed countries produce most of the high-tech vehicles and infrastructure needed to transform the sector, results in a boost to developed countries' exports and increases GDP by 1-2.2 percent relative to the 2030 baseline. In contrast, emerging markets must import some of the necessary machinery; this acts to dampen GDP by 1-3 percent relative to the 2030 baseline. Scenario 2 assumes that developed countries would shoulder the majority of the costs incurred by emerging economies to transform their transportation sector while also foregoing the net benefit deriving from increased capital exports, at a cost to the GDP of less than one percent compared with Scenario 1. In Scenario 2, the emerging economies see a boost in GDP of 0.1-0.9 percent relative to Scenario 1.

The impact on GDP is also reflected in employment, which in the emerging markets drops by $0-1.8$ percent relative to the baseline in 2030 for Scenario 2. In Scenario 1, for emerging economies the drop in employment is $0.35-1.84$ percent relative to the baseline. For countries that have a boost in GDP, employment increases of $0.5-1.1$ percent relative to the 2030 baseline are possible for Scenario 2 and increases of 1-1.75 percent are found for Scenario 1 . The changes for each country are affected by that nation's relative competitiveness (this is one of the transmission channels included in the macroeconomic model), which leads to differential economic impacts across the global economy.

The emissions reductions are estimated to reduce air qualityrelated mortality by about 20,000 lives per year in the six regions considered in 2030; India and China would account for about 90 percent of the total. In monetary terms, the reduced air-qualityrelated mortality would be equivalent to a total of $\$ 87$ billion (2010 dollars). The global impact from mitigation measures undertaken in the six focus regions results in a global net total of 21,040 lives saved per year in 2030 from avoided premature mortality. ${ }^{48}$ Ideally, to assess health impacts from urban transport, air pollution exposure measurements at the street level would be needed. This would be a daunting task; because this analysis relies on downscaled models to examine health impacts, it does not fully capture the expected impacts.

\section{Sector Policy Case Study 2: Energy- efficient Industry}

This case study includes three primary industrial sectors-iron and steel, cement, and chemicals-plus a mixed category labeled "other industry" (which includes most other industrial production activities except those related to oil and gas).

\section{Key Assumptions}

\section{Iron and Steel}

The iron and steel industry emitted $2.5 \mathrm{Gt} \mathrm{CO}_{2} \mathrm{e}$ in 2010 (approximately five percent of total global emissions), of which about 2.2 Gt were process-related and $0.3 \mathrm{Gt}$ were emitted in the power sector through the consumption of $\sim 777$ TWh of electricity.

In the BAU case, global iron and steel production is expected to grow by three percent per annum, while global emissions will grow by two percent per year, increasing emissions to $3.7 \mathrm{Gt}$ in 2030. The 0.7 percentage point difference is due to BAU decarbonization, ongoing industrial energy efficiency programs, and a 10 percent shift from basic oxygen furnace (BOF) to electric arc furnace (EAF) production.

The pursuit of available mitigation opportunities could reduce 2030 emissions to about 24 percent lower than 2010 levels, abat-

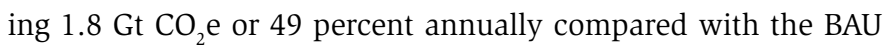
scenario. More than half (about 56 percent) of the abatement potential comes from China and India. The opportunities can be divided into four types:

- CCS (42 percent of total potential)

- Energy efficiency measures (39 percent of total potential)

- Process change (9 percent of total potential)

- Fuel shift measures (10 percent of total potential)

Breakthrough technologies for smelting and top gas recycling are expected within the 2030 timeframe. Fuel shift shows very limited capacity, because coke can be substituted only in small plants.

The average cost for all iron and steel abatement measures is - $\$ 65$ per ton of $\mathrm{CO}_{2}$ e in 2020 . This cost is expected to increase to $\$ 17$ per ton in 2030, due to implementation of CCS, despite the effects of capital cost reductions (learning rate improvements) and higher energy costs. Approximately $700 \mathrm{Mt}$ of the total abatement potential can be achieved at a negative cost. Total cumulative investment (CapEx) is approximately $\$ 64$ billion, offset by cumulative OpEx savings of approximately $\$ 28$ billion-from 2011-2030. The geographical breakdown is shown in Table C.5.

\section{Cement}

Cement is the main ingredient in concrete, which is, after water, the second-most-used substance. The cement industry accounted for $2.6 \mathrm{Gt}$ of $\mathrm{CO}_{2}$ emissions in 2010 (including indirect emissions); China represented the largest source of emissions (approximately

\footnotetext{
48 In general, only if a significant number of lives were saved in the multi-country scenarios were the impacts included as productivity gains in the macroeconomic model. There was no iteration between the health and macroeconomic model to reach equilibrium; in other words, lives saved were calculated based on static estimates of the energy and emissions energy savings. The iteration process would only produce minor changes relative to the initial estimates of lives saved, and these changes are unlikely to be significant from a macroeconomic perspective.
} 
Table C.5: Iron and steel: Changes in CapEx and OpEx, BAU vs. case study

\begin{tabular}{|l|r|r|}
\hline \multicolumn{3}{|c|}{$\begin{array}{c}\text { Change in iron \& steel capital expenditure vs. BAU } \\
\text { (in millions, 2010 USD) }\end{array}$} \\
\hline & 2020 & 2030 \\
\hline Brazil & $\$ 2,059$ & $\$ 9,379$ \\
\hline China & $\$ 9,637$ & $\$ 20,892$ \\
\hline EU & $\$ 13,521$ & $\$ 309$ \\
\hline India & $\$ 1,652$ & $\$ 18,351$ \\
\hline Mexico & $\$ 175$ & $\$ 329$ \\
\hline United States & $\$ 1,041$ & $\$ 1,648$ \\
\hline
\end{tabular}

\begin{tabular}{l|c|c|}
\hline \multicolumn{3}{|c|}{$\begin{array}{c}\text { Change in iron \& steel operating expenditure vs. BAU } \\
\text { (in millions, 2010 USD) }\end{array}$} \\
\hline & 2020 & 2030 \\
\hline Brazil & $-\$ 88$ & $-\$ 89$ \\
\hline China & $-\$ 1,006$ & $-\$ 1,387$ \\
\hline EU & $-\$ 121$ & $-\$ 16$ \\
\hline India & $-\$ 161$ & $-\$ 413$ \\
\hline Mexico & $-\$ 17$ & $-\$ 30$ \\
\hline United States & $-\$ 64$ & $-\$ 94$ \\
\hline
\end{tabular}

Table C.6: Cement: Changes in CapEx and OpEx, BAU vs. case study

\begin{tabular}{l|r|r|}
\multicolumn{3}{|c|}{$\begin{array}{c}\text { Change in cement capital expenditure vs. BAU } \\
\text { (in millions, 2010 USD) }\end{array}$} \\
\hline & 2020 & 2030 \\
\hline Brazil & $-\$ 10$ & $\$ 217$ \\
\hline China & $\$ 4,059$ & $\$ 6,794$ \\
\hline EU & $\$ 5,418$ & $\$ 186$ \\
\hline India & $-\$ 702$ & $\$ 2,001$ \\
\hline Mexico & $\$ 75$ & $\$ 177$ \\
\hline United States & $-\$ 77$ & $\$ 778$ \\
\hline
\end{tabular}

55 percent). More than half of cement emissions are from the clinker calcination process; these emissions can be abated only by reducing clinker production or applying CCS technology.

In the business-as-usual case, cement production will grow by 2.1 percent per year and direct emissions are projected to grow at approximately 1.9 percent per annum due to production growth (notably in Asia), increasing to $3.7 \mathrm{Gt}$ in 2030 (including indirect emissions).

The total abatement potential amounts to approximately 0.83 Gt $\mathrm{CO}_{2}$ in 2030, which would cut emissions by 23 percent and keep emissions approximately 10 percent above 2010 levels. Almost 90 percent of the abatement potential is based on conventional technologies, such as clinker substitution and alternative fuels. No breakthrough technology to greatly improve energy efficiency or carbon intensity is foreseen in the near term, and significant abatement potential from CCS is unlikely until after 2030.

Carbon capture and storage requires capital investments to build out capture capacity. ${ }^{49}$ The average cost for all abatement measures is $-\$ 32 / \mathrm{tCO}_{2} \mathrm{e}$ in 2020 and is expected to increase, due to the relatively higher cost of $\mathrm{CCS}$, to $-\$ 15 / \mathrm{tCO}_{2} \mathrm{e}$ in 2030 . From a societal perspective, the implementation of conventional levers can largely be achieved at a negative cost and negative cash flow,

\begin{tabular}{l|c|c|}
\hline \multicolumn{3}{|c|}{$\begin{array}{c}\text { Change in cement operating expenditure vs. BAU } \\
\text { (in millions, 2010 USD) }\end{array}$} \\
\hline & 2020 & 2030 \\
\hline Brazil & $-\$ 19$ & $-\$ 30$ \\
\hline China & $-\$ 548$ & $-\$ 484$ \\
\hline EU & $-\$ 37$ & $-\$ 39$ \\
\hline India & $-\$ 71$ & $-\$ 87$ \\
\hline Mexico & $-\$ 10$ & $-\$ 17$ \\
\hline United States & $-\$ 9$ & $-\$ 8$ \\
\hline
\end{tabular}

due to avoiding build-outs of clinker production capacity. Not all of the levers will carry a negative cost at the individual cement producer's level, however, due to non-marginal pricing by suppliers, taxes, and higher discount rates. The geographical breakdown of CapEx and OpEx is shown in Table C.6.

\section{Chemicals}

The chemical industry accounts for 16 percent of total industrial GHG emissions. Chemical production resulted in $2.9 \mathrm{Gt}$ of $\mathrm{CO}_{2} \mathrm{e}$ emissions in 2010, of which about $2 \mathrm{Gt}$ were process-related and $0.9 \mathrm{Gt}$ were emitted in the power sector through the consumption of $\sim 1,300$ TWh of electricity.

In the business-as-usual case, global chemical production is expected to grow by approximately 4 percent per annum and global emissions to grow by 3.5 percent per year, increasing current emissions to $5.7 \mathrm{Gt}$ in 2030 . The approximately 0.5 percentage point difference is due to BAU decarbonization via ongoing industrial energy efficiency programs.

49 Because CCS development has been slower than expected, the updated cost curve reflects a reduced abatement potential (compared with the 2009 version) of about $0.9 \mathrm{Gt} \mathrm{CO}_{2} \mathrm{e}$ for 2030 for the industrial sector. 
Table C.7: Chemicals: Changes in CapEx and OpEx, BAU vs. case study

\begin{tabular}{l|r|r|}
\hline \multicolumn{3}{|c|}{$\begin{array}{c}\text { Change in chemicals capital expenditure vs. BAU } \\
\text { (in millions, 2010 USD) }\end{array}$} \\
\hline & 2020 & 2030 \\
\hline Brazil & $\$ 851$ & $\$ 1,309$ \\
\hline China & $\$ 14,144$ & $\$ 22,060$ \\
\hline EU & $\$ 18,704$ & $\$ 748$ \\
\hline India & $\$ 1,966$ & $\$ 3,025$ \\
\hline Mexico & $\$ 276$ & $\$ 360$ \\
\hline United States & $\$ 5,911$ & $\$ 7,203$ \\
\hline
\end{tabular}

\begin{tabular}{l|c|c|}
\multicolumn{3}{|c|}{$\begin{array}{c}\text { Change in chemicals operating expenditure vs. BAU } \\
\text { (in millions, 2010 USD) }\end{array}$} \\
\hline & 2020 & 2030 \\
\hline Brazil & $-\$ 16$ & $-\$ 86$ \\
\hline China & $-\$ 254$ & $-\$ 627$ \\
\hline EU & $-\$ 109$ & $-\$ 60$ \\
\hline India & $-\$ 94$ & $-\$ 291$ \\
\hline Mexico & $-\$ 11$ & $-\$ 15$ \\
\hline United States & $-\$ 139$ & $-\$ 252$ \\
\hline
\end{tabular}

With a global $\mathrm{CO}_{2}$ abatement cost of up to $\$ 133 / \mathrm{tCO}_{2}$, abatement could hold 2030 emissions to 2015 levels, abating $2.0 \mathrm{Gt}$ annually compared with the BAU, of which approximately 42 percent could be achieved at a negative cost. Almost half of the abatement potential comes from China.

The abatement opportunities can be grouped in four categories:

- Energy efficiency

- Fuel shift

- Decomposition of non-CO $\mathrm{CO}_{2}$ GHG gases

- Carbon capture and storage

The average cost for all abatement measures is $-\$ 20$ per $\mathrm{tCO}_{2} \mathrm{e}$ in 2020. This cost is expected to increase to $-\$ 10$ per $\mathrm{tCO}_{2} \mathrm{e}$ in 2030, due to the introduction of CCS, despite capital cost reductions (learning rate improvements) and higher energy prices. The chemical sector requires high up-front capital investments of approximately $\$ 978$ billion in 2010-2030. However, cumulative operational savings of approximately $\$ 778$ billion, mostly due to lower energy expenditures, will offset the negative cash

Figure C.5: Chemicals: Energy intensity vs. BAU, 2030 (\%)

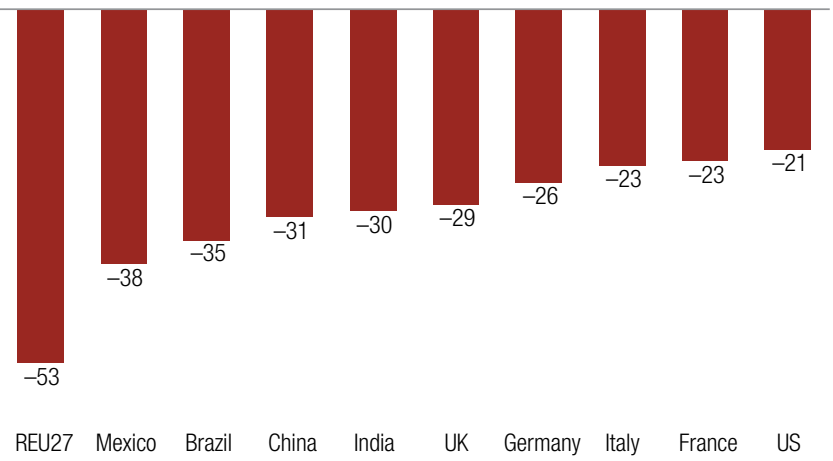

flow. The geographical breakdown of CapEx and OpEx is shown in the table above.

\section{Case Study Impacts}

Economically, the large capital investment is relatively balanced out by significant fuel savings and accompanying fossil fuel price impacts. In Scenario 1 the increase in capital expenditure provides a boost to developed countries, which are assumed to supply the bulk of the capital goods to all countries. Emerging markets also gain via improved competitiveness as a result of their larger potential reduction in energy consumption. When this potential is realized, the cost of production for iron and steel, cement, and chemicals falls more than in developed countries, allowing the emerging markets to gain global market share. In Scenario 2, these results are amplified by the fact that developed countries shoulder a large fraction of the costs of the transition for emerging economies.

Figure C.6: Industry marginal abatement cost curve, 2030 (six focus regions)

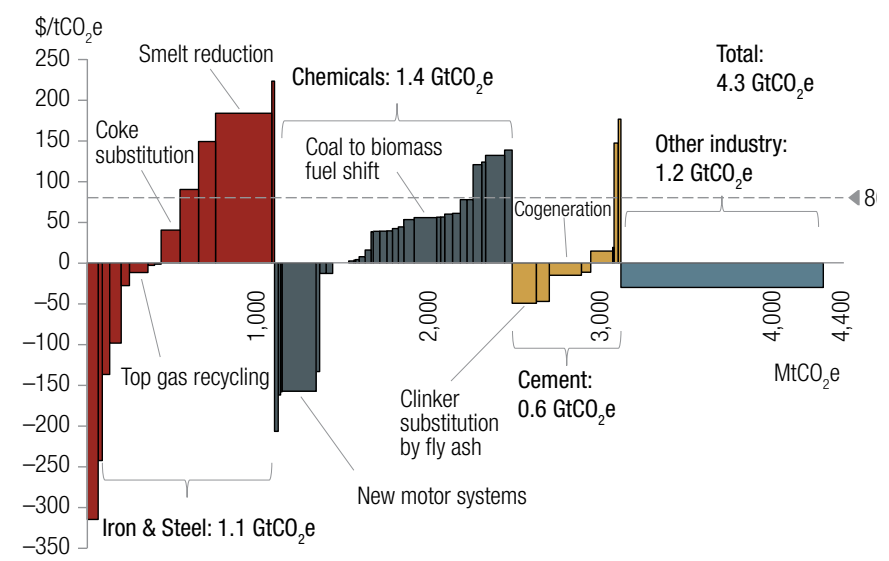


Overall, global GDP in the scenarios modeled is about 1-1.2 percent higher ( $\$ 1.2$ trillion- $\$ 1.4$ trillion, 2010 USD) in 2030 than in the baseline scenario. The key drivers of the increase in GDP are the additional capital expenditures and the reduction in energy consumption in the industrial sector, although this positive impact would be offset by having to pay for the capital in the long run. All the focus regions analyzed here see a relative increase of $0.1-2.4$ percent in their GDP in Scenario 1; in Scenario 2, only the EU countries have a cost to GDP of $0.8-0.2$ percent relative to the 2030 baseline, because their relative competitive advantage decreases.

The fuel switch assumed in the case study is estimated to reduce emissions-related mortalities by about 52,000 lives per year for the six focus regions, of which the vast majority are in India. The mitigation measures undertaken in the six focus regions are estimated to result in a global net total of 58,240 lives saved per year in 2030 from avoided premature mortality. The reduction in SLCPs in this sector is mainly from abatement of black carbon emissions by replacing traditional brick kilns with more energyefficient kilns, such as vertical shaft and simple tunnel brick kilns, and installation of electrostatic precipitators on coke ovens to capture process emissions (Dinkel et al. 2011). A majority of the drop in $\mathrm{BC}$ emissions occurs in India, which in turn realizes the highest savings in lives from reduced cardiopulmonary diseases. China, on the other hand, could see a larger reduction in methane emissions than the other countries analyzed, through degasification and gas capture in coalmines and oxidation of ventilation air methane ${ }^{50}$ (Dinkel et al. 2011). This saves more lives from respiratory-related causes (a reduction in methane emissions lowers formation of ozone). However, the health benefits indicated here are conservative due to the limited emissions data available in the MACC model.

In monetary terms, the estimated mortality savings from reduced SLCPs is equivalent to about $\$ 240$ billion (2010 dollars) for the six regions. In addition, agricultural productivity for the four crops (maize, wheat, rice, and soybeans) would increase by more than $1,255,000$ metric tons in the six regions considered as a result of reduced ozone damage to soils and crops. The mitigation measures undertaken in the six focus regions would result in a global net increase in crop yields of 1.72 million tons per year in 2030 . Although China has the highest reduction in $\mathrm{CH}_{4}$ emissions, most of the increase in crop yields is in the EU (followed by China). This is because of the EU's higher base crop production, which leads to greater benefits, and the downwind impacts of $\mathrm{CH}_{4}$ emissions in China (sensitivity tests with the FASST model indicate that without any $\mathrm{CH}_{4}$ abatement in China, European crop yields would be more than a third lower). The increase in crop yields is valued at $\$ 216$ million for the six regions. Again, this value is an underestimated because of the limited emissions data in the MACC model.

As previously outlined, Scenario 1 assumes that developed countries produce most of the high-tech infrastructure needed to transform the sector. As a result, these countries see a boost to their exports, which adds to the increase in domestic demand. Although this channel acts as a drag on emerging markets, they gain as a result of an improvement in their relative competitiveness. With much higher energy intensity levels in the baseline, these countries have the most to gain from investing in the new technologies; in addition, by reducing their production costs more than developed countries (on average), they gain global market share. Scenario 2 results in a redistribution of gains, with developed economies losing their edge. The shift in GDP is also reflected in employment in the emerging markets. In both scenarios, emerging economies experience significant job gains. In China, the number of people employed is $1.5-1.8$ percent higher than the 2030 baseline for Scenarios 1 and 2, respectively; in India and Brazil the increases are $0.6-2$ percent and $0.8-1.5$ percent, respectively.

\section{Sector Policy Case Study 3: Energy-efficient Buildings}

The buildings sector emitted an estimated $3.4 \mathrm{Gt} \mathrm{CO}_{2} \mathrm{e}$ in 2010, of which $2.1 \mathrm{Gt}$ ( 63 percent) was indirect emissions from energy use from the power sector.

\section{Key Assumptions}

In the business-as-usual scenario, new building construction, along with increased ownership of appliances and lighting, is projected to grow rapidly from 2010-30. Global emissions are expected to grow by 1.4 percent per year, increasing to $4.5 \mathrm{Gt}$ of $\mathrm{CO}_{2}$ e in 2030 in the absence of abatement measures.

About three Gt of low-cost carbon abatement opportunities have been identified in the buildings sector-half in the residential sector and half in commercial buildings. The majority (approximately $2.7 \mathrm{Gt}$ ) can be achieved at a negative lifecycle cost, or net savings. The biggest reductions can be achieved in efficient new construction ( $0.7 \mathrm{Gt} \mathrm{CO}_{2} \mathrm{e}$ of abatement potential), electronics and appliances (0.6 $\left.\mathrm{Gt} \mathrm{CO}_{2} \mathrm{e}\right)$, and building envelope retrofits $(0.4 \mathrm{Gt})$, with the remainder achievable through F-gas reductions $(0.3 \mathrm{Gt})$, high-efficiency lighting and lighting controls (0.2 Gt), and water heater and HVAC retrofits $(0.3 \mathrm{Gt})$.

Many of the negative-cost abatement opportunities are not realized under the BAU because of misaligned incentives and high perceived consumer discount rates and transaction costs. All

\footnotetext{
50 To prevent explosions, coal mines are constantly ventilated to blow in fresh air and suck out air containing methane. This ventilation air methane is the largest source of methane from coal mines. The concentration is too low to be sold as natural gas, but ventilation air methane can be oxidized to produce heat and electricity.
} 
abatement measures considered in this sector assume no impact on end-user comfort; behavioral changes could yield significantly higher emissions reductions. The marginal abatement cost curve for the six regions of interest is presented in Figure C.7.

The case study assumes significant increases in capital expenditure for service firms and households. The relevant figures for each of the regions considered are indicated in Table C.8.

The entire change in operational expenditures is assumed to derive from fuel savings, implying that there are no non-fuel OpEx savings in this scenario.

Developed economies and emerging markets are both assumed to implement these policies. As a result, energy consumption in buildings is lower across all countries (although at a higher cost of capital), and the impact of the combined capital expense and fuel savings feeds through the whole economy. The other key assumption is the change in energy efficiency across sectors. The shift in equilibrium energy intensity for residential and commercial buildings, shown in Figures C.8 and C.9, indicates the different gains across countries.

\section{Case Study IImpacts}

As in other sectors, the key transmission channels are the impact of the change in capital expenditures and reduced energy consumption. In the short run, capital expenditure is generally higher than in the baseline; as a result, GDP is increased as a result of the rise in expenditure. Over the long term (after the spending has taken place), however, the positive boost fades as firms must increase prices to cover their higher operating cost and households must adjust their spending to a lower level of disposable income. These new factors are a drag on GDP, which pulls output back down to (or even below) baseline levels. These effects are balanced by declining fuel prices as efficiency measures reduce global demand. At the country level, the net outcome of the scenario depends on a number of additional factors.
Figure C.7: Buildings marginal abatement cost curve, 2030 (six focus regions)

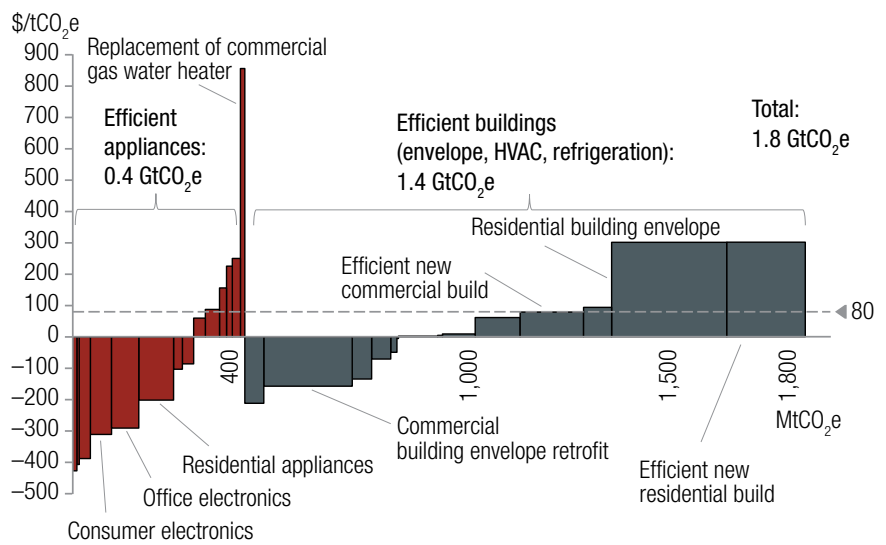

Figure C.8: Energy intensity vs. BAU, commercial buildings $(\%, 2030)$

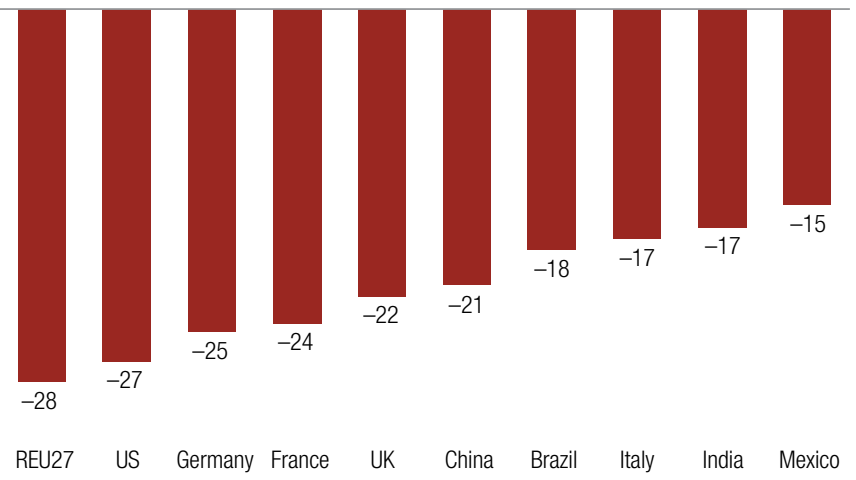

Note: (REU27 = rest of EU27).

Table C.8: Buildings: Commercial and residential CapEx changes, BAU vs. case study

\begin{tabular}{|l|r|r|}
\hline \multicolumn{3}{|c|}{$\begin{array}{c}\text { Change in commercial buildings capital expenditure vs. BAU } \\
\text { (in millions, 2010 USD) }\end{array}$} \\
\hline & 2020 & \multicolumn{1}{c|}{2030} \\
\hline Brazil & $\$ 668$ & $\$ 1,011$ \\
\hline China & $\$ 6,816$ & $\$ 12,925$ \\
\hline EU & $\$ 10,021$ & $\$ 10,668$ \\
\hline India & $\$ 1,063$ & $\$ 2,330$ \\
\hline Mexico & $\$ 301$ & $\$ 502$ \\
\hline United States & $\$ 15,332$ & $\$ 18,255$ \\
\hline
\end{tabular}

\begin{tabular}{l|c|c|}
\multicolumn{3}{|c|}{$\begin{array}{c}\text { Change in residential buildings capital expenditure vs. BAU } \\
\text { (in millions, 2010 USD) }\end{array}$} \\
\hline & 2020 & 2030 \\
\hline Brazil & $\$ 2,085$ & $\$ 2,743$ \\
\hline China & $\$ 61,450$ & $\$ 73,263$ \\
\hline EU & $\$ 24,375$ & $\$ 20,662$ \\
\hline India & $\$ 4,301$ & $\$ 5,596$ \\
\hline Mexico & $\$ 1,604$ & $\$ 2,243$ \\
\hline United States & $\$ 20,064$ & $\$ 16,719$ \\
\hline
\end{tabular}


Figure C.9: Energy intensity vs. BAU, residential buildings $(\%, 2030)$

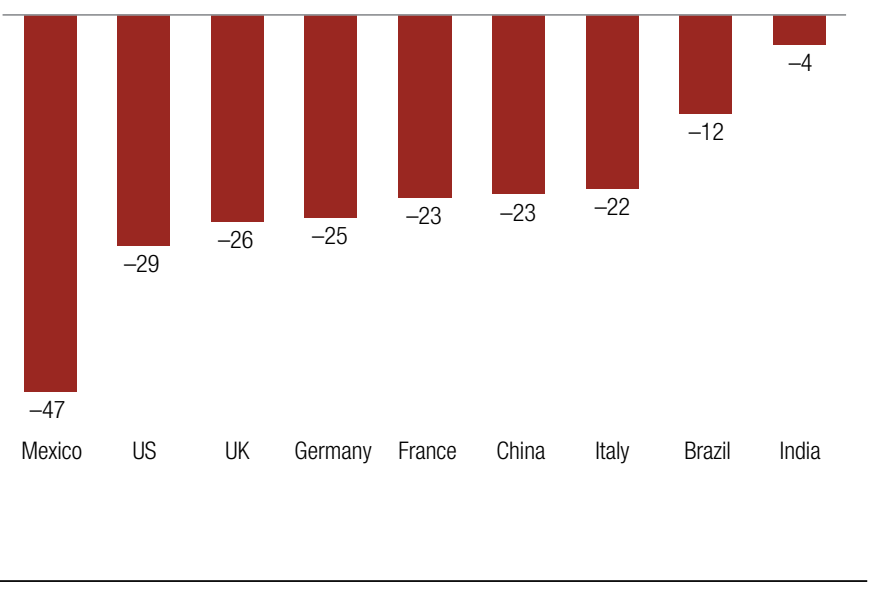

Overall, the scenarios modeled produce global GDP that is 0-0.2 percent higher (up to $\$ 240$ billion in 2010 dollars) in 2030 than in the baseline scenario. Again, the impacts are heterogeneous across countries due to a number of drivers. For households, the size of any gain/loss is determined by the amount of energy savings generated relative to the cost of the additional capital. For Mexico, households are able to improve their energy efficiency by more than any other country at a relatively low cost. As a result, household incomes in Mexico rise relative to the baseline (the cost in terms of additional capital spending is more than covered by the gains from lower energy bills), which increases consumption; as a result, GDP is $1-1.8$ percent higher relative to the 2030 baseline for the two scenarios considered.

The heterogeneous impact on GDP is also reflected in employment. Depending on the scenario, most countries see a small rise as a result of the increase in GDP. China and India gain the most in absolute numbers due to their size, but the dramatic increase in Mexico's GDP means it sees the greatest gain in employment relative to its labor force, with 1.3 percent more jobs created above the 2030 baseline.

The reduction in greenhouse gas emissions and air pollutants due to these energy efficiency improvements are estimated to lower air-pollution-related mortality by about 22,000 lives per year in the six focus regions. The vast majority of this impact occurs in India. Worldwide (including areas outside the six focus regions), the mitigation measures are estimated to save 23,855 per year in 2030 from avoided premature mortality. These health benefits result primarily from the large reduction in black carbon emissions in India (see Table C.9) when traditional residential cookstoves are replaced with more fuel-efficient ones or by a shift to liquid petroleum gas and other cleaner fuels (Dinkel et al. 2011). In monetary terms, the mortality savings are equivalent to $\$ 102$ billion (in 2010 dollars) for the six regions considered. However, the health benefits indicated here are underestimated due to the limited emissions data available in the MACC model (the model does not include $\mathrm{PM}_{2.5}$ ).

\section{Summary Tables for the Sector Policy Case Studies}

The following tables summarize the findings from ClimateWorks' analysis of the three sector policy case studies.

Reductions in non- $\mathrm{CO}_{2}$ emissions associated with technical abatement in the transport, industry, and buildings (including appliances) sectors for the years 2020 and 2030, as obtained from the MACC model (Enkvist et al. 2009; Dinkel et al. 2011), are shown in units of $\mathrm{MtCO}_{2} \mathrm{e}$. Although $\mathrm{N}_{2} \mathrm{O}$ emissions are listed, their health and agricultural impacts are not considered.

Table C.9: Changes in non- $\mathrm{CO}_{2}$ emissions for the three sector policy case studies

\begin{tabular}{|c|c|c|c|c|c|c|c|}
\hline \multirow{2}{*}{\multicolumn{2}{|c|}{$\begin{array}{l}\text { Abatement } \\
\left(\mathrm{MtCO}_{2} \mathrm{e}\right)\end{array}$}} & \multicolumn{2}{|c|}{ Transport } & \multicolumn{2}{|c|}{ Industry } & \multicolumn{2}{|c|}{ Buildings } \\
\hline & & \multirow{2}{*}{$\begin{array}{c}2020 \\
0\end{array}$} & \multirow{2}{*}{$\begin{array}{r}2030 \\
0\end{array}$} & \multirow{2}{*}{$\begin{array}{c}2020 \\
16\end{array}$} & \multirow{2}{*}{$\begin{array}{c}2030 \\
30\end{array}$} & \multirow{2}{*}{$\begin{array}{c}2020 \\
0\end{array}$} & \multirow{2}{*}{$\begin{array}{c}2030 \\
0\end{array}$} \\
\hline China & $\mathrm{N}_{2} \mathrm{O}$ & & & & & & \\
\hline & $\mathrm{CH}_{4}$ & 0 & 0 & 17 & 93 & 0 & 0 \\
\hline & $\mathrm{BC}$ & 33 & 44 & 25 & 64 & 12 & 10 \\
\hline \multirow[t]{3}{*}{ India } & $\mathrm{N}_{2} \mathrm{O}$ & 0 & 0 & 2 & 3 & 0 & 0 \\
\hline & $\mathrm{CH}_{4}$ & 0 & 0 & 3 & 19 & 0 & 0 \\
\hline & $\mathrm{BC}$ & 22 & 55 & 57 & 121 & 55 & 89 \\
\hline \multirow[t]{3}{*}{ US } & $\mathrm{N}_{2} \mathrm{O}$ & 0 & 0 & 16 & 22 & 0 & 0 \\
\hline & $\mathrm{CH}_{4}$ & 0 & 0 & 4 & 19 & 0 & 0 \\
\hline & $\mathrm{BC}$ & 5 & 0 & 0 & 0 & 0 & 0 \\
\hline \multirow[t]{3}{*}{ EU } & $\mathrm{N}_{2} \mathrm{O}$ & 0 & 0 & 31 & 42 & 0 & 0 \\
\hline & $\mathrm{CH}_{4}$ & 0 & 0 & 3 & 13 & 0 & 0 \\
\hline & $\mathrm{BC}$ & 19 & 2 & 0 & 0 & 0 & 0 \\
\hline \multirow{3}{*}{$\begin{array}{l}\text { Brazil \& } \\
\text { Mexico }\end{array}$} & $\mathrm{N}_{2} \mathrm{O}$ & 0 & 0 & 4 & 6 & 0 & 0 \\
\hline & $\mathrm{CH}_{4}$ & 0 & 0 & 1 & 5 & 0 & 0 \\
\hline & $\mathrm{BC}$ & 24 & 41 & 14 & 22 & 4 & 9 \\
\hline
\end{tabular}

Note: Reductions in non- $\mathrm{CO}_{2}$ emissions associated with technical abatement in the transport, industry, and buildings (including appliances) sectors for the years 2020 and 2030, as obtained from the MACC model (Enkvist et al., 2009; Dinkel et al., 2011), are shown in units of $\mathrm{Mt}_{\mathrm{CO}_{2}}$ e. Although $\mathrm{N}_{2} \mathrm{O}$ emissions are listed, their health and agriculture impacts are not considered. 
Table C.10: Avoided premature mortality for the three sector policy case studies

\begin{tabular}{l|r|r|r|r|r|r|}
\hline & \multicolumn{2}{|l|}{ Industry } & \multicolumn{2}{l|}{ Transport } & \multicolumn{2}{l|}{ Buildings } \\
\cline { 2 - 7 } $\begin{array}{l}\text { Pdult } \\
\text { mortality(>30 }\end{array}$ & & & & & & \\
years old) /year & 2020 & 2030 & 2020 & 2030 & 2020 & 2030 \\
\hline China & $-3,580$ & $-10,968$ & $-4,596$ & $-6,126$ & $-1,658$ & $-1,397$ \\
\hline India & $-13,154$ & $-29,483$ & $-5,027$ & $-12,576$ & $-12,613$ & $-20,452$ \\
\hline US & -113 & -523 & -411 & -11 & Negligible \\
\hline EU & -47 & -686 & $-2,518$ & -277 & Negligible \\
\hline Brazil \& Mexico & $-6,145$ & $-10,699$ & -443 & -752 & -81 & -162 \\
\hline
\end{tabular}

Note: Annual reductions in cardiopulmonary and respiratory disease and lung cancer associated with $\mathrm{BC}$ and $\mathrm{CH}$ emission changes in 2020 and 2030, as obtained from the FASST model (Van Dingenen et al. 2009) for the six focus regions
Table C.11: Increase in crop yields from a shift to energy efficient industry

\begin{tabular}{l|r|r}
\hline \multirow{2}{*}{$\begin{array}{l}\text { Increase in crop } \\
\text { yields }\end{array}$} & \multicolumn{2}{|c}{ Industry } \\
\cline { 2 - 3 } (metric tons/year) & 2020 & 2030 \\
\hline China & 27,400 & 402,000 \\
\hline India & 5,520 & 80,900 \\
\hline US & 19,200 & 281,000 \\
\hline EU & 32,300 & 475,000 \\
\hline Brazil \& Mexico & 1,129 & 16,510 \\
\hline
\end{tabular}

Note: Reduced emissions of $\mathrm{BC}$ and $\mathrm{CH}_{4}$ improve yields of maize, wheat, rice, and soybean in 2020 and 2030, as obtained from the FASST model (Van Dingenen et al. 2009) for the six focus regions.

Table C.12: Monetized health and agricultural benefits of the sector policy case studies

\begin{tabular}{|c|c|c|c|c|c|}
\hline \multicolumn{2}{|c|}{ Monetized Value (2010 USD) } & Industry & Transport & Buildings & Total \\
\hline \multirow[t]{2}{*}{ China } & Health & $\$ 39 B$ & $\$ 22 \mathrm{~B}$ & $\$ 5 B$ & $\$ 66$ B \\
\hline & Agriculture & $\$ 69.1 \mathrm{M}$ & $\mathrm{n} / \mathrm{a}$ & $\mathrm{n} / \mathrm{a}$ & $\$ 69.1 \mathrm{M}$ \\
\hline India & Agriculture & $\$ 13.9 \mathrm{M}$ & $\mathrm{n} / \mathrm{a}$ & n/a & $\$ 13.9 \mathrm{M}$ \\
\hline US & Health & $\$ 8 B$ & $\$ 164 \mathrm{M}$ & 0 & $\$ 8 B$ \\
\hline EU & Agriculture & $\$ 81.6 \mathrm{M}$ & $\mathrm{n} / \mathrm{a}$ & $\mathrm{n} / \mathrm{a}$ & $\$ 81.6 \mathrm{M}$ \\
\hline \multirow[t]{2}{*}{ Brazil \& Mexico } & Health & $\$ 49 B$ & $\$ 3 \mathrm{~B}$ & $\$ 738 \mathrm{M}$ & $\$ 53 \mathrm{~B}$ \\
\hline & Agriculture & $\$ 2.84 \mathrm{M}$ & $\mathrm{n} / \mathrm{a}$ & $\mathrm{n} / \mathrm{a}$ & $\$ 2.84 \mathrm{M}$ \\
\hline
\end{tabular}

Note: Based on the statistical value of life and a crop value of $\$ 171.80$ for the regions for 2030, using data shown in Tables C.10 and C.11.

Table C.13: Energy savings from sector policy case studies for the six focus regions, 2030

\begin{tabular}{l|r|r|r}
\hline $\begin{array}{l}\text { Energy Savings } \\
\text { (GWh) }\end{array}$ & Industry & Transport & Buildings \\
\hline China & $3,338,338$ & $1,215,979$ & $1,622,171$ \\
\hline India & 861,857 & 447,377 & 174,920 \\
\hline US & 602,326 & $1,193,521$ & $1,885,038$ \\
\hline EU & 545,069 & $1,476,108$ & $1,574,906$ \\
\hline Brazil \& Mexico & 393,588 & 363,249 & 142,162 \\
\hline
\end{tabular}

Note: (All fuels included.)
Table C.14: Annual avoided premature mortalities from the sector policy case studies, 2020*

\begin{tabular}{l|c|c|c}
\hline $\begin{array}{l}\text { Premature mortality } \\
(>30 \text { years old) /year }\end{array}$ & Industry & Transport & Buildings \\
\hline China & $-113,182$ & $-11,869$ & $-25,571$ \\
\hline India & $-162,207$ & $-6,899$ & $-39,842$ \\
\hline
\end{tabular}

Note: Reduced cardiopulmonary and respiratory disease and lung cancer from the FASST model (Van Dingenen et al. 2009) associated with emission changes in 2020 as obtained from the GAINS model from Wagner et al. (2013) for China and India (see footnote 51).

* From alternate modeling scenario. 
Table C.15: Annual increase in crop yields from the sector policy case studies, $2020^{*}$

\begin{tabular}{l|c|c|c}
\hline $\begin{array}{l}\text { Increase in crop yields } \\
\text { (metric tons/year) }\end{array}$ & Industry & Transport & Buildings \\
\hline China & 921,000 & 172,000 & 198,000 \\
\hline India & 564,000 & 98,600 & 125,000 \\
\hline
\end{tabular}

Note: Reduced cardiopulmonary and respiratory disease and lung cancer from the FASST model (Van Dingenen et al. 2009) associated with emission changes in 2020 as obtained from the GAINS model from Wagner et al. (2013) for China and India (see footnote 51).

${ }^{\star}$ From alternate modeling scenario.

\section{Conclusions from the Sector Policy Case Studies}

Aggregating the results of the three sector policy case studies results in significant multiple benefits. The annual benefits of these policies in the six focus regions in 2030 include 8.5 billion metric tons of avoided $\mathrm{CO}_{2} \mathrm{e}$ emissions and almost 16 billion kilowatt-hours of energy saved. This is worth almost $\$ 800$ billion. Approximately 94,000 premature deaths could be avoided each year, with a monetized value of $\$ 429$ billion. Reduced crop damage increases yields by 1.3 million metric tons, valued at $\$ 216$ million. Globally, GDP would grow by $\$ 1.8-\$ 2.6$ trillion per year.

Again, the full benefits of reduced emissions are not captured in this study because of the limited availability of data in the MACC model. ${ }^{51}$ As a result, the labor productivity benefits of fewer lost work days and greater longevity, and the GDP impacts from increased agricultural productivity, were not included in the macroeconomic analyses due to their small size relative to the overall workforce. A recent analysis by Sanderson et al. (2013) demonstrates that when such effects are included, they can be large enough to offset the entire cost of mitigation. These types
Table C.16: Social cost of carbon (SCC) for 2030 for the three sectors, using the values associated with the different discount rates (US Interagency Working Group on Social Cost of Carbon, 2013) described in Chapter 3

\begin{tabular}{l|c|c|c|c|} 
& \multirow{2}{*}{} & & \multicolumn{3}{|c}{ SCC (in billions) } \\
\cline { 3 - 5 } & $\begin{array}{c}\text { Gt CO} \\
\text { Sectors }\end{array}$ & $\begin{array}{c}5 \% \\
\text { discount, } \\
\$ 17 / \mathrm{tCO}_{2} \mathrm{e}\end{array}$ & $\begin{array}{c}3 \% \\
\text { discount, } \\
\$ 55 / \mathrm{tCO}_{2} \mathrm{e}\end{array}$ & $\begin{array}{c}2.5 \% \\
\text { discount, } \\
\$ 80 / \mathrm{tCO}_{2} \mathrm{e}\end{array}$ \\
\hline Industry & 4.3 & $\$ 73$ & $\$ 237$ & $\$ 344$ \\
\hline Transport & 2.4 & $\$ 41$ & $\$ 132$ & $\$ 192$ \\
\hline Buildings & 1.8 & $\$ 31$ & $\$ 99$ & $\$ 144$ \\
\hline
\end{tabular}

Note: Monetized values (in 2010 USD) are calculated for the emissions mitigated in each of the sectors for the six regions considered. The main text uses the central $3 \%$ discount rate.

of integrated scenarios with additional macroeconomic linkages should be investigated in future work.

51 Wagner et al. (2013) used the GAINS model to estimate emissions reductions for $\mathrm{SO}_{2}, \mathrm{NOx}, \mathrm{PM}_{2.5}, \mathrm{BC}, \mathrm{OC}, \mathrm{CO}$, NMVOC, and $\mathrm{NH}_{3}$ from GHG mitigation measures that cost less than $\$ 80 / \mathrm{tCO}_{2} \mathrm{e}$ for China and India for 2020 for the industry, transport, and buildings sectors. The 2020 health benefits of these emissions reductions were estimated at 150,622 and 208,948 avoided premature mortalities per year for China and India, respectively. The MACC model used in the sector policy case studies in this report estimates 9,834 and 30,794 avoided premature mortalities per year for China and India, respectively. The Wagner et al. (2013) study estimated crop yield increases at 1.3 million and 0.8 million metric tons for China and India, respectively, whereas the MACC data indicated increases of 27,400 and 5,520 metric tons. (The majority of the benefits are in the industrial sector; see Tables C-14 and C-15.) If these estimates were included in the GEIM analysis, the expected impacts would include increased worker and agricultural productivity that would boost GDP. A secondary effect of increased crop yields would be reduced food prices, which increase disposable household income and hence GDP in the long-term. These larger benefits estimates from the detailed data set in the Wagner et al. (2013) study clearly need to be considered in an updated study that would also include the other focus regions. 


\section{Annex D: Detailed Development Project Case Studies}

\section{Development Project Case Study 1: Sustainable Transportation in India}

\section{Background: Pimpri-Chinchwad BRT}

In order to develop the information to conduct a national-scale analysis of expanded sustainable bus rapid transit (BRT) in India, the Pimpri-Chinchwad BRT project was analyzed in some depth to establish the benefits that can be expected under real-world conditions. Currently 68 percent of urban transportation demand in this city is satisfied by individual two-wheelers; public transportation accounts for less than four percent. Of the total investment for this project (roughly $\$ 345$ million), about $\$ 147$ million ( $\$ 44$ million in IBRD lending) is dedicated to the Pimpri-Chinchwad sustainable transport plan that was used as the model project.

Major components of the model project include:

- Construction of two new road-cum-BRT corridors (19 km).

- Passenger access to BRT stations on two previously built BRT corridors, such as overpasses and underpasses and improved at-grade crossings using GPS system to control BRT operation.

- Three bus terminals to serve the previously built BRT corridors.

- Technical assistance and capacity building, including transport planning; BRT service plan, fare structure, and fare collection; assistance to build up the proposed BRT management structure; and capacity building and training for BRT staff.

An analysis of these and other details as a standalone project was conducted using the Transportation Emissions Evaluation
Models for Projects (TEEMP) framework developed by Clean Air Asia. TEEMP quantifies emissions from the proposed project, as well as other benefits (e.g., reduced accidents and travel time, and rough, or "sketch", economics) to determine the feasibility of the project.

Some key assumptions for the analysis, such as ridership data for the base year, 2008, were taken from the project appraisal document. Ridership growth rate was derived from data within the project appraisal document. In addition, data on total BRT ridership within the municipality (taken from the municipal transportation plan) were used to develop a projection of ridership along the BRT corridor. These ridership assumptions suggest that about 200,000 trips/day, or 68 million/year in 2014 (rising to more than a half million per day, or 170 million/year by 2033) are shifted to BRT. This represents about seven percent of total city passenger trips in 2014. Other key assumptions had to be estimated using expert judgment or exogenous empirical available data.

Some of the key assumptions include:

- 20-year timeframe, with BRT operational in 2014 and economic lifetime running through 2033.

- Construction materials and emissions taken from Reducing Carbon Emissions from Transport Projects. ${ }^{52}$

- Mode shifts assumed to follow existing transportation mode share (23 percent car, 17 percent two-wheeler, 16 percent

52 http://www.adb.org/documents/reducing-carbon-emissions-transport-projects. 
three-wheeler, 42 percent bus), based on the Pimpri-Chinchwad Comprehensive Mobility Plan. ${ }^{53}$

- Average speed and trip length (25 km/hr declining to $15 \mathrm{~km} /$ hr by 2033) for the non-BRT traffic in both the counterfactual and BRT scenario derived from the India Ministry of Urban Development study, Traffic and Transportation Strategies and Policies in Urban Areas.

- Occupancy for the counterfactual and BRT scenarios (1.4 for cars, 1.1 for two-wheelers, 1.9 for three-wheelers, and 35 for bus) taken from the Comprehensive Mobility Plan.

- Complete implementation of existing standards (Euro 3/4 for cars; Euro III/IV for all diesels; Euro 1 for gasoline two- and three-wheeler four-stroke engines) but no strengthening of these standards.

- BRT development follows typical development patterns established for India, including closed-system BRTs with central lanes, no multiple lane stations, and medium demand.

Using the assumptions listed above, the TEEMP framework found that large reductions of time, emissions, fuel use, and traffic fatalities can be achieved by shifting passenger traffic away from current transportation patterns and onto a modern BRT system consistent with project documentation and historic Indian BRT development patterns.

Over the 20-year analysis timeframe, benefits include:

- 5,761 billion vehicle kilometers traveled (VKT) saved.

- 201 million hours of travel time saved (about 5 minutes per trip).

- 691 traffic-related fatalities avoided.

- 10,368 traffic-related injuries avoided.

- Approximately $\$ 1$ billion in fuel savings.

- 1,300 tons of NOx emissions avoided.

- 1.1 million tons of $\mathrm{CO}_{2}$ emissions avoided.

- 300 tons per year of $\mathrm{PM}_{10}$ avoided (145 tons per year emitted as BC).

These results are in line with $\mathrm{CO}_{2}$ and PM savings from other BRT projects in Asia (on a per-km basis).

\section{Nationwide Scale-up Analysis}

The results of the Pimpri-Chinchwad BRT analysis and a Ministry of Urban Development (MOUD) study of more than 87 cities across India were used to estimate the length of viable BRT routes that could realistically be developed across India (approximately 1,000 $\mathrm{km}$ in the scale-up scenario, including more than $422 \mathrm{~km}$ that is already included in government plans), as well as the per-kilometer costs and benefits of such development. This is contrasted against a "no BRT" case that consists of no new BRT development.
In order to scale up the benefits of the single Pimpri-Chinchwad BRT system to the assumed nationwide BRT scenario $(1,000 \mathrm{~km})$, additional key assumptions were made:

- National statistics and traffic demographics derived from a 2007-2008 Ministry of Urban Development survey ${ }^{54}$ of 30 cities in India.

- Key data that included the distribution of cities by population range, transportation demand, and trip mode-share by city population.

- Occupancy values, emission factors, fuel split, and technology data taken from the Pimpri-Chinchwad analysis.

- New investments of \$3-\$4 billion.

Two development timelines were explored for the national scale-up scenario: an optimal case, which completes 1,000 km of new BRT in six years, and a somewhat more realistic (based on recent BRT experience) 12-year case that deploys the same length of BRT, but over a longer period. Both timelines are subject to economic analysis for the period 2013-2032.

Six-year timeline: Based on the analysis, development of 1,000 $\mathrm{km}$ of BRT lines in 15-20 cities across India within six years and would result in the following benefits between 2013 and 2032:

- 380 tons per year of $\mathrm{BC}$ reduction relative to the reference case starting in 2019 (6,000 tons in aggregate).

- 1,975 reduced fatalities per year (from reduced traffic accidents and improved air quality) starting in 2019 (31,000 in aggregate).

- $\$ 2.6$ billion/year in fuel savings starting in 2019.

- Three million tons/year of $\mathrm{CO}_{2}$ emissions reductions starting in 2019 (49 Mt in aggregate).

Twelve-year timeline: Under a somewhat delayed implementation, the following benefits would occur during the same 2013-2032 analysis period:

- 380 tons per year of $\mathrm{BC}$ reduction relative to the reference case starting in 2024 (5,200 tons in aggregate).

- 1,975 reduced fatalities per year (from reduced traffic accidents and improved air quality) starting in 2024 (27,000 in aggregate).

- $\$ 2.6$ billion/year in fuel savings starting in 2024 .

\footnotetext{
53 https://www.pcmcindia.gov.in/CMP.pdf. Sensitivity simulations were conducted using a 47-percent mode shift from buses and a 6-percent shift from cars based on actual mode-shift data from the Ahmedabad BRT project (52 percent buses, 30 percent rickshaws, 14 percent 2 -wheelers, two percent cars, and 2 percent bicycles). The sensitivity resulted in greater $\mathrm{BC}$ reductions (65-percent higher, leading to greater health benefits) but lower fuel savings (a 38-percent lower $\mathrm{CO}_{2}$ benefit).

54 http://urbanindia.nic.in/programme/ut/final_report.pdf.
} 
- Three million tons/year of $\mathrm{CO}_{2}$ emissions reduction starting in 2024 (42 Mt in aggregate).

Additional savings include reductions in vehicle-km traveled, travel time, other injuries, and NOx; these were not quantified for the national analysis.

\section{Air Quality and Agricultural Analysis}

As described in Chapter 3, the FASST tool can directly and rapidly assess the approximate public health and agricultural benefits of air quality improvements. The tool also monetizes these benefits using health valuation functions and prevailing crop values.

The FASST tool estimates for 2030 that reducing emissions of $\mathrm{CO}_{2}$ by three million tons per year and $\mathrm{BC}$ by nearly 380 tons per year (approximately 800 tons/year of $\mathrm{PM}_{2.5}$ ) leads to significant local and global benefits, including at least 200 avoided deaths (approximately 175 in India) from respiratory illnesses in the 15-20 cities with new BRTs. ${ }^{55}$ In addition, crop losses are reduced by 3,400 tons of grain, worth about $\$ 490,000$ (most of the avoided losses $-2,700$ tons of grain worth about $\$ 460,000$ - occur in India).

The avoided premature mortality is probably very conservative because the atmospheric model used here assumed uniform emissions reductions across India, rather than concentrating the reductions in the 15-20 cities with new BRT systems (where the population would have greater than average exposure and higher median wages).

\section{Macroeconomic Analysis}

From a macroeconomic perspective, the direct and indirect impact of the BRT project will be felt through four channels. The most important of these is the impact on India's economy from capital spending from the project. The short-run investment in the transport network is expected to provide a boost to domestic demand and, as a result, GDP and employment. In addition to the boost to domestic demand, the improvement in the country's infrastructure increases India's capital stock and, as a result, potential output. This means that the increase in GDP is sustained over the long term because the improvement in the country's infrastructure increases the amount of output India can produce. Although this channel is partially offset by the additional cost to the government/operator associated with operating the BRT, the net impact is overwhelmingly positive.

In addition to these direct impacts, the BRT project offers a number of indirect benefits. Despite the additional operating costs, the switch to a mass transit system reduces the overall cost of transport per passenger kilometer as passengers switch from cars and motorbikes to the BRT system. The reduction in the cost of transport feeds through to the rest of the economy, boosting firms' profit margins and households' real incomes. These indirect benefits are in addition to others identified previously by the TEEMP analysis (reduced traffic fatalities and injuries) and FASST analysis (reduced premature mortality and increased agriculture productivity).

The faster, six-year BRT implementation results in higher benefits over the project's forecast horizon (2013-2032), as India's economy enjoys the benefits over a longer period. In this case, the net present value of the project (discounted using a 3 percent social discount rate) is $\$ 13.5$ billion (in 2010 dollars). In the more realistic 12-year implementation case, the delayed timetable reduces the net present value of the project to $\$ 11.5$ billion.

The economic benefits are also felt in the labor market. In the short run (2013-17), faster implementation creates approximately 91,000 new jobs, while the more realistic implementation scenario increases employment by an average of 48,000 jobs. The two timelines have the same long-run impact on employment, with about 128,000 jobs created by the early 2030 s.

\section{Monetization of Benefits and Comparison with Stated Project Benefits}

The macroeconomic analysis does not reflect the monetary value of the avoided deaths. However, the additional benefits can be estimated using the 2010 value of a statistical life (VSL) in India. The VSL is listed in the literature at about $\$ 375,000$. After adjusting for income and purchasing power, this is equal to $\$ 967,998$ in 2010 (See Chapter 3).

Based on this future stream of welfare benefits, the net present value of the avoided mortalities (as a result of air quality improvements and reduced traffic fatalities) is calculated at $\$ 39-54$ billion (assuming a 3 percent discount rate). Given that the avoided mortality occurs predominantly in higher-wage cities, the value would likely be even higher. Time savings (approximately five minutes per trip, or about 500 million hours per year) also occur predominantly in higher-wage cities. These productivity gains were not included in the macroeconomic analysis, but they could have an effect if they occur on a large enough scale.

Agricultural benefits and $\mathrm{CO}_{2}$ reductions have also been quantified as net present value, following the same procedure of interpolating benefits streams between 2011-2031 and then aggregating and discounting at three percent. The results indicate nearly $\$ 3$ million in agricultural benefits; using a social cost of carbon, more than $\$ 1.3$ billion in value can be ascribed to $\mathrm{CO}_{2}$ reductions.

55 The specific number of cities would depend on the distribution of length of BRT lanes among the largest Indian cities. Based on $20 \mathrm{~km}$ of BRT track for a city the size of Pimpri-Chinchwad, it is likely that $15-20$ cities would receive new BRT lanes. 
Project appraisal documents were reviewed to compare the multiple development benefits of this case study with current evaluation practices. The project economic analysis included the following economic benefits from construction of the new BRT corridors: (i) a reduction in unit road-user costs in all types of vehicles for use of the new improved road (gasoline and time savings), (ii) reductions in unit road user costs from trips transferred from two-wheelers to public transportation (gasoline and time savings), and (iii) reductions in GHG emissions from trips transferred from two-wheelers to public transportation. Because the large time and fuel savings are included in the project's stated benefits, they have not been monetized as additional benefits in this case study. Because the (negligible) $\mathrm{CO}_{2}$ benefits estimated by the project documentation seem too small relative to the true potential, the case study includes instead the large $\mathrm{CO}_{2}$ benefits identified by TEEMP. The $\$ 185$ million in net present value for $19 \mathrm{~km}$ of BRT in Pimpri has been scaled up to $\$ 9.7$ billion, based on the $1,000 \mathrm{~km}$ of BRT lines to be constructed under this case study.

\section{Summary and Conclusions}

By exploring the multiple benefits of effective BRT systems (beyond the traditional measures of successful transportation initiatives and the economic net present value typically calculated in project financial analysis), it is possible to provide a more comprehensive picture and a greater monetized value of the project being examined. These benefits include time and fuel savings, reduced environmental impacts, reduced traffic and air-quality-related mortality and morbidity, and significant macroeconomic gains. Table D. 1 categorizes these results as global public goods versus local socioeconomic benefits and presents a sensitivity analysis to the value of the social discount rate used (including 2.5 percent and five percent for comparison).

\section{Development Project Case Study 2: Integrated Solid Waste Management in Brazil}

\section{Background: Benefits of Integrated Solid Waste Management}

Effective management of municipal solid waste (MSW) poses "one of the biggest challenges [to] the urban world" (UN-Habitat 2010) - and the challenge is growing. In low-income countries, most cities collect less than half of the waste generated, and only half of the collected waste is processed to minimum acceptable environmental and health standards. Along with rapid urbanization and population growth, MSW generation from the world's cities is increasing at unprecedented and alarming rates-from 1.3 billion tons (in 2006) to 2.2 billion tons (by 2025) - and this growth is centered in developing countries. These cities lack funding for proper waste management; the annual municipal budgetary shortfall in World Bank client countries is $\$ 40$ billion (Hoornweg and Bhada-Tata 2012). World Bank solid waste activities aim to improve waste management where the need is most pressing.

Table D.1: Multiple benefits potential of sustainable transportation (BRT) initiatives in India

\begin{tabular}{|c|c|c|c|c|c|c|}
\hline \multicolumn{3}{|c|}{ Global Public Goods } & \multicolumn{4}{|c|}{ Local Socioeconomic Benefits } \\
\hline $42-49$ & $\sim 360$ & 7 & $27,000-31,000$ & 28 & $\begin{array}{l}\text { 44-91 short-term; } \\
128 \text { long-term }\end{array}$ & N/A \\
\hline \multicolumn{7}{|c|}{ Monetized NPV of Benefits Using 2.5\% Social Disount Rate (million 2010 USD) } \\
\hline$\$ 2,000-2,400$ & $\sim \$ 535$ & $\$ 0.80$ & $\$ 53,000-59,000$ & $\$ 3.2$ & N/A & $\$ 12,400-14,500$ \\
\hline \multicolumn{7}{|c|}{ Monetized NPV of Benefits Using 3\% Social Disount Rate (million 2010 USD) } \\
\hline $\begin{array}{l}\text { Social value of } \\
\text { carbon }\end{array}$ & Global Lives Saved & $\begin{array}{c}\text { Global Crop Losses } \\
\text { Avoided }\end{array}$ & Local Lives Saved & $\begin{array}{l}\text { Local Crop Losses } \\
\text { Avoided }\end{array}$ & Local Jobs & Local GDP \\
\hline$\$ 280-340$ & $\sim \$ 360$ & $\$ 0.55$ & $\$ 35,000-40,000$ & $\$ 2.2$ & N/A & $\$ 8,600-10,200$ \\
\hline
\end{tabular}


Though more visibly a local problem, MSW affects public health and the environment on a global scale-most notably by emitting methane (primarily from landfills). Properly managing waste to minimize methane emissions offers a variety of local and global benefits. Locally, improper waste management, especially open dumping and burning, pollutes water bodies, contaminates air and land, attracts disease vectors, and clogs drains, contributing to flooding. People who live near or work with solid waste have increased disease burdens (Giusti 2009). At the global scale, post-consumer waste is an emerging contributor to climate change, emitting five percent of global GHGs and 12 percent of methane (Bogner et al. 2007). Most methane from solid waste is emitted from landfills, and these emissions are growing fastest in emerging economies. However, waste has the potential to be a net sink of GHGs when used as a resource, through recycling and reuse (Bogner et al. 2007). Burning waste without proper air pollution controls also affects the environment on a global scale by creating dioxins and furans, globally mixed persistent organic pollutants (POPs) that are toxic to humans and the environment. Improper disposal is also polluting the oceans at a global scale, threatening ecosystem functions, fisheries, and tourism (Law et al. 2010). Properly managing waste to minimize methane emissions also leads to improved water, air, and soil quality.

Though methane emissions only occur at the point of treatment and disposal, efforts to reduce these emissions can occur at every stage in the value chain: planning, waste generation, collection, treatment, and disposal. Moreover, the more efforts are focused upstream, the bigger the reductions that can be realized. For example, incentive plans to reduce waste generation and increase source separation yield two types of SLCP reductions. First, they directly reduce the amount of methane produced in a landfill (and other GHGs downstream in the value chain); second, they prevent other sources of SLCP (and GHG) emissions by displacing fertilizers for agriculture and natural gas for electricity.

\section{Nationwide Scale-up Analysis}

This case study estimates the emissions reductions from an integrated solid waste management approach in Brazil by simulating a scale-up of a model project to the national level. It shows that greater emission reductions can be achieved using an integrated solid waste approach than by targeting only one technology.

The model project selected is an integrated solid waste management project with an innovative carbon finance platform. The registered carbon finance methodology integrates a seamless payment structure within solid waste management investments greatly facilitating the sale of credits and the additional benefits that can be captured from those resources. It is a $\$ 50$ million financial intermediary loan for on-lending to borrowers with solid waste subprojects. The project aims to improve the treatment and disposal of municipal solid waste; its success is measured by the number of open dumps closed and the increased volume of waste disposed in sanitary landfills, composted, or recycled. Brazil was selected for scale-up due to the existing strong regulatory structure and finance instruments available in this sector.

In this analysis, methane reductions from improved solid waste management across Brazil are estimated by the EASEWASTE solid waste lifecycle assessment model, developed by the Technical University of Denmark (Kirkeby et al. 2008). This model follows waste through its lifecycle, from generation through collection, transportation, and treatment, and calculates the environmental emissions and impacts from alternative treatment scenarios. Data specific to Brazil are used for generation rates, composition, the electricity grid, landfill behavior, cost data (including purchase, operations, maintenance) and debt service for each option (Hoornweg and Bhada-Tata 2012). Potential program costs have not been considered here. Generic data are used to model the composting facilities and anaerobic digesters.

Four different policy scenarios for managing Brazil's waste were assessed with respect to a reference baseline case:

1. Baseline: The current state of solid waste management in Brazil, with 58 percent of waste going to sanitary landfills and the remainder to dumps. The majority of sanitary landfills flare the methane produced in the landfill; open dumps simply vent the methane produced.

2. All landfill scale-up: All generated waste ends up in a sanitary landfill (no more open dumping); 50 percent of landfill gas (LFG) is collected and flared.

3. All landfill with electricity generation: Similar to the previous scenario, but 50 percent of LFG collected is flared, and 50 percent is used to generate electricity (displacing natural gas on the electrical grid). An engine efficiency of 30 percent is assumed.

4. Anaerobic digestion (with electricity generation) for organic waste: Organic waste is sorted and 75 percent is routed to anaerobic digesters, producing electricity (displacing natural gas on the grid); the resulting compost is used on land (but no market value or fertilizer substitutions are made). Again, an engine efficiency of 30 percent is assumed.

5. Composting for organic waste: Organic waste is sorted and 75 percent is composted. Again, the compost is not assumed to displace any fertilizer (though if it did, greater environmental benefits would be seen).

For all the scenarios explored, the most relevant result is the difference between a given scenario and the baseline. Implementing these organic waste treatment technologies on a large scale could reduce methane emissions by up to 29 million metric tons 
of $\mathrm{CO}_{2}$ e per year. ${ }^{56}$ Lifecycle GHG emissions are shown for each scenario in Figure D.1.

The baseline scenario results in about 11 million metric tons of $\mathrm{CO}_{2} \mathrm{e}$ emissions each year (on a lifecycle basis). In the "all landfill scale-up" scenario, emissions are reduced relative to the baseline and are actually negative because the landfill is able to sequester more than it emits; this results in about -3.6 million metric tons of $\mathrm{CO}_{2} \mathrm{e}$ or a reduction of nearly 15 million metric tons relative to the reference case. The "all landfill with electricity generation" scenario is similar to the all landfill scale-up, but instead of flaring the collected gas, roughly half of it is used to offset some natural gas power generation, further reducing $\mathrm{CO}_{2} \mathrm{e}$ emissions.

Emissions are lowest in the "anaerobic digestion" scenario because organic waste is diverted from the landfill to an anaerobic digester, where methane emissions are maximized, captured, and used for energy. This results in the largest reduction of methane emissions-about 29 million metric tons-and the largest displacement of fossil fuels. The composting scenario leads to the second-lowest emissions (about 20 million metric tons) because diversion of organic waste from landfills reduces methane emissions, but it does not displace fossil fuel emissions through electric generation.

\section{Public Health and Agricultural Benefits}

The reduced methane emissions (15-29 million metric tons of $\mathrm{CO}_{2} \mathrm{e}$ avoided per year by 2030 relative to the reference case) are input to the FASST tool to estimate the additional annual public health

Figure D.1: Life-cycle GHG emissions $\left(\mathrm{MtCO}_{2} / \mathrm{yr}\right)$ for all scenarios

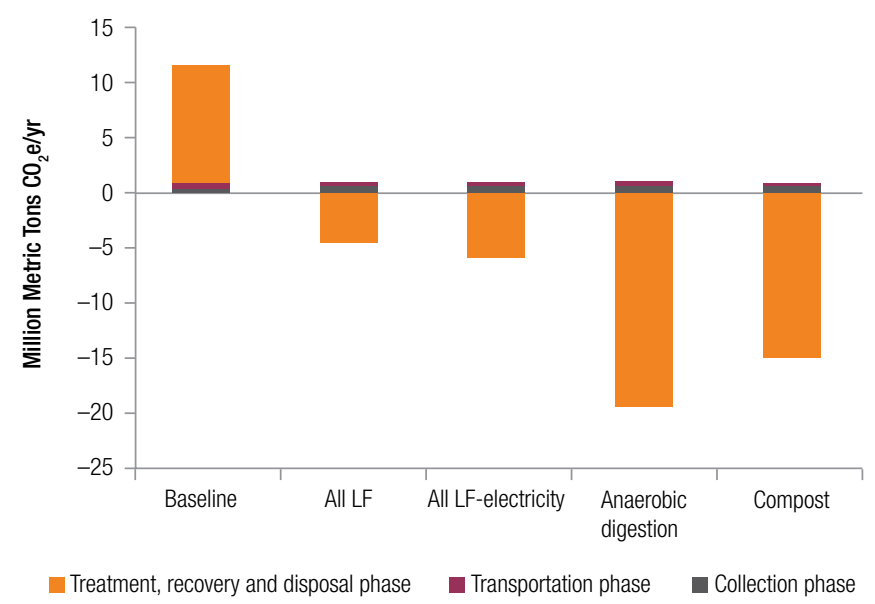

Note: Anaerobic digestion and composting offer the greatest emission reductions, 20 million-29 million metric tons annually. and crop benefits from reduced ground-level ozone formation. These could result in 246-468 avoided deaths around the world annually by 2030 from respiratory illnesses and 53,000-101,000 tons of avoided crop losses each year.

\section{Macroeconomic Benefits}

The direct economic impacts of improved waste disposal are assessed through four main channels. The additional capital and operating expenditures needed to run the sanitary landfill, anaerobic digestion, or composting facilities will provide a significant boost to GDP in the short run. This effect will fade over the medium term as the cost of investment is paid through higher prices (which depress real incomes and profitability). With a significant amount of international finance providing the up-front capital investment, however, the full crowding-out effect generated by the short-term rise in demand would not be felt by the economy. As a result, some of the short-run boost to investment is retained, which allows GDP to rise in the long run.

A number of other benefits are also associated with the investment in waste management. Agricultural productivity is increased via improved soil and water quality (in addition to the increases in agricultural yield discussed above). Electricity costs are lowered as a result of burning methane instead of natural gas to produce power.

Based on these effects, a publicly financed and leveraged investment of $\$ 1-\$ 2$ billion/year in collection, transportation, and sanitary waste disposal alternatives (e.g. sanitary landfill, composting, and anaerobic digestion) yields a range of macroeconomic benefits over the 20-year analysis period (using a 10 percent economic discount rate within the GEIM model, but a 3 percent social discount rate to calculate the NPV of the GDP benefits). In all three cases, the impact was found to be significant and positive. The composting alternative provided the smallest positive boost, with the net present value of the increase in GDP estimated to be $\$ 13.3$ billion; the sanitary landfill alternative provided a $\$ 18.6$ billion boost; and the anaerobic digestion alternative $\$ 35.2$ billion (all in 2010 dollars).

The increase in GDP is also reflected in the labor market. By the end of the forecast horizon (2032), the number of people employed increases by 44,000 (in the maximum composting alternative), 58,000 (in the sanitary landfill alternative), and 110,000 (in the anaerobic digestion alternative). Finally, between $0.5-1.1$ percent of national power demand is satisfied as an additional benefit of two of these scenarios.

\footnotetext{
56 Assumes effective source separation of organic waste, no market for compost (no substitution for fertilizer), and that the electricity produced displaces natural gas on the grid.
} 


\section{Monetization of Benefits and Comparison to Stated Project Benefits}

As in the India case study, the present value of avoided mortality can be estimated over the 20-year analysis period. Given that the health benefits from methane reductions are global in nature and do not necessarily accrue to Brazil, this benefit has not been monetized for Brazil specifically. Rather, benefits have been estimated for the six focus regions for which data is available, and all other avoided mortalities have been ascribed to a conservative estimate of VSL (in this case, India). The aggregate 2,500-4,900 avoided deaths over 20 years have an estimated net present monetized value of $\$ 5.5$ - $\$ 10.6$ billion (2010 dollars).

Using a 2010 market price of approximately $\$ 170 /$ ton, the avoided crop losses have been interpolated over the analysis period, monetized, and discounted at three percent to estimate their net present value at more than $\$ 60$ million, or $\$ 120$ million if the larger emissions reductions are achieved. In addition, applying the social cost of carbon (U.S. Interagency Working Group on Social Cost of Carbon 2013) to projected $\mathrm{CO}_{2}$ reductions over the analysis period provides significant value in excess of the carbon finance value-a total value of $\$ 4.8-\$ 9.7$ billion, or an additional increment of $\$ 3.2-\$ 6.5$ billion.

These benefits should be compared with the project benefits stated in the model project documentation, which include: (i) population surpluses resulting from the closing of open-air dumps and construction (and adequate operation) of regional landfills; (ii) health and environmental improvements (although these were not quantified); and (iii) distribution of project benefits and impacts among stakeholders. The documentation further states that the "economic benefits are assumed to be represented by the financial income (fees) generated by the project. Due to lack of data, this proxy is assumed to represent the totality of benefits." Using simple cost-benefit analysis, the net present value of the financial income for a sanitary landfill for a municipality of approximately 200,000 people ( $\$ 100$ million) was scaled up to the national population of Brazil; this estimates the net present value of the stated project benefits at roughly $\$ 100$ billion.

\section{Summary and Conclusions}

Improved organic waste treatment, through anaerobic digestion and composting, offers the greatest potential for methane reduction from solid waste in Brazil, on the order of 30 million metric tons of $\mathrm{CO}_{2}$ equivalent per year. In order for these wasteto-resource technologies to be used on a large scale, major annual investments of $\$ 1-\$ 2$ billion are required in upstream waste reduction and source separation. (Without separation of waste at the household level, neither composting nor anaerobic digestion is economically feasible.) An integrated approach that considers every step in the waste value chain, from generation in the household through final disposal, is needed to effectively manage waste as a resource.

In summary, annual deployment of $\$ 1-\$ 2$ billion of leveraged public and private sector investment in sanitary landfills, anaerobic digestion, or composting programs, with increased emphasis on waste collection, could result in 20-year aggregate benefits of:

- 158-315 million metric tons of $\mathrm{CO}_{2}$ e reduction of methane worth \$4.8-\$9.7 billion (an increment of \$3.2-\$6.5 billion in added value over scaled-up stated project estimates).

- More than 2,500-4,900 avoided instances of premature mortality from air pollution globally, with a value of more than $\$ 5.5-\$ 10.6$ billion.

- \$61-\$120 million in avoided crop losses (but only \$390,000$\$ 735,000$ in Brazil).

- Between 44,000 and 110,000 jobs created.

- Between 0.5-1.1 percent of national electricity demand offset.

- \$13.3-\$35.2 billion in GDP benefit from 2012-2031.

Table D. 2 categorizes these results as global public goods or local socioeconomic benefits and presents a sensitivity analysis to the value of social discount rate used (including 2.5 percent and five percent for comparison).

\section{Development Project Case Study 3: Cleaner Cookstoves in Rural China}

\section{Background: Domestic Energy and Solid Fuels}

China has made great strides in expanding energy access and providing cleaner cooking fuels and improved stoves throughout the country. However, more than half of China's population, located mainly in rural areas, still relies on solid fuels (coal and biomass) for cooking and heating, and many are likely to continue to do so in the near future. Switching to modern energy alternatives would be the most effective way to reduce cooking and heating emissions and should be encouraged; however, such fuels are more expensive than solid fuels and require more costly stoves and delivery infrastructure. Poorer rural households without access to affordable modern fuels such as LPG and natural gas are unlikely to transition up the energy ladder on a large scale. The International Energy Agency estimates some 241 million people in China will still rely on solid fuels for cooking and heating in 2030 (World Energy Outlook 2013). This analysis builds on the World Bank engagement with the government of China for the China Clean Stoves Initiative (World Bank 2013c). 
Table D.2: Multiple benefits potential of integrated solid waste management in Brazil

\begin{tabular}{|c|c|c|c|c|c|}
\hline \multicolumn{3}{|c|}{ Global Public Goods } & \multicolumn{3}{|c|}{ Local Socioeconomic Benefits } \\
\hline \multicolumn{6}{|c|}{ Multiple Benefits } \\
\hline $\mathrm{MtCO}_{2} \mathrm{e}$ & Global Lives Saved & $\begin{array}{c}\text { Global Crop Losses } \\
\text { Avoided } \\
\text { (thousand tons) }\end{array}$ & $\begin{array}{c}\text { Local Crop Losses } \\
\text { Avoided } \\
\text { (thousand tons) }\end{array}$ & $\begin{array}{l}\text { Local Jobs } \\
\text { (thousands) }\end{array}$ & Local GDP \\
\hline $158-315$ & $2,500-4,900$ & $550-1,100$ & $3.5-6.8$ & $44-110$ & N/A \\
\hline \multicolumn{6}{|c|}{ Monetized NPV of Benefits Using 2.5\% Social Disount Rate (million 2010 USD) } \\
\hline$\$ 7,700-15,400$ & $\$ 6,000-11,400$ & $\$ 65-129$ & $\$ 0.4-0.8$ & N/A & $\$ 14,100-37,300$ \\
\hline \multicolumn{6}{|c|}{ Monetized NPV of Benefits Using 3\% Social Disount Rate (million 2010 USD) } \\
\hline $\begin{array}{l}\text { Social value of } \\
\text { carbon }\end{array}$ & Global Lives Saved & $\begin{array}{c}\text { Global Crop Losses } \\
\text { Avoided }\end{array}$ & $\begin{array}{c}\text { Local Crop Losses } \\
\text { Avoided }\end{array}$ & Local Jobs & Local GDP \\
\hline$\$ 1,100-2,200$ & $\$ 4,100-7,800$ & $\$ 46-92$ & $\$ 0.3-0.5$ & $N / A$ & $\$ 10,800-28,200$ \\
\hline
\end{tabular}

Effective interventions to scale up the dissemination of cleanburning, fuel-efficient stoves for household cooking and heating can mitigate the health hazards of burning solid fuels. In China, household burning of solid fuels ranks fourth among all risk factors for poor health. It is estimated that household air pollution from solid fuel use results in more than one million premature deaths each year in China (Lim et al. 2012).

\section{Nationwide Analysis: Clean Cookstoves for the Rural Poor}

While heating systems or combined cooking and heating stoves also represent important opportunities to reduce indoor and outdoor air pollution, to simplify this analysis this case study focuses on cleaner cookstoves.

The case study assumes a publicly supported plan to encourage rural households to switch to more fuel-efficient and environmentally friendly cookstoves starting in 2015. For the first five years, the public sector would support clean cookstove market transformation by subsidizing the cost of the clean cookstoves in addition to providing technical assistance (such as awareness campaign and support to private sector development) under a national clean stove program. By 2020, 40 percent of rural, poor households relying primarily on solid fuel for cooking are assumed to have switched, and by 2030 all households are assumed to use a clean stove. This is against a backdrop of increasing urbanization and rising household incomes, which has already established a trend toward the use of modern fuels and cleaner stoves. This program is expected to help establish a robust private sector market for cleaner stoves.
Key assumptions used for this analysis include the following:

- The baseline assumes natural penetration of cleaner cookstoves and modern fuel cookstoves, which also takes into consideration population growth and urbanization rates. Under the baseline scenario, there are over 49 million rural households relying on traditional stoves and 10 million rural households relying on cleaner cookstoves in 2030.

- Subsidies offered from 2015-2020 increase deployment of three types of clean cookstoves: about 10 million improved biomass cookstoves costing $\$ 85$ each (efficiency of 30 percent in 2013, rising to 40 percent by 2030); more than 6.75 million advanced clean-fuel cookstoves costing $\$ 100$ each (efficiency of 35 percent in 2013, rising to 49 percent by 2030); and 3.5 million solar cookers costing $\$ 25$ each (efficiency of 40 percent in 2013, rising to 55 percent in 2030).

- Deployment rates rise from 1.3 million per year in 2015 (500,000 improved, 500,000 advanced, and 300,000 solar cookers) to about 5.5 million per year in 2020 when the subsidy program ends (three million improved, 1.75 million advanced, and 750,000 solar cookers).

- Deployment between 2020-2030 dips somewhat after the subsidy ends but largely holds steady through the end of 2030, when more than 72 million cleaner stoves will have been deployed and 100 percent of rural poor households will have switched to cleaner cookstoves and modern fuel cookstoves.

- These deployments include replacements after five years and use empirical data to estimate the replacement rate at 90 percent (the percentage of clean stove users who purchase another clean 
stove when replacement was needed) and an acceptance rate of 78 percent (the number of clean stove users who accept the new stoves). These rates are assumed to rise to 100 percent by 2030 .

- After 2020, a robust market will have been established and private investment will continue throughout the analysis timeframe.

Based on these assumptions, the fuel and energy savings and emissions reductions in $\mathrm{PM}_{2.5}$ and $\mathrm{CO}$ each year throughout 2033 are estimated by the EAP CSI team, along with the air quality and agricultural impacts, and the broader macroeconomic effects have been further estimated through macroeconomic modeling in the GEIM model.

\section{Public Health and Agricultural Benefits}

The emission rate per megajoule (MJ) of heat content was used to estimate $\mathrm{PM}_{2.5}$ and $\mathrm{CO}$ emissions reductions from the calculated solid fuel reductions in the case study. These emissions reductions were input into the FASST tool to estimate the public health and crop benefits. Based on the estimated emissions reductions in 2030, premature mortalities from outdoor air pollution were estimated to be reduced by approximately 87,900 annually; the majority of these $(85,700)$ will occur in China. This has a significant economic value, given the Chinese value of a statistical life of $\$ 700,635$ in 2010. Given that more than a million lives are lost annually due to household air pollution in China as per the Global Burden of Disease (Lim et al. 2012), the estimate of lives saved is clearly underestimated as indoor exposure was not assessed.

\section{Macroeconomic Benefits}

The direct and indirect impacts of the cookstoves project are felt through three key transmission channels. In the short run, the most important channel is the impact of the additional expenditure (to buy the cookstoves) on private consumption and, as a result, on GDP. The increase in spending boosts GDP in the short run. This channel is maintained until 2033 (the last year of cookstove purchases in the case study); over the medium term, however, the positive boost is offset by the negative impact of the additional cost on households' real income, crowding out some portion of other household spending and returning the economy to baseline levels. The composition of private sector spending does change over the scenario's horizon: spending on cookstoves is higher, while spending in other areas is lower. As a result, the long-term impact of this channel in isolation would be negative, although the impact would be smaller because the cost of clean stoves is subsidized by the public sector for the first five years.

In addition to the extra spending needed to purchase clean cookstoves, the project would also generate small administrative costs to run the subsidy program for five years. As with consumer spending, these costs would provide both a positive boost and a negative shock to GDP. The positive boost would come from the additional goods and services demanded by the public sector to run the program initially, although these would be broadly offset by the negative impact on inflation.

The switch to more fuel-efficient cookstoves would also have a small but significant impact on energy consumption in China's economy. Most rural, poor households currently use non-commercial biomass fuel for cooking (though a significant fraction use coal). All households would consume considerably less energy than in the baseline and, as a result, aggregate energy consumption and energy prices would be lower. The effect on energy prices is only from the reduction in coal use. This has a positive impact on households, which have to spend less of their income on energy, and this helps to offset the higher cost of the cookstoves. More importantly, lower fuel prices would have a significant positive impact on the wider economy. The cheaper cost of electricity lowers firms' production costs and increases the economy's productive potential and, as a result, long-run output is higher. This channel therefore has an unambiguously positive impact on the economy which builds over time as the number of fuel-efficient stoves increases.

The economic impact has been assessed using a number of metrics: the additional employment generated over the short term (2013-2017), the cumulative increase in GDP over the short term (2013-2017), and the net present value of the cumulative increase in GDP over the case study horizon (20 years). ${ }^{57}$ The general finding is that the plan would have a positive impact on China's economy in both the short term and the long run.

In the near-to-medium term (2015-19), the increase in consumer spending ( $\$ 1.2$ billion spent by households on the switch to cleaner cookstoves) results in GDP rising by a cumulative $\$ 1.6$ billion (2010 USD). This in turn generates 22,000 new jobs.

Over the medium-to-long term, the positive boost from the increase in consumption diminishes as spending is completed and the negative shock to households' real income comes through. However, the positive shock from households' reduced energy consumption and the impact this has on fuel prices increases China's potential output. As a result, GDP is increased in the long run; the net present value of this increase is around $\$ 10.7$ billion (2010 dollars).

\section{Monetization of Benefits and Comparison to Stated Project Benefits}

This project is not based on an actual investment program; rather, it is a simulation based on the stocktaking exercise for various

57 The net present value (in 2010 dollars) of the cumulative increase in GDP was calculated using a social discount rate of 2.5 , three, and five percent in Table D.3. 
clean stove options identified under the China Clean Stove Initiative (World Bank, 2013c). Thus there are no stated project benefits to scale up and compare.

However, the value of the benefits identified above can be estimated as net present values by interpolating the estimated 85,700 premature mortalities avoided annually in 2030 over the 2014-2030 time period and extrapolating the declining avoided mortality between 2030-2033 (as baseline rates of clean stove adoption rise to meet the policy scenario) and monetizing based on the estimated VSL for China now and in the future as national income grows. Based on this future stream of welfare benefits, the net present value is calculated, assuming a social 3 percent discount rate, at more than $\$ 1.5$ trillion from avoided mortality. Given that the reduced emissions in this case study affect the rural poor, rather than the urban populations, it may overstate the monetized benefit. However, because the estimate of lives saved only reflects reduced exposure to outdoor pollution and does not account for the indoor exposure, it is more likely to underestimate the true value.

\section{Summary and Conclusions}

Deployment of more than 72 million cleaner stoves between 2014-2033 would require a public investment of $\$ 400$ million in the near term (through 2020) to establish a robust private market. The annual benefits in 2030 of such a scenario are estimated to include:

- 87,900 avoided instances of premature mortality from outdoor air pollution globally, of which 85,700 would be within China (corresponding to an aggregate benefit of more than one million lives saved through 2033 and a monetized net present value of more than $\$ 1.5$ trillion).

- Reduced energy use of $450 \mathrm{GJ}$ per year in 2030.

- Near-term employment gains of about 22,000 jobs.

- $\$ 10.7$ billion in net present value from GDP increases between 2014-2033.

Table D. 3 categorizes these results as global public goods or local socioeconomic benefits and presents a sensitivity analysis to the value of social discount rate used (including 2.5 percent and five percent for comparison).

\section{Development Project Case Study 4: Biogas Digesters and Photovoltaics in Mexican Agriculture}

\section{Background: Mexican Agriculture}

Over the past 15 years,Mexico's rural sector has experienced substantial reforms, which have led to a largely liberalized, market-oriented, and private sector-driven rural economy. Agriculture remains an important part of the Mexican economy and an employer of a large share of the rural population. A number of second-generation reforms are needed, however, to diversify the country's productive pattern and respond to the challenges of an increasingly integrated global market. According to Mexico's Fifth

Table D.3: Multiple benefits potential of clean cooking solutions in China

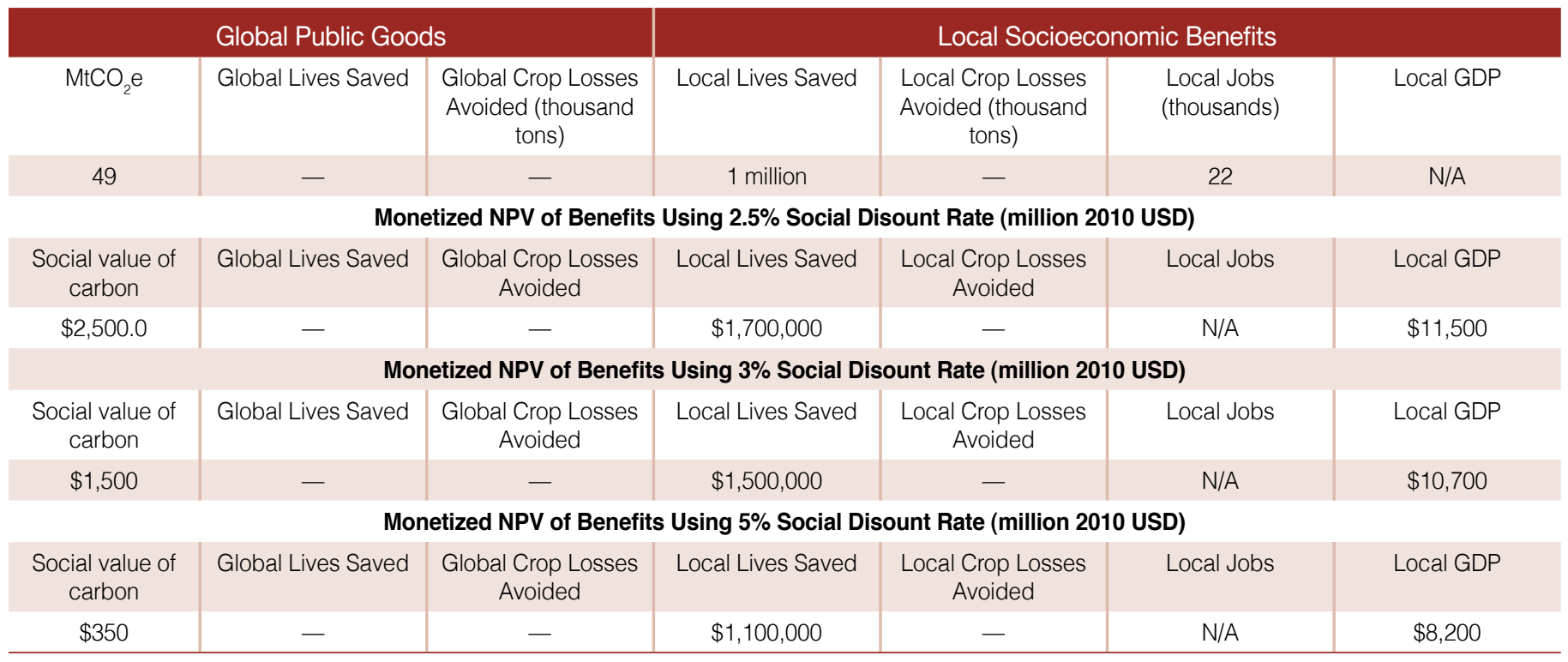


National Communication to the UN Framework Convention on Climate Change, agriculture continues to be an important source of the country's emissions (12 percent of its GHG emissions in 2010 including both methane and nitrous oxide), primarily through land-use change, tillage, synthetic fertilizers, and anaerobic decomposition of organic materials. To partially address these emissions and to improve the agricultural sector's contribution to the overall economy, the Government of Mexico has prioritized increasing the competitiveness and environmental sustainability of agriculture and agri-businesses by promoting energy efficiency (including renewable energy) and biomass practices.

The successful Mexico Sustainable Rural Development Project $-\$ 100$ million in World Bank loans blended with a $\$ 10.5$ million GEF grant and additional contributions from the Government of Mexico and project beneficiaries-promotes investments to reduce GHG emissions from agribusiness, primarily from livestock production and value-added agro-processing. The project was based on four pillars: (i) the proportion of Mexico's GHG emissions contributed by the agricultural sector; (ii) the Mexican government's prioritization of climate change adaptation and mitigation; (iii) the strong demand from Mexican producers and agro-processors for technologies to save energy and reduce pollutants; and (iv) the World Bank's comprehensive engagement to support the Mexican government's Climate Change Agenda, including the promotion of renewable energy and energy efficiency in rural areas, as well as sustainable, climate-smart agriculture.

Since January 2010, the project has supported a number of emissions reducing and energy-efficient technologies. A majority of the funds have supported the fixed cost of installation of biodigesters in pig and dairy farms, based on demand from farmers. As of May 2013, 303 biodigesters were installed-half in pig farms and the other half in dairy farms. By the end of 2012, the entire original $\$ 50$ million loan had been fully committed, and a further $\$ 50$ million loan had been sought and approved. This indicates the steadily increasing demand for biodigesters, which is expected to continue as biodigester technology becomes more widespread, more cost-effective, and better adapted to the different production scales in Mexico.

\section{Nationwide Scale-up Analysis: Biodigesters and PV Systems for Pig and Dairy Farms}

While the original project has many components that support a range of energy-efficient technologies, this case study focused exclusively on continued deployment of biodigesters on pig farms and a combination of biodigesters with motogenerators and PV systems on dairy farms, where the higher electrical demand for milk cooling systems favors the added expense of electrical generation add-ons.

The case study assumes that public funding is available to continue leveraging the private sector investment in these technologies through 2031, when 90 percent of pig and dairy farms would have added manure biodigestion capacity and 90 percent of dairy farms would have installed motogenerators and PV systems.

Key assumptions in this analysis include:

- Emissions reductions, technology costs, and energy savings will scale according to data gathered from initial deployments under this program. Total dairy cattle herd was estimated at 3.2 million head and pig herd is estimated at 15 million head based on USDA production forecasts. ${ }^{58}$

- Project co-financing factors will remain, on average, about 1.61 for biodigesters (in other words, for every $\$ 1.00$ invested by the project, $\$ 1.61$ is invested by the project beneficiary), 1.35 for generators, and 1.15 for PV systems. This level of beneficiary contribution indicates important buy-in by farmers and supports the assumption of full coverage of operation and maintenance (O\&M) variable costs by farmers and producers during the lifespan of the biodigester and renewable energy systems.

- One-third of the biodigesters funded under the project currently include an accompanying biogas generator for on-site energy generation. This proportion is expected to grow to one-half as generators become more cost-effective and the number of suppliers in Mexico increases (currently there were only two generator suppliers in the country in early 2013).

- The amount of electricity generation from biogas generators presented in the case study is conservative. The farms currently generate sufficient energy for their own operation (which reduces electricity costs and improves the continuity of their electricity supply). Current policy restricts small-scale producers from uploading excess energy (or net metering) to the national grid. This could change, however, allowing for the sale of excess energy to the grid.

- Given consistently high (and increasing) private sector demand for project activities and the Mexican government's regionleading, committed role to climate change adaptation and mitigation strategies, public investment for this program will scale linearly to achieve 30 percent of the national sector potential for biodigester and PV systems in 2016-2021, 60 percent in 2021-2026, and 90 percent in 2026-2031. Potential for biodigester installation was estimated based on national statistics of pig and dairy-cow herds, with all calculations broken down on a per-head basis and scaled accordingly. Private sector versus public sector investment leverage ratios (by sector) in initial fixed capital costs, as well ongoing O\&M costs, were assumed and projected over time based on actual project data. An underlying assumption is that the Government

58 http://www.thefarmsite.com/reports/contents/MexicoLivestock6March2014.pdf 
of Mexico will continue to support the uptake of the new technologies, with this financial support decreasing (in real terms) over time as the technologies become more widespread and cheaper. Hence the linear projection of this full implementation simulation is based on the assumed technology uptake, with important underlying dynamics related to tradeoffs in costs (public and private), scale, number of beneficiaries, and regulatory changes (related to energy policy and climate change targets).

The project benefits include the reduction of nearly $10 \mathrm{Mt} /$ year of $\mathrm{CO}_{2} \mathrm{e}$ (mostly as methane recovered from the biodigesters and either flared as $\mathrm{CO}_{2}$ or utilized to generate electricity). In addition, the project generates new jobs (with specific benefits for women and indigenous populations) and improved sanitary conditions due to manure treatment. While these benefits may have significant value, the current analysis focuses on those benefits that can be quantified and valued.

\section{Public Health and Agricultural Benefits}

The methane reductions, estimated as $9.4 \mathrm{Mt}$ of $\mathrm{CO}_{2}$ e per year in 2030, can significantly lower the health and agricultural damages from global background ozone. Estimated benefits include 180 avoided instances of premature mortality from air pollution annually (but relatively few within Mexico) and 39,000 tons of avoided crop losses per year (again, mostly outside Mexico).

\section{Macroeconomic Benefits}

The direct and indirect impacts of this case study have been assessed to be realized through two key channels. In the short term, the most important channel is the impact of changes in spending as a result of investment. The increase in spending provides a positive boost to GDP in the short term, although some of the increase is offset by the need to import capital goods. In the short term (2013-2021), the increase in investment results in GDP rising by a cumulative $\$ 450$ million (2010 dollars) as a result of the $\$ 270$ million spent by farming operations and public bodies on the new capital stock. This in turn would generate approximately 1,400 new jobs.

The second key transmission channel is the impact of the reduction in energy (specifically electricity) consumption in the agriculture sector. A significant reduction in electricity use would have a positive impact on the sector, via a reduction in output prices, which would trigger an increase in demand. In isolation, this channel would have an unambiguously positive impact (in both the short term and the long term) on Mexico's agriculture sector and the wider macroeconomy.

Over the medium-to-long term, the positive boost from the increase in consumption would diminish as agricultural production costs go up and these costs are ultimately passed on to other sectors. But the positive impact of lower energy consumption in the agriculture sector, coupled with the partial offsetting of crowding out from the public subsidy, would result in a net positive impact on the economy as a whole. As a result, the net present value of the case study project through 2026 is $\$ 600$ million, which rises to $\$ 1$ billion by 2031 .

While this project has significant benefits for the environment, the agricultural sector, and the broader Mexican economy, its true potential benefits are far larger. For instance, policy reforms that would enable excess electricity generated to be sold back to utilities could lead to significantly greater benefits to farmers who generate electricity. This would enable the Mexican agricultural sector to supply a significantly larger fraction of its own electrical demand and provide additional carbon-free electricity generation to the grid. A detailed economic analysis of such a scenario is recommended.

\section{Monetization of Benefits and Comparison to Stated Project Benefits}

As with the Brazil case study, the health benefits from methane reductions are global in nature and do not necessarily accrue to Mexico (only about 1-2 of the 180 annual avoided instances of premature mortality would occur in Mexico). This aggregates to more than 1,900 premature mortalities avoided between 2012-2031, monetized here at more than $\$ 4.1$ billion. Using a 2010 global commodity market price of approximately $\$ 170 /$ ton, the avoided crop losses have been interpolated over the analysis period, monetized, and discounted at three percent to estimate the net present value of this benefit at about $\$ 45$ million. In addition, applying the social cost of carbon (U.S. Interagency Working Group on Social Cost of Carbon 2013) to projected $\mathrm{CO}_{2}$ reductions over the analysis period provides a significant present value of $\$ 3.2$ billion-or $\$ 2.2$ billion in excess of the carbon finance value (approximately $\$ 16$ / ton based on project documentation).

These benefits should be compared with the stated benefits in the project documentation. Project documentation estimated that "about 1.5 million tons of $\mathrm{CO}_{2}$ equivalent of possible emissions reductions (ERs) would be generated through biodigesters under the project over a period of five years. This would translate into some $\$ 24.0$ million of carbon credits." Interpolating the reduction potential between current estimates from Mexico's Shared Risk Trust (FIRCO) and this report's scaled estimates of full implementation at the $9.4 \mathrm{Mt} \mathrm{CO}_{2}$ e national potential in 2031 results in a 20 -year cumulative reduction of $103 \mathrm{Mt}$. Using the $\$ 16 /$ ton value listed in project documentation, a carbon finance value of $\$ 1.047$ billion is derived-less than one-third the value based on the social cost of carbon. Subtracting present value costs (public and private sector investment over the period 2012-2031) of $\$ 623$ 
Table D.4: Multiple benefits potential of sustainable agriculture in Mexico

\begin{tabular}{|c|c|c|c|c|c|c|}
\hline \multicolumn{3}{|c|}{ Global Public Goods } & \multicolumn{4}{|c|}{ Local Socioeconomic Benefits } \\
\hline $\mathrm{MtCO}_{2} \mathrm{e}$ & Global Lives Saved & $\begin{array}{c}\text { Global Crop Losses } \\
\text { Avoided (thousand } \\
\text { tons) }\end{array}$ & Local Lives Saved & $\begin{array}{c}\text { Local Crop Losses } \\
\text { Avoided (thousand } \\
\text { tons) }\end{array}$ & $\begin{array}{l}\text { Local Jobs } \\
\text { (thousands) }\end{array}$ & Local GDP \\
\hline \multicolumn{7}{|c|}{ Monetized NPV of Benefits Using 2.5\% Social Disount Rate (million 2010 USD) } \\
\hline $\begin{array}{c}\text { Social value of } \\
\text { carbon }\end{array}$ & Global Lives Saved & $\begin{array}{c}\text { Global Crop Losses } \\
\text { Avoided }\end{array}$ & Local Lives Saved & $\begin{array}{c}\text { Local Crop Losses } \\
\text { Avoided }\end{array}$ & Local Jobs & Local GDP \\
\hline \multicolumn{7}{|c|}{ Monetized NPV of Benefits Using 3\% Social Disount Rate (million 2010 USD) } \\
\hline $\begin{array}{c}\text { Social value of } \\
\text { carbon }\end{array}$ & Global Lives Saved & $\begin{array}{c}\text { Global Crop Losses } \\
\text { Avoided }\end{array}$ & Local Lives Saved & $\begin{array}{c}\text { Local Crop Losses } \\
\text { Avoided }\end{array}$ & Local Jobs & Local GDP \\
\hline$\$ 3,200$ & $\$ 4,100$ & $\$ 45.0$ & $\$ 50$ & $\$ 0.16$ & N/A & $\$ 1,070$ \\
\hline
\end{tabular}

million yields a net present value of $\$ 424$ million for the project's stated benefits.

\section{Summary and Conclusions}

The Mexican government's commitment to greater competitiveness and environmental sustainability in agribusinesses and the agricultural sector can be demonstrated through sustained investment in manure biodigesters and photovoltaics. A sustained investment that achieves 90 percent penetration in Mexican farms of anaerobic digestion of pig and dairy cattle manure, and motogenerators and PV electricity generation at dairy farms, would derive significant economic, public health, agricultural, and environmental benefits. These benefits include:

- More than 9.4 million $\mathrm{Mt}$ of $\mathrm{CO}_{2} \mathrm{e}$ reduction in methane per year in 2030 (103 million tons over 20 years) with a net present value of $\$ 3.2$ billion based on the social cost of carbon (an additional $\$ 2.2$ billion in carbon value beyond the stated benefits).

- More than 1,900 avoided instances of premature deaths from air pollution, with a NPV of more than $\$ 4.1$ billion (mostly outside Mexico).

- Nearly 410,000 tons of avoided crop losses worth \$45 million (mostly outside Mexico).

- A gain of 1,400 jobs.

- An 11 percent offset in national electricity demand.

- Increase of \$1.1 billion in GDP between 2012-2031.

Table D.4 categorizes these results as global public goods or local socioeconomic benefits and presents a sensitivity analysis to the value of the social discount rate used (including 2.5 percent and five percent for comparison). 
WORLD BANK GROUP

1818 H Street, N.W.

Washington, DC 20433 